\title{
ATP infusions in palliative home care
}

Citation for published version (APA):

Beijer- van Eck, S. (2009). ATP infusions in palliative home care. [Doctoral Thesis, Maastricht University]. Datawyse / Universitaire Pers Maastricht. https://doi.org/10.26481/dis.20090701sb

Document status and date:

Published: 01/01/2009

DOI:

10.26481/dis.20090701sb

Document Version:

Publisher's PDF, also known as Version of record

\section{Please check the document version of this publication:}

- A submitted manuscript is the version of the article upon submission and before peer-review. There can be important differences between the submitted version and the official published version of record.

People interested in the research are advised to contact the author for the final version of the publication, or visit the DOI to the publisher's website.

- The final author version and the galley proof are versions of the publication after peer review.

- The final published version features the final layout of the paper including the volume, issue and page numbers.

Link to publication

\footnotetext{
General rights rights.

- You may freely distribute the URL identifying the publication in the public portal. please follow below link for the End User Agreement:

www.umlib.nl/taverne-license

Take down policy

If you believe that this document breaches copyright please contact us at:

repository@maastrichtuniversity.nl

providing details and we will investigate your claim.
}

Copyright and moral rights for the publications made accessible in the public portal are retained by the authors and/or other copyright owners and it is a condition of accessing publications that users recognise and abide by the legal requirements associated with these

- Users may download and print one copy of any publication from the public portal for the purpose of private study or research.

- You may not further distribute the material or use it for any profit-making activity or commercial gain

If the publication is distributed under the terms of Article $25 \mathrm{fa}$ of the Dutch Copyright Act, indicated by the "Taverne" license above, 
ATP infusions in palliative home care 
The study presented in this thesis was supported by a grant within the programme 'Palliative Care in the Terminal Phase' of the Netherlands Organisation for Health Research and Development (ZonMw), and by the 'Stichting Nationaal fonds tegen kanker', W.G. Plein 187, 1054 SC Amsterdam.

Financial support for printing of this thesis has kindly been provided by the 'Stichting Nationaal fonds tegen kanker'.

\section{(2) ZonMw}

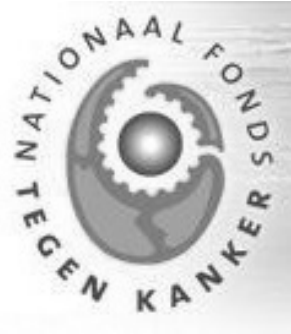

The study was performed within the Nutrition and Toxicology Research Institute Maastricht (NUTRIM), which participates in the Graduate School VLAG (Food Technology, Agrobiotechnology, Nutrition and Health Sciences), accredited by the Royal Netherlands Academy of Arts and Sciences.
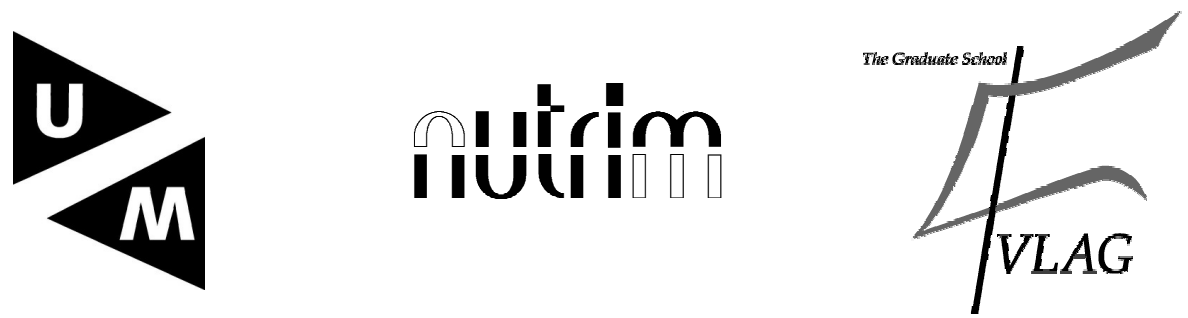

Painting cover: Dhr. W. Reintjens

Layout: Sandra Beijer

Production: Datawyse | Universitaire Pers Maastricht

ISBN: 978-90-5278-838-8

(C) Copyright, Sandra Beijer, Maastricht 2009 


\title{
ATP infusions in palliative home care
}

\author{
Proefschrift
}

ter verkrijging van de graad van doctor aan de Universiteit Maastricht, op gezag van de Rector Magnificus,

Prof. mr. G.P.M.F. Mols, volgens het besluit van het College van Decanen, in het openbaar te verdedigen

op woensdag 1 juli 2009 om 16:00 uur

door

Sandra Beijer

Geboren op 27 december 1966 te Heerlen

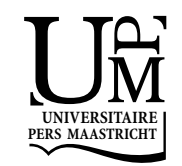




\section{Promotor}

Prof. dr. ir. P.A. van den Brandt

\section{Copromotor}

Dr. ir. P.C. Dagnelie

\section{Beoordelingscommissie}

Prof. dr. M.F. von Meyenfeldt (voorzitter)

Dr. J.F.B.M. Fiolet

Prof. dr. P.A.B.M. Smits (Radboud Universiteit Nijmegen)

Dr. S.C.C.M. Teunissen (Universitair Medisch Centrum Utrecht)

Prof. dr. V.C.G. Tjan-Heijnen 
"Behalve lotgenoten zal niemand kunnen invoelen wat ik heb moeten ondergaan, moeten doorstaan......lichamelijk en geestelijk. Je zo machteloos voelen door de verlammende vermoeidheid, geen vertrouwen meer hebben in je lijf door de dagelijkse verslechteringen, de afmattende koorts, het eten en drinken als een kwelling te moeten ervaren. 'Lekker' is een ver-van-mijn-bed begrip, want niets is lekker. Lekker is uit mijn leven verbannen. Je immobiliteit en zeer beperkte horizon, 'leven binnen 4 muren', leven met al zijn onzekerheden voor de toekomst, het zo afhankelijk zijn, niet weken maar maanden".

Uit het dagboek van Riky Lamers († 2008) 



\section{CONTENTS}

Chapter $1 \quad$ General introduction

Chapter 2 Determinants of overall quality of life in

preterminal cancer patients

Chapter 3 Application of adenosine 5'-triphosphate (ATP)

infusions in palliative home care: design of a

randomised clinical trial

Chapter $4 \quad$ Intravenous ATP infusions can be safely administered in the home setting: a study in preterminal cancer patients

Chapter $5 \quad$ Treatment adherence and patients' acceptance of home infusions with adenosine $5^{\prime}$-triphosphate (ATP) in palliative home care

Chapter 6 Effect of ATP infusions on the nutritional status and survival of preterminal cancer patients

Chapter $7 \quad$ Randomised clinical trial on the effects of ATP infusions on quality of life, functional status and fatigue in preterminal cancer patients

Chapter $8 \quad$ General discussion

Chapter $9 \quad$ Summary

Samenvatting

Dankwoord

Over de auteur 

Chapter 1

General introduction 



\section{CANCER}

Cancer is a major public health problem. In 2002, 10.9 million new cancer cases and 6.7 million cancer deaths were reported worldwide, and the world prevalence was 24.6 million persons [1-3]. The most commonly diagnosed cancers worldwide in 2002 were lung (1.3 million), breast ( 1.15 million), and colorectal cancer ( 1 million); the most common causes of cancer death in 2002 were lung cancer (1.18 million deaths), stomach cancer (700,000 deaths), and liver cancer (598,000 deaths) [1-3]. In the Netherlands, in 2003, about 73,000 new cancer cases were detected, 37,500 in men and 35,500 in women [4]. The most commonly diagnosed cancers are breast cancer followed by colon cancer, lung cancer and prostate cancer. Ageadjusted incidence per tumour location is shown in Table 1.

Table 1. Age-adjusted incidence per 100,000 men and women per year in the Netherlands, 2003 (The Netherlands Cancer Registry).

\begin{tabular}{lcc}
\hline Tumour location & Men & Women \\
\hline Head and neck & 20 & 8 \\
Oesophagus & 12 & 4 \\
Stomach & 15 & 6 \\
Pancreas & 8 & 6 \\
Colon / rectum & 61 & 43 \\
Lung & 72 & 31 \\
Breast & 1 & 124 \\
Ovary & - & 11 \\
Cervix & - & 6 \\
Endometrial & - & 17 \\
Bladder & 21 & 5 \\
Prostate & 93 & - \\
Kidney & 11 & 6 \\
Melanoma & 14 & 18 \\
Leukaemia & 10 & 6 \\
Hodgkin lymphoma & 3 & 2 \\
Non-Hodgkin lymphoma & 16 & 11 \\
Multiple myeloma & 5 & 4 \\
Brain tumours & 6 & 5 \\
\hline
\end{tabular}

In the Netherlands, cancer is, together with cardiovascular diseases, the major cause of death. In 2003, 38,200 persons died from cancer [4]. Survival probabilities depend on the tumour type and the stage of disease at diagnosis. Approximately half of the cancer patients can be cured. Curative treatment can be achieved by surgery, radiation therapy, chemotherapy, hormonal therapy, or a combination of these treatments. 


\section{PALLIATIVE CARE}

The World Health Organisation defines palliative care as 'an approach to care which improves the quality of life (QoL) of patients and their families facing the problem associated with life-threatening illness, through the prevention and relief of suffering by means of early identification and impeccable assessment and treatment of pain and other problems, physical, psychosocial and spiritual' $[5,6]$. The palliative phase starts at the moment that cure is not or no longer possible. The transition point in the continuum of cancer care is the moment in which treatment with curative intent must give way to treatment restricted to improvement or maintenance of QoL (Figure 1) [7, 8].

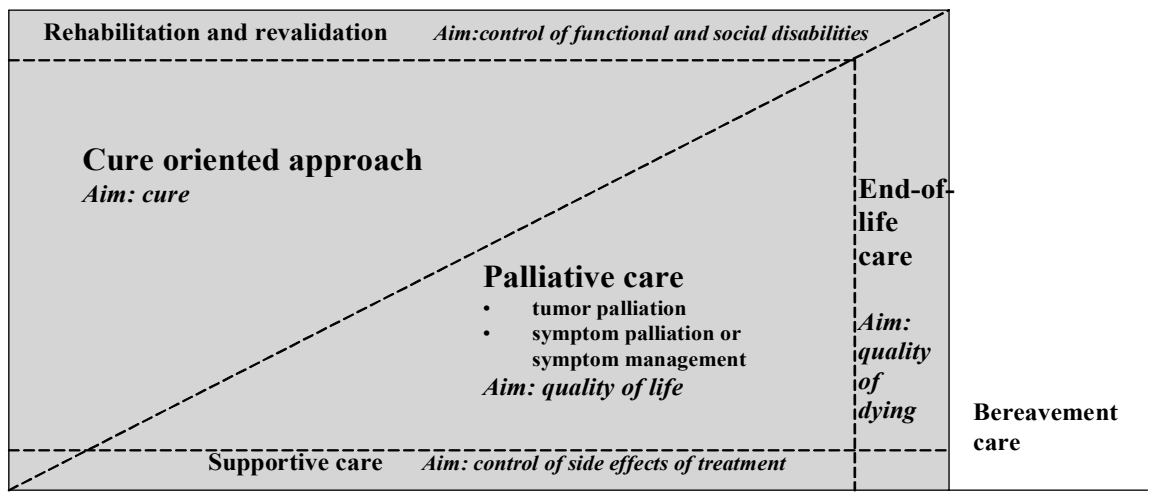

Diagnosis

Death

Figure 1. The continuum of cancer care: From S. Teunissen [7] with permission.

The aim of palliative treatment is to relieve disease symptoms in order to optimize the QoL of the patient as well as his/her family and friends [9]. A distinction must be made between tumour-directed palliation (i.e. palliative chemotherapy, radiotherapy or surgery) and symptom-oriented palliative therapy [7], which are often administered together. Tumour-directed palliation can be given to treat symptoms but also to potentially prolong a patient's life. However, as the disease advances and there is proportionately less to offer in terms of life prolongation, the focus of care progressively shifts towards comfort and QoL [10]. Furthermore, when perceived benefits are not outweighing the disadvantages, it is important to discontinue tumour-directed palliation and to restrict further treatment to symptom-oriented palliative care [8]. 


\section{QUALITY OF LIFE}

Despite the widespread use of the term 'quality of life', no precise common definition exists [11]. The World Health Organisation defines quality of life (QoL) as 'individuals' perceptions of their position in life in the context of the culture and value system in which they live and in relation to their goals, standards, and concerns' [12].

The major domains of QoL include physical, psychological and spiritual well-being, and social aspects [13]. Advanced cancer dramatically affects all dimensions of QoL $[14,15]$. For physical well-being, this is paramount as terminal ill patients and families confront multiple symptoms such as pain, shortness of breath, nausea, and restlessness [13]. Psychological well-being is threatened by fears, as well as by anxiety and depression, and social well-being is threatened by the loss of one's roles and relationships, as well as the intense financial burden of illness. Hwang et al. [14] reported steady deterioration in QoL from 6 months prior to death, with significant acceleration in the last 2-3 months prior to death. Each domain demonstrated its own pattern of acceleration.

Patients with the same level of objective symptoms may differ in QoL because of differences in perceived importance of the symptom or other social or psychological factors [16]. QoL depends on the unique experience of life for each person, so patients are the only proper judges of their QoL.

Benoliel [17] was one of the first researchers to focus on symptoms and to recognize the link between symptoms and QoL concerns. Symptom control is an important element of effective palliative care. A large number of studies have shown a high prevalence of debilitating symptoms in patients with advanced cancer. Patients often suffer from progressive fatigue, anorexia, weight loss and a decline in their general condition, leading to reduced functional status and impaired QoL [18-24].

\section{CANCER-RELATED FATIGUE}

Cancer-related fatigue is reported by $60 \%$ to $90 \%$ of patients with advanced cancer as their most frequent and debilitating symptom, even more so than pain [25-28]. The National Comprehensive Cancer Network defines cancer-related fatigue as a 'distressing, persistent, subjective sense of tiredness or exhaustion related to cancer or cancer treatment that is not proportional to recent activity and interferes with usual functioning' [29]. Cancer-related fatigue is qualitatively quite different from fatigue described by healthy individuals after normal physical or mental exertion, and is only partially or not at all relieved by rest or sleep [30-32]. 
Fatigue is generally recognized as a multidimensional construct, with a physical and cognitive dimension. Physical fatigue relates to the inability to maintain power output, and is perceived as a sensation of weakness and/or a sense of greater effort required to accomplish a task. Additionally, fatigue includes psychological dimensions such as mental fatigue and reduced motivation expressed as reduced capacity for attention, concentration, as well as a disturbance in short-term memory [25].

The pathophysiology of fatigue in advanced cancer is not fully understood. Fatigue can either be caused directly by the underlying cancer (primary fatigue), or be related to concurrent syndromes such as anaemia, cachexia, fever, infections, dehydration, electrolyte imbalance, and pain (secondary fatigue). Also psychological factors like depression, anxiety and sleep disturbances, as well as sedative drugs for symptom control can contribute to the feeling of fatigue [32-34]. Primary fatigue is thought to be related to the tumour itself, by mechanisms which may be related to high levels of cytokines or tumour-related factors [31, 33, 35].

Based on the finding of reduced levels of ATP in the skeletal muscle of cancer patients [36], it has also been hypothesized that cancer and/or its treatment lead to a defect in the mechanism for regenerating ATP in skeletal muscle, thereby compromising the ability to perform mechanical tasks [37]. Evidence of disruption of ATP metabolism in the muscles of patients with cancer is limited. However, patients with cancer often have reduced energy intake, which may limit ATP repletion in different organs. For instance, Leij-Halfwerk et al. [38] showed significantly lower ATP levels in the liver of patients with $\geq 5 \%$ weight loss compared to patients with $<5 \%$ weight loss and healthy subjects.

The treatment of cancer-related fatigue first of all includes treatment of potentially underlying causes of secondary fatigue. Pain is to be managed; blood transfusions can be given to correct anaemia; infections and fever can be treated; and biphosphonates can be given in case of electrolyte imbalance [33]. Where there is no obvious aetiology for fatigue or no reversible cause can be identified, symptomatic interventions may be applied.

Although methylphenidate (psycho stimulant) was reported to ameliorate fatigue in patients with advanced cancer $[39,40]$, a recent placebo-controlled trial has challenged these results, as both methylphenidate and placebo improved fatigue with no significant advantage of methylphenidate [41]. Anecdotal observation and very limited data from controlled trials support the use of low-dose corticosteroids in fatigued patients with advanced cancer and multiple symptoms [42]. In a randomised trial in patients with advanced cancer, methylprednisolone resulted in improved daily activity in $68 \%$ of the patients [43]. Other randomised trials showed no significant effect of corticosteroids on strength [44], and no or only transient improvement of weakness $[45,46]$. Fatigue was not a primary outcome parameter in these studies, and evidence on the impact of steroids on fatigue is still pending 
[33]. However, clinical experience suggests that corticosteroids may be effective in relieving fatigue for a short period of time, usually one or two weeks [33].

Physical exercise has attracted increased interest in rehabilitation of oncological patients in general and also in palliative care [47], but still little information is available on incurable cancer patients with limited life expectancy [48]. Results of an uncontrolled (phase II) study in incurable cancer patients with a life expectancy between 3 and 12 months showed that a 50-minute group exercise programme twice per week for 6 weeks was reported to reduce fatigue [48] and that a high proportion of incurable cancer patients were willing to participate in this structured exercise programme [49].

\section{CACHEXIA-ANOREXIA SYNDROME}

The cancer cachexia-anorexia syndrome is characterized by anorexia, decreased food intake, progressive involuntary weight loss with depletion of lean body mass, muscle wasting and weakness, oedema, impaired immune response and a decline in mental function. Cancer cachexia-anorexia is thus associated with poor performance status and compromised QoL $[50,51]$. The prevalence of cancer cachexia is high, with figures up to $80 \%$ being reported in patients with advanced cancer [51-53]. Cancer cachexia is associated with a worse prognosis [54-57], and in some cases, excessive weight loss may itself be the direct cause of death $[53,58]$. The pathophysiology of cancer-associated cachexia has two main components: a failure of food intake and a systemic hypermetabolism/hypercatabolism syndrome [59-61].

A significant number of patients consume less energy than required to cover even the basal costs of metabolism [55, 57, 59, 62-64]. Many symptoms reported in patients with advanced cancer such as pain, dry mouth, early satiety, taste and smell change, food aversion, constipation, anorexia, bloating, nausea and vomiting can diminish nutritional intake dramatically. Also psychological factors, including anxiety, depression, and family and spiritual distress, may contribute to the patient's inability to eat. The inability to eat can be distressful, especially for family members [65]. Family members may press the patient to eat, and although this may be done in the sincere belief that it is in the patient's best interest and constitutes a means of fighting back or exerting control over the disease, this may become a considerable source of conflict between the patient and the family [65].

Decreased food intake can not by itself account for the complex organic alterations seen in the cachexia-anorexia syndrome. Whereas starvation and chronic malnutrition in otherwise healthy persons are associated with adaptive decreases in metabolic rate, increased economy of energy fuel utilization and loss of body fat with sparing of skeletal muscle [51], cancer cachexia is characterized by marked 
metabolic abnormalities in carbohydrate, protein and lipid metabolism $[50,60,66]$. Abnormalities in carbohydrate metabolism include decreased glucose tolerance, insulin resistance, as well as increased gluconeogenesis and Cori cycle activity (the hepatic recycling of lactate, produced by red blood cells and muscle during anaerobic respiration, to glucose). Pathological changes in protein metabolism include increased protein turnover, muscle catabolism, liver acute phase protein synthesis, and increased tumour protein synthesis, whereas muscle protein synthesis is decreased. Abnormalities in lipid metabolism include enhanced lipid mobilization, elevated whole-body lipolysis, decreased lipogenesis, and decreased lipoprotein lipase activity [50, 67-70].

A number of proinflammatory cytokines produced by the tumour, or by the host immune system in response to the tumour, including interleukin 1 (II-1), II-6, tumour necrosis factor (TNF)- $\alpha$, interferon (IFN)- $\gamma$ are proposed to play a pivotal role in the aetiology of the cancer cachexia-anorexia syndrome [50, 59-61, 71]. Elevated serum concentrations of II-1, II-6 and TNF- $\alpha$ have been found in cancer patients and the concentration of these cytokines seems to be correlated with tumour progression [72].

So far, no effective treatment options for the cancer cachexia-anorexia syndrome are available. Nutritional supplementation alone is not able to effectively reverse the process of cachexia [51, 60,61,68]. Pharmacological approaches have also been disappointing. Progestative agents (megestrol acetate; medroxyprogesterone acetate) were reported to improve food intake and weight gain in patients with cancer [50, 59, 73, 74], but have numerous limitations. First, they are only effective in $\approx 30 \%$ of subjects; second, weight gain is invariably composed of fat; and third, they are catabolic to skeletal muscle [59].

Corticosteroids induce a usually temporary (limited to a few weeks) effect on symptoms such as appetite, food intake, nausea, sensation of well-being and performance status, but no beneficial effect on body weight. In view of the wide range of well-known adverse effects of corticosteroids, they are only recommended in patients in the end-stage of cancer with a short expected survival [75].

A number of drugs such as cyproheptadine and hydralazine failed to show a beneficial effect on appetite or body weight. For appetite stimulants (cannabinoids, ghrelin), anabolic drugs (steroids, growth hormone, insulin-like growth factor 1) and anti-inflammatory drugs (cytokine inhibitors, statins, thalidomide), there is no substantial evidence of an effect on appetite and body weight in cancer patients $[50,59]$.

Although supplementation with eicosapentanoic acid (EPA) seemed to be beneficial in two uncontrolled phase II trials [76, 77], three randomised trials failed to show any beneficial effect in patients with cancer cachexia [78-80]. Furthermore, EPA 
supplementation alone or in combination with megestrol acetate did not improve weight or appetite better than megestrol acetate alone [81].

Because neither nutritional supplementation nor pharmacological interventions have been able to reverse cachexia, research on novel approaches to counteract cancer cachexia remains highly relevant.

\section{ADENOSINE 5'-TRIPHOSPHATE AS A NOVEL MODALITY TO IMPROVE NUTRITIONAL STATUS AND QOL IN PATIENTS WITH CANCER}

Adenosine $5^{\prime}$-triphosphate (ATP) is a naturally occurring nucleotide consisting of a purine base (adenine), ribose and three phosphate groups, which is present in every cell of the human body (Figure 2 ).

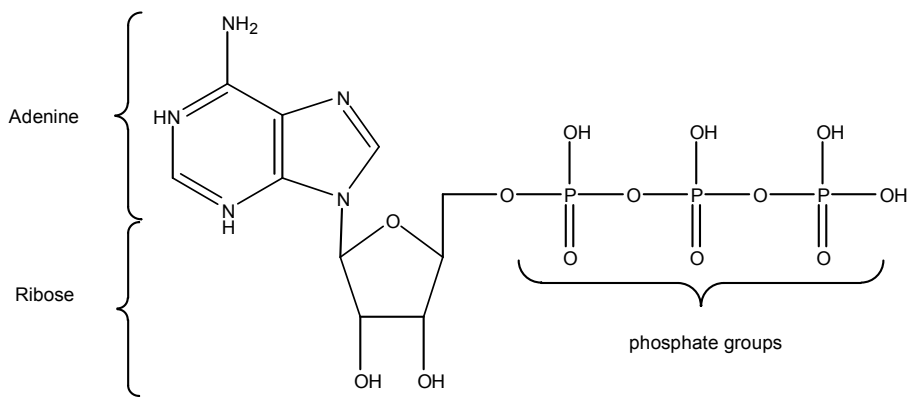

Figure 2. Structure of ATP.

Whereas ATP is primary known for its role in intracellular energy metabolism, it is also widely distributed outside the cell. Extracellular ATP and its breakdown product adenosine are involved in the regulation of numerous biological processes such as neurotransmission, muscle contraction, cardiac function, platelet function, vasodilatation, and liver glycogen metabolism [82]. These effects are mediated by both P1 and P2 receptors. In general, the effects of adenosine are thought to be mediated through P1 receptors, whereas ATP binds to P2 receptors.

Recently, it has been shown that ATP has an inhibitory effect on release of TNF- $\alpha$ [83], a proinflammatory cytokine which plays a direct role in cancer-associated cachexia and fatigue. Two small uncontrolled studies, a phase I study in patients of mixed tumour types [84] and a phase II study in patients with non-small-cell lung cancer (NSCLC) [85], suggested that infusion of ATP $(50-100 \mu \mathrm{g} / \mathrm{kg} \cdot \mathrm{min}$, in 3 series of $96 \mathrm{~h}$ given at 4-weeks intervals) might inhibit weight loss, improve performance 
status, and increase survival. A randomised clinical trial (RCT) with ATP in patients with NSCLC performed by Agteresch et al. [86, 87], showed that ATP infusions, given over $30 \mathrm{~h}$ at 2- to 4- week intervals for a period of 24 weeks, had marked beneficial effects on nutritional status and QoL. Mean weight changes per 4-week period were $-1.0 \mathrm{~kg}$ in the control group and $0.2 \mathrm{~kg}$ in the ATP group. The control group lost $-0.6 \mathrm{~kg}$ of fat mass and $-0.5 \mathrm{~kg}$ of fat free mass per 4 weeks whereas no change in body composition was found in the ATP group. Elbow flexor muscle strength declined by $-5.5 \%$ per 4 weeks in the control group but remained stable in the ATP treated patients. A similar difference was observed in knee extensor muscles [86]. QoL showed significant less deterioration in the ATP group than in the control group for physical, functional and overall QoL scores. Comparison of single items showed significant beneficial effects of ATP on tiredness, lack of energy, appetite, shortness of breath, sore muscles, shivering, constipation, and difficulties in concentrating [86]. ATP treatment was also associated with a significant increase in survival in patients with stage IIIB NSCLC and previous weight loss (defined as $\geq 5 \%$ overall weight loss, i.e. long-term weight loss since the begin of the disease) [88].

\section{AIMS OF THE THESIS}

Based on the favourable effects of intravenous ATP administration in patients with advanced NSCLC on nutritional status and QoL, the aim of the present study was to investigate the clinical effects of ATP infusions on fatigue, physical restriction and QoL (primary outcomes), and on the nutritional status (secondary outcome) of preterminal cancer patients. Based on the previously observed effects of ATP on survival in patients with advanced NSCLC, we also investigated the effect of ATP on survival. Moreover, in order to reduce the burden of repeated hospital visits for patients, and based on the favourable safety profile of ATP, we developed and implemented a standardized protocol for ATP administration in the home setting. In the present study, we evaluated the safety and logistic aspects, as well as patients' acceptance, of ATP infusions at home.

\section{OUTLINE OF THE THESIS}

This thesis is structured as follows. Chapter 2 focuses on the contribution of different determinants on the overall QoL in preterminal cancer patients. Chapter 3 describes the design of a RCT in patients with preterminal cancer with mixed tumour types. In the chapters 4-7, the results of this RCT are reported: chapter 4 describes the side effects of ATP infusions. This is followed by a description of the 
treatment adherence and patients' acceptance of ATP infusions at home in chapter 5. Chapter 6 describes the effects of ATP on nutritional status and survival and chapter 7 the effects on QoL, functional status, muscle strength and fatigue. Finally, in chapter 8 , the findings described in the earlier chapters are discussed. 


\section{REFERENCES}

1. GLOBOCAN 2002, Cancer incidence, mortality and prevalence worldwide, IARC CancerBase No. 5, version 2.0, IARC Press. Lyon, France. http://www-dep.iarc.fr/globocan/database.htm

2. Parkin DM, Bray F, Ferlay J, Pisani P. Global cancer statistics, 2002. CA Cancer J Clin 2005; 55: 74108.

3. Kamangar F, Dores GM, Anderson WF. Patterns of cancer incidence, mortality, and prevalence across five continents: defining priorities to reduce cancer disparities in different geographic regions of the world. J Clin Oncol 2006; 24: 2137-50.

4. The Netherlands Cancer Registry. http//www.ikcnet.nl.

5. World Health Organization. Definition of palliative care. www.who.int/cancer/palliative/definition, 2006.

6. Sepulveda C, Marlin A, Yoshida T, Ullrich A. Palliative Care: the World Health Organization's global perspective. J Pain Symptom Manage 2002; 24: 91-6.

7. Teunissen S. In palliative cancer care symptoms mean everything. Symptoms \& symptom management in palliative care for cancer patients. Faculty of Medicine. Utrecht: University Utrecht; 2007: 9-23.

8. Zylicz Z, Teunissen SCCM, de Graeff A. Inleiding. In: de Graeff A, Hesselmann GM, Krol RJA, Kuyper $\mathrm{MB}$, Verhagen $\mathrm{EH}$, Vollaard EJ, editors. Palliatieve zorg: richtlijnen voor de praktijk. Utrecht: Vereniging voor Integrale Kankercentra; 2006: 13-32.

9. Kim A, Fall P, Wang D. Palliative care: optimizing quality of life. J Am Osteopath Assoc 2005; 105: S9-14.

10. Byock I. Completing the continuum of cancer care: integrating life-prolongation and palliation. CA Cancer J Clin 2000; 50: 123-32.

11. Kaasa S, Loge JH. Quality of life in palliative care: principles and practice. Palliat Med 2003; 17: 1120.

12. Ahmedzai SH, Costa A, Blengini C, Bosch A, Sanz-Ortiz J, Ventafridda V, et al. A new international framework for palliative care. Eur J Cancer 2004; 40: 2192-200.

13. Ferrell BR. Overview of the domains of variables relevant to end-of-life care. J Palliat Med 2005; 8: S22-9.

14. Hwang SS, Chang VT, Fairclough DL, Cogswell J, Kasimis B. Longitudinal quality of life in advanced cancer patients: pilot study results from a VA medical cancer center. J Pain Symptom Manage 2003; 25: 225-35.

15. Lo RS, Woo J, Zhoc KC, Li CY, Yeo W, Johnson P, et al. Quality of life of palliative care patients in the last two weeks of life. J Pain Symptom Manage 2002; 24: 388-97.

16. Steele LL, Mills B, Hardin SR, Hussey LC. The quality of life of hospice patients: patient and provider perceptions. Am J Hosp Palliat Care 2005; 22: 95-110.

17. Benoliel JQ. The nurse and the dying patient. New York: McMillan; 1967.

18. Walsh D, Donnelly S, Rybicki L. The symptoms of advanced cancer: relationship to age, gender, and performance status in 1,000 patients. Support Care Cancer 2000; 8: 175-9.

19. de Vogel-Voogt E. Living till the end: Cancer patients in the last phase of life. Rotterdam: Erasmus University; 2006: 37-51.

20. Teunissen SC, Wesker W, Kruitwagen C, de Haes HC, Voest EE, de Graeff A. Symptom prevalence in patients with incurable cancer: a systematic review. J Pain Symptom Manage 2007; 34: 94-104.

21. Stromgren AS, Groenvold M, Pedersen L, Olsen AK, Sjogren P. Symptomatology of cancer patients in palliative care: content validation of self-assessment questionnaires against medical records. Eur J Cancer 2002; 38: 788-94.

22. Von Roenn JH, Paice JA. Control of common, non-pain cancer symptoms. Semin Oncol 2005; 32 : 200-10.

23. Schuit KW, Sleijfer DT, Meijler WJ, Otter R, Schakenraad J, van den Bergh FC, et al. Symptoms and functional status of patients with disseminated cancer visiting outpatient departments. J Pain Symptom Manage 1998; 16: 290-7.

24. Potter J, Hami F, Bryan T, Quigley C. Symptoms in 400 patients referred to palliative care services: prevalence and patterns. Palliat Med 2003; 17: 310-4. 
25. Ryan JL, Carroll JK, Ryan EP, Mustian KM, Fiscella K, Morrow GR. Mechanisms of cancer-related fatigue. Oncologist 2007; 12: S22-34.

26. Vogelzang NJ, Breitbart W, Cella D, Curt GA, Groopman JE, Horning SJ, et al. Patient, caregiver, and oncologist perceptions of cancer-related fatigue: results of a tripart assessment survey. The Fatigue Coalition. Semin Hematol 1997; 34: S4-12.

27. Curt GA, Breitbart W, Cella D, Groopman JE, Horning SJ, Itri LM, et al. Impact of cancer-related fatigue on the lives of patients: new findings from the Fatigue Coalition. Oncologist 2000; 5: 35360.

28. Stone P, Hardy J, Broadley K, Tookman AJ, Kurowska A, A'Hern R. Fatigue in advanced cancer: a prospective controlled cross-sectional study. Br J Cancer 1999; 79: 1479-86.

29. National Comprehensive Cancer Network. Definition of cancer-related fatigue. www.nccn.org/physician_gls/PDF/fatigue.pdf

30. Morrow GR, Shelke AR, Roscoe JA, Hickok JT, Mustian K. Management of cancer-related fatigue. Cancer Invest 2005; 23: 229-39.

31. Gutstein HB. The biologic basis of fatigue. Cancer 2001; 92: S1678-83.

32. Barnes EA, Bruera E. Fatigue in patients with advanced cancer: a review. Int J Gynecol Cancer 2002; 12: 424-8.

33. Radbruch L, Strasser F, Elsner F, Goncalves JF, Loge J, Kaasa S, et al. Fatigue in palliative care patients -- an EAPC approach. Palliat Med 2008; 22: 13-32.

34. Zylicz Z, Teunissen SCCM, de Graeff A. Vermoeidheid bij kanker in de palliatieve fase. In: de Graeff A, Hesselmann GM, Krol RJA, Kuyper MB, Verhagen EH, Vollaard EJ, editors. Palliatieve zorg: richtlijnen voor de praktijk. Utrecht: Vereniging voor Integrale Kankercentra; 2006: 729-44.

35. Kurzrock R. The role of cytokines in cancer-related fatigue. Cancer 2001; 92: S1684-8.

36. Collins $\mathrm{P}$, Bing $\mathrm{C}$, McCulloch $\mathrm{P}$, Williams G. Muscle UCP-3 mRNA levels are elevated in weight loss associated with gastrointestinal adenocarcinoma in humans. Br J Cancer 2002; 86: 372-5.

37. Andrews PLR, Morrow GR, Hickok JT. Mechanisms and models of fatigue associated with cancer and its treatment: Evidence of pre-clinical and clinical studies. In: Armes J, Krishnasamy M, Higginson I, editors. Fatigue in cancer. Oxford: Oxford University Press; 2004: 51-87.

38. Leij-Halfwerk S, Dagneli PC, Kappert P, Oudkerk M, Sijens PE. Decreased energy and phosphorylation status in the liver of lung cancer patients with weight loss. J Hepatol 2000; 32: 887-92.

39. Sugawara Y, Akechi T, Shima Y, Okuyama T, Akizuki N, Nakano T, et al. Efficacy of methylphenidate for fatigue in advanced cancer patients: a preliminary study. Palliat Med 2002; 16: 261-3.

40. Sarhill N, Walsh D, Nelson KA, Homsi J, LeGrand S, Davis MP. Methylphenidate for fatigue in advanced cancer: a prospective open-label pilot study. Am J Hosp Palliat Care 2001; 18: 187-92.

41. Bruera E, Valero V, Driver L, Shen L, Willey J, Zhang T, et al. Patient-controlled methylphenidate for cancer fatigue: a double-blind, randomized, placebo-controlled trial. J Clin Oncol 2006; 24: 2073-8.

42. Portenoy RK, Itri LM. Cancer-related fatigue: guidelines for evaluation and management. Oncologist 1999; 4: 1-10.

43. Bruera E, Roca E, Cedaro L, Carraro S, Chacon R. Action of oral methylprednisolone in terminal cancer patients: a prospective randomized double-blind study. Cancer Treat Rep 1985; 69: 751-4.

44. Moertel CG, Schutt AJ, Reitemeier RJ, Hahn RG. Corticosteroid therapy of preterminal gastrointestinal cancer. Cancer 1974; 33: 1607-9.

45. Popiela T, Lucchi R, Giongo F. Methylprednisolone as palliative therapy for female terminal cancer patients. The Methylprednisolone Female Preterminal Cancer Study Group. Eur J Cancer Clin Oncol 1989; 25: 1823-9.

46. Della Cuna GR, Pellegrini A, Piazzi M. Effect of methylprednisolone sodium succinate on quality of life in preterminal cancer patients: a placebo-controlled, multicenter study. The Methylprednisolone Preterminal Cancer Study Group. Eur J Cancer Clin Oncol 1989; 25: 1817-21.

47. Cheville A. Rehabilitation of patients with advanced cancer. Cancer 2001; 92: S1039-48.

48. Oldervoll LM, Loge JH, Paltiel H, Asp MB, Vidvei U, Wiken AN, et al. The effect of a physical exercise program in palliative care: A phase II study. J Pain Symptom Manage 2006; 31: 421-30. 
49. Oldervoll LM, Loge JH, Paltiel H, Asp MB, Vidvei U, Hjermstad MJ, et al. Are palliative cancer patients willing and able to participate in a physical exercise program? Palliat Support Care 2005; 3: 281-7.

50. Mantovani G, Maccio A, Massa E, Madeddu C. Managing cancer-related anorexia/cachexia. Drugs 2001; 61: 499-514.

51. Argiles JM. Cancer-associated malnutrition. Eur J Oncol Nurs 2005; 9: S39-50.

52. Strasser F, Bruera ED. Update on anorexia and cachexia. Hematol Oncol Clin North Am 2002; 16: 589-617.

53. Nelson KA. The cancer anorexia-cachexia syndrome. Semin Oncol 2000; 27: 64-8.

54. Dewys WD, Begg C, Lavin PT, Band PR, Bennett JM, Bertino JR, et al. Prognostic effect of weight loss prior to chemotherapy in cancer patients. Eastern Cooperative Oncology Group. Am J Med 1980; 69: 491-7.

55. Bosaeus I, Daneryd P, Lundholm K. Dietary intake, resting energy expenditure, weight loss and survival in cancer patients. J Nutr 2002; 132: S3465-6.

56. Stone PC, Lund S. Predicting prognosis in patients with advanced cancer. Ann Oncol 2007; 18: 9716.

57. Fearon KC, Voss AC, Hustead DS. Definition of cancer cachexia: effect of weight loss, reduced food intake, and systemic inflammation on functional status and prognosis. Am J Clin Nutr 2006; 83: 1345-50.

58. Warren S. The immediate cause of death. Am J Med Sci 1932; 184: 610-5.

59. Baracos VE. Cancer-associated cachexia and underlying biological mechanisms. Annu Rev Nutr 2006; 26: 435-61.

60. Tisdale MJ. Cancer cachexia: metabolic alterations and clinical manifestations. Nutrition 1997; 13: 1-7.

61. Argiles JM, Busquets S, Moore-Carrasco R, Figueras M, Almendro V, Lopez-Soriano FJ. Targets in clinical oncology: the metabolic environment of the patient. Front Biosci 2007; 12: 3024-51.

62. Bosaeus I, Daneryd P, Svanberg E, Lundholm K. Dietary intake and resting energy expenditure in relation to weight loss in unselected cancer patients. Int J Cancer 2001; 93: 380-3.

63. Ravasco P, Monteiro-Grillo I, Vidal PM, Camilo ME. Nutritional deterioration in cancer: the role of disease and diet. Clin Oncol (R Coll Radiol) 2003; 15: 443-50.

64. Hutton JL, Martin L, Field CJ, Wismer WV, Bruera ED, Watanabe SM, et al. Dietary patterns in patients with advanced cancer: implications for anorexia-cachexia therapy. Am J Clin Nutr 2006; 84: 1163-70.

65. McClement SE, Degner LF, Harlos MS. Family beliefs regarding the nutritional care of a terminally ill relative: a qualitative study. J Palliat Med 2003; 6: 737-48.

66. Tisdale MJ. Cancer anorexia and cachexia. Nutrition 2001; 17: 438-42.

67. Tisdale MJ. Biology of cachexia. J Natl Cancer Inst 1997; 89: 1763-73.

68. Skipworth RJ, Fearon KC. The scientific rationale for optimizing nutritional support in cancer. Eur J Gastroenterol Hepatol 2007; 19: 371-7.

69. Zuijdgeest-van Leeuwen SD, van den Berg JW, Wattimena JL, van der Gaast A, Swart GR, Wilson JH, et al. Lipolysis and lipid oxidation in weight-losing cancer patients and healthy subjects. Metabolism 2000; 49: 931-6.

70. Leij-Halfwerk S, Dagnelie PC, van Den Berg JW, Wattimena JD, Hordijk-Luijk CH, Wilson JP. Weight loss and elevated gluconeogenesis from alanine in lung cancer patients. Am J Clin Nutr. 2000 Feb;71(2):583-9.

71. Ramos EJ, Suzuki S, Marks D, Inui A, Asakawa A, Meguid MM. Cancer anorexia-cachexia syndrome: cytokines and neuropeptides. Curr Opin Clin Nutr Metab Care 2004; 7: 427-34.

72. Mantovani G, Maccio A, Mura L, Massa E, Mudu MC, Mulas C, et al. Serum levels of leptin and proinflammatory cytokines in patients with advanced-stage cancer at different sites. J Mol Med 2000; 78: 554-61.

73. Berenstein EG, Ortiz Z. Megestrol acetate for the treatment of anorexia-cachexia syndrome. Cochrane Database Syst Rev 2005: CD004310.

74. Mateen F, Jatoi A. Megestrol acetate for the palliation of anorexia in advanced, incurable cancer patients. Clin Nutr 2006; 25: 711-5. 
75. Tisdale MJ. Clinical anticachexia treatments. Nutr Clin Pract 2006; 21: 168-74.

76. Wigmore SJ, Barber MD, Ross JA, Tisdale MJ, Fearon KC. Effect of oral eicosapentaenoic acid on weight loss in patients with pancreatic cancer. Nutr Cancer 2000; 36: 177-84.

77. Barber MD, McMillan DC, Preston T, Ross JA, Fearon KC. Metabolic response to feeding in weightlosing pancreatic cancer patients and its modulation by a fish-oil-enriched nutritional supplement. Clin Sci (Lond) 2000; 98: 389-99.

78. Fearon KC, Barber MD, Moses AG, Ahmedzai SH, Taylor GS, Tisdale MJ, et al. Double-blind, placebo-controlled, randomized study of eicosapentaenoic acid diester in patients with cancer cachexia. J Clin Oncol 2006; 24: 3401-7.

79. Bruera E, Strasser F, Palmer JL, Willey J, Calder K, Amyotte G, et al. Effect of fish oil on appetite and other symptoms in patients with advanced cancer and anorexia/cachexia: a double-blind, placebocontrolled study. J Clin Oncol 2003; 21: 129-34.

80. Fearon KC, Von Meyenfeldt MF, Moses AG, Van Geenen R, Roy A, Gouma DJ, et al. Effect of a protein and energy dense N-3 fatty acid enriched oral supplement on loss of weight and lean tissue in cancer cachexia: a randomised double blind trial. Gut 2003; 52: 1479-86.

81. Jatoi A, Rowland K, Loprinzi CL, Sloan JA, Dakhil SR, MacDonald N, et al. An eicosapentaenoic acid supplement versus megestrol acetate versus both for patients with cancer-associated wasting: a North Central Cancer Treatment Group and National Cancer Institute of Canada collaborative effort. J Clin Oncol 2004; 22: 2469-76.

82. Agteresch HJ, Dagnelie PC, van den Berg JW, Wilson JH. Adenosine triphosphate: established and potential clinical applications. Drugs 1999; 58: 211-32.

83. Swennen EL, Bast A, Dagnelie PC. Immunoregulatory effects of adenosine 5'-triphosphate on cytokine release from stimulated whole blood. Eur J Immunol 2005; 35: 852-8.

84. Haskell CM WM, Williams A, Lee LY. Phase I trial of extracellular adenosine 5'-triphosphate in patients with advanced cancer. Med Pediatr Oncol 1996; 27: 165-73.

85. Haskell CM ME, Pisters KM, Fossella FV, Figlin RA. Phase II study of intravenous adenosine 5'triphosphate in patients with previously untreated stage IIIB and stage IV non-small cell lung cancer. Invest New Drugs 1998; 16: 81-5.

86. Agteresch HJ, Dagnelie PC, van der Gaast A, Stijnen T, Wilson JH. Randomized clinical trial of adenosine 5 '-triphosphate in patients with advanced non-small-cell lung cancer. J Natl Cancer Inst 2000; 92: 321-8.

87. Agteresch HJ, Rietveld T, Kerkhofs LG, van den Berg JW, Wilson JH, Dagnelie PC. Beneficial effects of adenosine triphosphate on nutritional status in advanced lung cancer patients: a randomized clinical trial. J Clin Oncol 2002; 20: 371-8.

88. Agteresch HJ, Burgers SA, van der Gaast A, Wilson JH, Dagnelie PC. Randomized clinical trial of adenosine 5 '-triphosphate on tumor growth and survival in advanced lung cancer patients. Anticancer Drugs 2003; 14: 639-44. 



\section{Chapter 2}

\section{Determinants of overall quality of life in preterminal cancer patients}

S. Beijer, G.I. Kempen, M.C. Pijls-Johannesma, A. de Graeff, P.C. Dagnelie

International Journal of Cancer 2008; 123: 232-235 


\section{ABSTRACT}

\section{Aim}

Recently, a few studies reported that fatigue was a predominant contributor to patient-perceived overall quality of life (QoL) in patients with different types of cancer in a relatively early stage of disease. In the present study, we aimed to investigate whether fatigue is also a major contributor to overall QoL in preterminal cancer patients.

\section{Methods}

Ninety-eight preterminal cancer patients, mainly lung (44\%) and gastrointestinal cancer (25\%), with an estimated life expectancy of 1-6 months were included. QoL domains as well as overall QoL were measured using the EORTC QLQ-C30 questionnaire. Data were analysed by Pearson's correlations and multivariate modelling.

\section{Results}

Fatigue showed the strongest correlation with overall QoL $(r=-0.63, p<0.001)$, followed in decreasing order by role functioning ( $r=0.53)$, physical functioning ( $r=$ $0.47)$, social functioning ( $r=0.44)$, nausea ( $r=-0.37)$, cognitive functioning ( $r=0.33)$, appetite loss $(r=-0.31)$, dyspnoea $(r=-0.26)$ and emotional functioning $(r=0.24)$. Multivariate analysis confirmed that the fatigue scale paid by far the highest individual contribution to overall QoL (standardized regression coefficient (SRC): $0.41, p=0.002$ ), followed by social functioning (SRC: $0.18, p=0.05$ ). None of the other domains or symptom scales contributed independently to overall QoL.

\section{Conclusion}

Our results clearly demonstrate that in preterminal cancer patients, fatigue is a major contributor of overall QoL, corroborating reports in cancer patients in earlier disease stages. 


\section{INTRODUCTION}

Symptom management and improvement of patients' quality of life (QoL) are nowadays considered as important health care goals. According to the World Health Organisation (WHO), the ultimate goal of palliative care is the achievement of the best QoL for patients and their families [1]. To reach this goal, it is important to recognize problems and symptoms that interfere with patients' experience of QoL.

Preterminal cancer patients often suffer from a wide variety of complaints [2]. Fatigue and pain have been reported to be the most common symptoms, reported by respectively $80-96 \%$ and $86-91 \%$ of these patients; other frequently reported symptoms are dyspnoea, anorexia, weight loss and impaired physical functioning [3-8]. A systematic review in patients with incurable cancer showed that five symptoms (fatigue, pain, lack of energy, weakness and appetite loss) were present in more than $50 \%$ of the patients. Four symptoms (fatigue, weight loss, weakness, and appetite loss) were present in $>50 \%$ of patients during the last $1-2$ weeks of life [9].

A number of reports have described patients' views on the impact of symptoms on their QoL. When patients were asked to name and prioritise up to five symptoms that they considered the most troublesome, pain was prioritised most often, followed by fatigue, poor physical function, reduced appetite, and nausea/vomiting [10]. Groenvold et al. [11] interviewed patients in palliative care to determine the patient-perceived appropriateness, relevance and importance of the various domains of the EORTC QLQ-C30. The pain scale was most frequently selected and was rated as highly relevant, followed by the physical functioning and fatigue scales [11]. Cohen and Leis [12] also interviewed patients receiving palliative care in order to understand the primary determinants relevant to the QoL of terminally ill cancer patients. Five broad domains were perceived by patients to be important determinants of their QoL: the patient's own state (including physical functioning, cognitive functioning, psychological state and physical condition); quality of palliative care; physical environment; relationships and outlook. Physical symptoms most commonly cited were pain, fatigue/lack of energy, sleep disturbances and nausea/vomiting.

Despite the aforementioned on patient-perceived relevance of different symptoms and domains of functioning to their overall QoL, there are relatively few reports on the quantitative contribution of these domains to overall QoL in cancer patients. Allison et al. [13] described the correlation between individual scores on the EORTC QLQ-C30 domains and global QoL score in patients with cancer in the upper aerodigestive tract in different stages of disease. The physical, fatigue and emotional domains had the strongest correlation with global QoL scores. A study from Arndt et al. [14] in women with breast cancer one year after diagnosis showed 
that fatigue explained 39\% of the variance of overall QoL measured by the EORTC QLQ-C30. Other symptoms explained very little of the remaining variance. Ahlberg et al. [15] showed a significant inverse relationship between general fatigue and global QoL over time in patients with uterine cancer during radiotherapy. Östlund et al. [16] explored which dimensions of health-related QoL predict global ratings of overall QoL in lung cancer patients in different stages of disease. In multiple regression analyses, the only significant predictors of overall QoL were emotional functioning and fatigue. Dagnelie et al. [17] recently evaluated the relative impact of different QoL domains/scales on overall QoL in patients with lung and breast cancer selected for high-dose radiotherapy, i.e. a relatively early stage of cancer. Results showed that, again, of all QoL domains/scales, fatigue was the predominant contributor to patient-perceived overall QoL in these patients. Fatigue is a multidimensional concept with several modes of expression: physical, cognitive, in activity or in motivation; fatigue can be either acute or chronic [18].

So far, little is known regarding the relative contributions of different domains of functioning and symptoms to overall QoL in preterminal cancer patients. These contributions might be quite different compared to earlier stages of disease [19, 20]. Since knowledge about aspects determining patients' perceived QoL during deterioration of disease is important to further improve end-of-life care, we investigated the relative contributions of different domains of functioning and symptoms to overall QoL in preterminal cancer patients, defined as an estimated life expectancy of 1-6 months.

\section{PATIENTS AND METHODS}

\section{Study population and design}

The present study was part of a randomised clinical trial aimed at evaluating the effects of ATP infusions over eight weeks (versus no ATP) on QoL, fatigue, and physical restriction in preterminal cancer patients [21]. Baseline measurements were used to assess several QoL domains, symptoms and overall QoL in a crosssectional design. Eligible were patients with cytologically or histologically confirmed cancer, for whom medical treatment options were restricted to supportive care, who had a life expectancy $<6$ months, had a WHO performance status 1 or 2 , and suffered from at least one of the following complaints: fatigue, weight loss $>5 \%$ over the last 6 months or anorexia. Exclusion criteria were symptomatic angina pectoris, symptomatic heart failure, atrioventricular block as assessed by electrocardiogram, life expectancy $<4$ weeks, concurrent palliative chemotherapy, cognitive dysfunction and the presence of other diseases hampering adequate follow-up. Patients were recruited through the Departments of Medical Oncology and Pulmonology of five hospitals in different regions in the Netherlands 
(Maastricht, Eindhoven, Utrecht and Heerlen) and through general practitioners in the region of Maastricht. The study was approved by the ethical committee of the University Hospital Maastricht and Maastricht University, and all patients signed written informed consent prior to the study.

\section{Measurement instruments}

Background variables included age, gender, diagnosis, WHO performance status, percent weight loss over the last 6 months and pre-treatment (surgery, radiotherapy and/or chemotherapy). QoL was assessed using the EORTC Quality of Life Questionnaire (QLQ-C30, version 3.0) [22, 23]. The QLQ-C30 is a 30-item cancer-specific questionnaire that addresses various domains of QoL. It contains five function scales (physical functioning, role functioning, emotional functioning, cognitive functioning and social functioning), three symptom scales (fatigue, pain and nausea/vomiting), two items assessing global health and QoL, and a number of single items addressing various symptoms and perceived financial impact. A high score on a functioning or global QoL-scale represents a high level of functioning or global QoL, whereas a high score on a symptom scale or item represents a high level of symptoms or problems.

\section{Statistical analysis}

To study univariate relations between QoL scales and overall QoL, Pearson's correlation coefficients were calculated. As the dependent variable 'overall QoL', item 30 of the EORTC QLQ-C30 ('How would you rate your overall quality of life during the past week?') was used. As a check for outliers, Spearman correlations were also calculated, but as results were similar (data not shown), Pearson correlations are reported throughout this paper. To investigate the relative contribution of functioning and symptom scales and single items to overall QoL, a linear regression model was fitted. As independent variables, we included all significant QLQ-C30 scales in the univariate analysis. In order to check for potential confounding, individual potential confounders were included one by one in the regression model. Only variables that changed the regression coefficient of symptoms/scales which significantly predicted overall QoL by $>10 \%$ were included in the final model. The following variables were tested: age, gender, tumour type (lung cancer, colon cancer, other), WHO performance status, percent weight loss over the last 6 months relative to pre-illness stable weight, pre-treatment by chemotherapy (yes/no) and pre-treatment by radiotherapy (yes/no). Because none of these variables changed the regression coefficient by $>10 \%$, these variables were not included as covariates in the final model. Collinearity tests showed the absence of multicollinearity between any of the determinants included in the regression model, as shown by variance inflation factor (VIF) values $<10$ for all determinants. To compare the impact of fatigue relative to all other scales on overall QoL, two 
models were fitted, and an $F$ test ( $F$ change) was used to compare the variance (adjusted $\mathrm{R}^{2}$ ) in overall QoL explained by these models. P-values $<0.05$ (two-tailed) were considered statistically significant.

Table 1. Characteristics of the study population $(\mathrm{N}=98)$.

\begin{tabular}{|c|c|}
\hline Age (years) & $66.4 \pm 10.3^{1}$ \\
\hline \multicolumn{2}{|l|}{ Gender } \\
\hline Male & $67 \%$ \\
\hline Female & $33 \%$ \\
\hline \multicolumn{2}{|l|}{ Tumour type } \\
\hline Lung & $44 \%$ \\
\hline Gastrointestinal tract & $25 \%$ \\
\hline Other & $31 \%$ \\
\hline \multicolumn{2}{|l|}{ WHO performance status } \\
\hline 1 & $69 \%$ \\
\hline 2 & $31 \%$ \\
\hline$\%$ Weight loss last 6 months & $4.9 \pm 6.4$ \\
\hline Global health status / quality of life ${ }^{2,3}$ & $48.5 \pm 20.6$ \\
\hline Global health $^{4}$ & $47.3 \pm 21.4$ \\
\hline Overall quality of life ${ }^{5}$ & $49.7 \pm 23.6$ \\
\hline \multicolumn{2}{|l|}{ Function scales ${ }^{2}$} \\
\hline Physical functioning & $44.8 \pm 26.0$ \\
\hline Role functioning & $34.9 \pm 35.0$ \\
\hline Emotional functioning & $67.4 \pm 25.7$ \\
\hline Cognitive functioning & $75.5 \pm 27.4$ \\
\hline Social functioning & $69.6 \pm 29.2$ \\
\hline \multicolumn{2}{|l|}{ Symptom scales / items ${ }^{2}$} \\
\hline Fatigue & $61.8 \pm 26.9$ \\
\hline Nausea and vomiting & $19.0 \pm 25.6$ \\
\hline Pain & $35.7 \pm 33.9$ \\
\hline Dyspnoea & $38.8 \pm 35.1$ \\
\hline Insomnia & $20.7 \pm 30.5$ \\
\hline Appetite loss & $45.9 \pm 36.0$ \\
\hline Constipation & $22.4 \pm 32.0$ \\
\hline Diarrhoea & $7.8 \pm 21.8$ \\
\hline Financial difficulties & $8.2 \pm 21.4$ \\
\hline
\end{tabular}

${ }^{1}$ Values represent mean \pm SD, or percent if indicated; ${ }^{2}$ Scale from 0-100. Higher scores represent better levels for global health status, overall quality of life and all functioning scales; higher scores represent higher levels of symptoms/distress for all symptom scales/items (fatigue, pain etc.); ${ }^{3} \mathrm{QLQ}-\mathrm{C} 30$ scale of combined items 29 and 30; ${ }^{4}$ QLQ-C30 item 29; ${ }^{5}$ QLQ-C30 item 30. 


\section{RESULTS}

\section{Study population}

One hundred patients were enrolled for the study. Of these, one patient was ineligible because of missing cytologically or histologically confirmation of malignancy and from one patient no QoL data were available at baseline, leaving 98 patients for data analysis. Patient characteristics are presented in Table 1. Mean age of the study population was 66 years. The large majority of patients were male (67\%), and the most common diagnosis was lung cancer (44\%). Sixty-nine percent of patients had WHO performance status 1 and 31\% WHO performance status 2 . Mean weight loss over the previous 6 months amounted to $4.9 \% \pm 6.4$ (mean \pm SD).

\section{Contributions of different QoL scales to overall QoL}

Univariate correlations between functional and symptom scales and items of the QLQ-C30 and overall QoL are shown in Table 2.

Table 2. Pearson's correlations between different EORTC QLQ-C30 scales and overall QoL in preterminal cancer patients $(\mathrm{N}=98)$.

\begin{tabular}{lcc}
\hline Scale/Symptom & Correlation & P value \\
\hline Fatigue & -0.63 & $<0.001$ \\
Role functioning & 0.53 & $<0.001$ \\
Physical functioning & 0.47 & $<0.001$ \\
Social functioning & 0.44 & $<0.001$ \\
Nausea and vomiting & -0.37 & $<0.001$ \\
Cognitive functioning & 0.33 & 0.001 \\
Appetite loss & -0.31 & 0.002 \\
Dyspnoea & -0.26 & 0.009 \\
Emotional functioning & 0.24 & 0.02 \\
Pain & -0.12 & 0.25 \\
Insomnia & -0.08 & 0.45 \\
Constipation & -0.08 & 0.43 \\
Diarrhoea & -0.07 & 0.48 \\
Financial difficulties & -0.07 & 0.47 \\
\hline
\end{tabular}

Fatigue showed the strongest correlation with overall QoL $(r=-0.63, p<0.001)$, followed in decreasing order by role functioning $(r=0.53)$, physical functioning ( $r=$ $0.47)$, social functioning ( $r=0.44)$, nausea ( $r=-0.37)$, cognitive functioning ( $r=0.33)$, appetite loss $(r=-0.31)$, dyspnoea $(r=-0.26)$ and emotional functioning $(r=0.24)$. The correlation of fatigue with overall QoL was stable over time, as shown by reassessment at 8 weeks after the first measurement $(r=-0.60, p<0.001)$. 
In Table 3, the independent contributions of QLQ-C30 scales to overall QoL are shown, based on multivariate analyses. The total model explained $41 \%$ (adjusted $\mathrm{R}^{2}$ ) of the variance of overall QoL. The fatigue scale paid by far the highest individual contribution to overall QoL (standardized regression coefficient (SRC): $0.41, p=0.002$ ) followed by social functioning (SRC: $0.18, p=0.05$ ). None of the other domains or symptom scales contributed independently to overall QoL. In fact, fatigue alone explained almost the same proportion (adjusted $R^{2}=39 \%$ ) of variance in overall QoL, as when fatigue was combined with other functioning and symptoms scales in multivariate analysis (adjusted $R^{2}=41 \% ; R^{2}$ change $=2 \%$, n.s.).

Table 3. Contribution of different scales to overall QoL in preterminal cancer patients ( $\mathrm{N}=98)$.

\begin{tabular}{lll}
\hline Scale/Symptom & $\begin{array}{l}\text { Standardized regression } \\
\text { coefficients }\end{array}$ & P value \\
\hline Fatigue & -0.41 & 0.002 \\
Social functioning & 0.18 & 0.05 \\
Role functioning & 0.14 & 0.31 \\
Emotional functioning & -0.12 & 0.26 \\
Cognitive functioning & 0.11 & 0.27 \\
Dyspnoea & -0.08 & 0.36 \\
Nausea and vomiting & -0.06 & 0.53 \\
Appetite loss & -0.02 & 0.82 \\
Physical functioning & -0.01 & 0.95 \\
\hline
\end{tabular}

Total model: adjusted $\mathrm{R}^{2}=0.41$.

\section{DISCUSSION}

The aim of the present study was to assess the relative contributions of different subdomains of functioning and symptoms to overall QoL in preterminal cancer patients, defined as an estimated life expectancy of 1-6 months. As far as we know, no similar studies have been conducted so far in preterminally ill cancer patients.

Our present results clearly demonstrate that the impact of fatigue on overall QoL largely overruled the impact of any other scale or item, as shown by an univariate correlation with overall QoL of -0.63 and confirmed by multivariate analysis.

The high observed impact of fatigue on overall QoL in our study quantitatively corroborates previous qualitative studies. Fatigue has been reported to be the most frequent symptom in palliative care, which is experienced by virtually all patients with advanced disease [7, 9, 24-27]. Cancer patients in an earlier stage of disease who had received radiotherapy or chemotherapy felt that fatigue affected their daily lives more adversely than pain (61\% vs. $19 \%$ of patients) [28]. In the study from Allison et al. [13] in patients with cancer in the upper aerodigestive tract, assessing the empirical relations between different domains/scales and 
overall QoL, the physical, fatigue and emotional domains had the strongest correlation with global QoL scores. Results from the study from Dagnelie et al. [17] who evaluated the relative impact of different QoL domains/scales on overall QoL in patients with lung and breast cancer selected for high-dose radiotherapy, i.e. in a relatively early stage of cancer, also showed that, of all QoL domains/scales, fatigue was by far the predominant contributor to patient-perceived overall QoL.

The results from the present study show that pain, which is mentioned in the literature as one of the most frequent and aggravating symptom in patients with preterminal cancer, had a very low correlation with overall QoL $(r=-0.12)$, which was not statistically significant. Dagnelie et al. [17] also showed a low correlation between pain and overall QoL $(r=-0.36)$ in cancer patients preceding high-dose radiotherapy. de Vogel-Voogt [29] reported that, in cancer patients, all functional domains and most symptoms gradually deteriorated during the last year of life, with an accelerated deterioration of these parameters in the last months preceding death. However, even though pain and dyspnoea also deteriorated over time, no acceleration of this process over the last months of life was observed [29]. The authors suggested that this might indicate good symptom management in the last months of life. A recent review showed that, in the last 1-2 weeks of life in cancer patients, weight loss was significantly more prevalent and pain, nausea and urinary symptoms were significantly less prevalent as compared to the preceding period [9]. A study from Kwon et al. [30] in terminal cancer patients showed that pain was the most common and severe symptom, but that fatigue was the most important symptom interfering in the lives of terminal cancer patients. This study, however, was different from our study. The M.D. Anderson Symptom Inventory was used with 13 items to assess the patients' symptoms and 6 items to assess how much symptoms interfered with various aspects of the patients' life including general activity, mood, waking ability, normal work, relationships with others, and enjoyment of life. Stepwise multiple regression analysis was used to identify the symptom most interfering with the lives of terminal cancer patients (the sum value of the 6 interference items) and not with overall QoL [30].

Several potential limitations of the present study need consideration. First, it might be argued that the inclusion criterion: 'suffering from at least one of the following complaints: fatigue, weight loss or anorexia' might have resulted in an overestimation of the correlation between fatigue and overall QoL at baseline. However, from a statistical point of view, if the variability in fatigue in a population is less (patients with fatigue will all have relatively high fatigue scores), correlations with other variables, such as overall QoL will tend to be lower. The low empirically observed correlation between appetite loss and overall QoL in our study population (Table 2) supports this view. We therefore consider it less likely that the major impact of fatigue on overall QoL in our study would have been a mere artifact due to patient selection. 
Second, the majority of patients in our study were male, possibly affecting the results. Sex-specific analyses showed a lower correlation between fatigue and overall QoL in women. One possible explanation of this finding is that the level and variability (SD) of fatigue were lower in women than in men (data not shown), but it is also conceivable that, in women, other aspects such as role functioning are more important determinants of overall QoL than fatigue. In view of the relatively small number of females in our study population, further research is needed to investigate the gender-specific impact of fatigue on overall QoL in preterminal cancer patients.

A third possible limitation of this study is the heterogeneity of the study population with regard to tumour types. However, this issue appears to be less relevant, since some authors have reported that the course of symptoms and restrictions in functioning towards the end of life seems rather uniform for patients with different types of cancer [29, 31]. Also, the population was heterogeneous with regard to EORTC scores on both function/symptom scales and single items; however, statistically, this is not a disadvantage but rather an advantage since it would not have been possible to show correlations in a patient population which is totally homogeneous with respect to QoL and its determinants, such as fatigue.

A final limitation is that the study was not designed to gain deeper understanding of the concept of fatigue. In our study, fatigue was defined as a general feeling of debilitating tiredness or loss of energy. Although the study was not aimed to investigate the relation between fatigue and psychological factors (i.e. depressed mood), results showed a low baseline value $(32.0 \pm 33.5)$ for item 24 of the EORTC QLQ-C30 ('Did you feel depressed?') compared to fatigue (61.8 \pm 26.9$)$, indicating that depression did not play a major role in our patient population. Furthermore, low correlations were seen between item 24 and fatigue $(r=0.41)$ and item 24 and overall QoL ( $r=-0.31)$. We also did not investigate the relation between fatigue and physical factors (e.g. haemoglobin), but in a previous study, cancer patients preceding radiotherapy had high levels of fatigue despite normal haemoglobin in virtually all patients [17]. The lack of physical associates of cancer-related fatigue is one important factor limiting the treatment of fatigue, which needs further study for better understanding. Finally, since we did not interview patients about their QoL and feelings of tiredness, it could be argued that our measurement of the concept fatigue was rather limited. However, when we assessed fatigue using the Short Fatigue Questionnaire [32], the correlation with overall QoL was quite similar ( $r=-0.66, p<0.001)$, supporting the robustness of our findings. This is also illustrated by a previous study in patients with lung and breast cancer selected for curative high-dose radiotherapy [33], in which the concept of fatigue was assessed both by the Piper Fatigue Scale (PFS) [34], the Multidimensional Fatigue Inventory (MFI) [35] and the EORTC QLQ-C30. Results showed that fatigue, as measured by either of these scales, showed similar correlations with overall QoL as in the 
present study (correlation between EORTC QLQ-C30 item 30 and (i) PFS total score: $r=-0.67, p<0.001$, (ii) MFI general score: $r=-0.71, p<0.001$ ).

In conclusion, also in cancer patients with an estimated life expectancy of 1-6 months, fatigue is by far the predominant contributor to patient-perceived overall QoL. This finding emphasizes the need for the development of intervention strategies to reduce fatigue, so that the best possible overall QoL can be achieved in this preterminal stage of the disease. For improving the management of cancerrelated fatigue, better understanding of the underlying mechanism is urgently needed so that target-specific therapies can be developed. 


\section{REFERENCES}

1. Sepulveda C, Marlin A, Yoshida T, Ullrich A. Palliative Care: the World Health Organization's global perspective. J Pain Symptom Manage 2002; 24: 91-6.

2. Tsai JS, Wu CH, Chiu TY, Hu WY, Chen CY. Symptom patterns of advanced cancer patients in a palliative care unit. Palliat Med 2006; 20: 617-22.

3. Doorenbos AZ, Given CW, Given B, Verbitsky N. Symptom experience in the last year of life among individuals with cancer. J Pain Symptom Manage 2006; 32: 403-12.

4. Langendijk JA, ten Velde GP, Aaronson NK, de Jong JM, Muller MJ, Wouters EF. Quality of life after palliative radiotherapy in non-small cell lung cancer: a prospective study. Int J Radiat Oncol Biol Phys 2000; 47: 149-55.

5. Ross DD, Alexander CS. Management of common symptoms in terminally ill patients: Part I. Fatigue, anorexia, cachexia, nausea and vomiting. Am Fam Physician 2001; 64: 807-14.

6. Stromgren AS, Groenvold M, Pedersen L, Olsen AK, Sjogren P. Symptomatology of cancer patients in palliative care: content validation of self-assessment questionnaires against medical records. Eur J Cancer 2002; 38: 788-94.

7. Kaasa S, Loge JH. Quality of life in palliative care: principles and practice. Palliat Med 2003; 17: 1120.

8. Von Roenn JH, Paice JA. Control of common, non-pain cancer symptoms. Semin Oncol 2005; 32: 200-10.

9. Teunissen SC, Wesker W, Kruitwagen C, de Haes HC, Voest EE, de Graeff A. Symptom prevalence in patients with incurable cancer: a systematic review. J Pain Symptom Manage 2007; 34: 94-104.

10. Stromgren AS, Sjogren P, Goldschmidt D, Petersen MA, Pedersen L, Groenvold M. Symptom priority and course of symptomatology in specialized palliative care. J Pain Symptom Manage 2006; 31: 199-206.

11. Groenvold M, Petersen MA, Aaronson NK, Arraras JI, Blazeby JM, Bottomley A, Fayers PM, de Graeff A, Hammerlid E, Kaasa S, Sprangers MA, Bjorner JB. The development of the EORTC QLQC15-PAL: a shortened questionnaire for cancer patients in palliative care. Eur J Cancer 2006; 42: 55-64.

12. Cohen SR, Leis A. What determines the quality of life of terminally ill cancer patients from their own perspective? J Palliat Care 2002; 18: 48-58.

13. Allison PJ, Locker D, Wood-Dauphinee S, Black M, Feine JS. Correlates of health-related quality of life in upper aerodigestive tract cancer patients. Qual Life Res 1998; 7: 713-22.

14. Arndt V, Stegmaier C, Ziegler H, Brenner H. A population-based study of the impact of specific symptoms on quality of life in women with breast cancer 1 year after diagnosis. Cancer 2006; 107: 2496-503.

15. Ahlberg K, Ekman T, Gaston-Johansson F. The experience of fatigue, other symptoms and global quality of life during radiotherapy for uterine cancer. Int J Nurs Stud 2005; 42: 377-86.

16. Ostlund $U$, Wennman-Larsen A, Gustavsson $P$, Wengstrom $Y$. What symptom and functional dimensions can be predictors for global ratings of overall quality of life in lung cancer patients? Support Care Cancer 2007; 15: 1199-205.

17. Dagnelie P, Pijls-Johannesma M, Lambin P, Beijer S, De Ruysscher D, Kempen G. Impact of fatigue on overall quality of life in lung and breast cancer patients selected for high-dose radiotherapy. Ann Oncol 2007; 18: 940-4.

18. Smets EM, Garssen B, Schuster-Uitterhoeve AL, de Haes JC. Fatigue in cancer patients. Br J Cancer 1993; 68: 220-4.

19. Lo RS, Woo J, Zhoc KC, Li CY, Yeo W, Johnson P, Mak Y, Lee J. Quality of life of palliative care patients in the last two weeks of life. J Pain Symptom Manage 2002; 24: 388-97.

20. Lundh Hagelin C, Seiger A, Furst CJ. Quality of life in terminal care--with special reference to age, gender and marital status. Support Care Cancer 2006; 14: 320-8.

21. Beijer S, van Rossum E, Hupperets PS, Spreeuwenberg C, van den Beuken M, Winkens RA, Ars L, van den Borne BE, de Graeff A, Dagnelie PC. Application of adenosine 5'-triphosphate (ATP) infusions in palliative home care: design of a randomized clinical trial. BMC Public Health 2007; 7: 4. Available from URL: http://www.biomedcentral.com/1471-2458/7/4 [accessed Feb 1, 2007]. 
22. Aaronson NK, Ahmedzai S, Bergman B, Bullinger M, Cull A, Duez NJ, Filiberti A, Flechtner $H$, Fleishman SB, de Haes JC. The European Organization for Research and Treatment of Cancer QLQC30: a quality-of-life instrument for use in international clinical trials in oncology. J Natl Cancer Inst 1993; 85: 365-76.

23. Aaronson NK, Cull AM, Kaasa S, Sprangers MAG. The European Organization for Research and Treatment of Cancer (EORTC) Modular Approach to Quality of Life Assessment in Oncology: An Update. In: Spilker B, editor. Quality of Life and Pharmacoeconomics in Clinical Trials, 2nd edition. Philadelphia: Lippincott-Raven, 1996: 179-189.

24. Rao A, Cohen HJ. Symptom management in the elderly cancer patient: fatigue, pain, and depression. J Natl Cancer Inst Monogr 2004; 32: 150-7.

25. Stone $P$, Richards $M, A^{\prime}$ Hern $R$, Hardy J. A study to investigate the prevalence, severity and correlates of fatigue among patients with cancer in comparison with a control group of volunteers without cancer. Ann Oncol 2000; 11: 561-7.

26. Barnes EA, Bruera E. Fatigue in patients with advanced cancer: a review. Int J Gynecol Cancer 2002; 12: 424-8.

27. Davis MP, Khoshknabi D, Yue GH. Management of fatigue in cancer patients. Curr Pain Headache Rep 2006; 10: 260-9.

28. Vogelzang NJ, Breitbart W, Cella D, Curt GA, Groopman JE, Horning SJ, Itri LM, Johnson DH, Scherr $\mathrm{SL}$, Portenoy RK. Patient, caregiver, and oncologist perceptions of cancer-related fatigue: results of a tripart assessment survey. The Fatigue Coalition. Semin Hematol 1997; 34: S4-12.

29. de Vogel-Voogt E. Living till the end: Cancer patients in the last phase of life. Rotterdam: Erasmus University; 2006.

30. Kwon YC, Yun YH, Lee KH, Son KY, Park SM, Chang YJ, Wang XS, Mendoza TR, Cleeland CS. Symptoms in the lives of terminal cancer patients: which is the most important? Oncology 2006; 71: 69-76.

31. Reuben DB, Mor V, Hiris J. Clinical symptoms and length of survival in patients with terminal cancer. Arch Intern Med 1988; 148: 1586-91.

32. Alberts M, Smets EM, Vercoulen JH, Garssen B, Bleijenberg G. 'Verkorte vermoeidheidsvragenlijst': een praktisch hulpmiddel bij het scoren van vermoeidheid. NTVG 1997; 141: 1526-30.

33. Pijls-Johannesma MC, Pijpe A, Kempen GI, Lambin P, Dagnelie PC. Health related quality of life assessment instruments: a prospective study on preference and acceptability among cancer patients referred for radiotherapy. Eur J Cancer 2005; 41: 2250-6.

34. Piper BF, Dibble SL, Dodd MJ, Weiss MC, Slaughter RE, Paul SM. The revised Piper Fatigue Scale: psychometric evaluation in women with breast cancer. Oncol Nurs Forum 1998; 25: 677-84.

35. Smets EM, Garssen B, Bonke B, De Haes JC. The Multidimensional Fatigue Inventory (MFI) psychometric qualities of an instrument to assess fatigue. J Psychosom Res 1995; 39: 315-25. 



\section{Chapter 3}

\section{Application of adenosine 5'-triphosphate (ATP) infusions in palliative home care: design of a randomised clinical trial}

S. Beijer, E. van Rossum, P.S. Hupperets, C. Spreeuwenberg, M. van den Beuken, R.A. Winkens, L. Ars, B.E. van den Borne, A. de Graeff, P.C. Dagnelie 


\section{ABSTRACT}

\section{Aim}

Palliative care in cancer aims at alleviating the suffering of patients. A previous study in patients with advanced non-small-cell lung cancer showed that adenosine 5 'triphosphate (ATP) infusions had a favourable effect on fatigue, appetite, body weight, muscle strength, functional status and quality of life. The present study was designed 1. To evaluate whether ATP has favourable effects in preterminal cancer patients, 2. To evaluate whether ATP infusions may reduce family caregiver burden and reduce the use of professional health care services, and 3 . To test the feasibility of application of ATP infusions in a home care setting.

\section{Methods/design}

The study can be characterized as an open-labelled randomised controlled trial with two parallel groups. The intervention group received usual palliative care, two visits by an experienced dietician for advice, and regular ATP infusions over a period of 8 weeks. The control group received palliative care as usual and dietetic advice, but no ATP. This paper gives a description of the study design, selection of patients, interventions and outcome measures.

\section{Discussion}

From March 2002 through October 2006, a total of 100 patients have been randomised. Follow-up of patients was completed in December 2006. 


\section{INTRODUCTION}

The World Health Organisation (WHO) noted that 'the ultimate goal of palliative care is the achievement of the best quality of life (QoL) for patients and their families' [1]. Complaints like progressive fatigue, deterioration in performance status, weight loss and reduced functional abilities have a substantial impact on the QoL, and also lead to frequent and intensive use of professional health care services $[2,3]$. It is therefore important to develop therapies that contribute to the alleviation of these complaints in terminally ill patients.

Adenosine 5'-triphosphate (ATP) is a naturally occurring purine nucleotide which is present in every cell of the human body, well-known because of its intracellular energy-transferring role [4]. Furthermore, extracellular ATP is involved in the regulation of a variety of biological processes such as neurotransmission, muscle contraction, cardiac function, platelet function, vasodilatation, and liver glucose metabolism [4]. A previous randomised clinical trial (RCT) in 58 patients with advanced non-small-cell lung cancer (NSCLC) showed that 10 intravenous 30-h ATP infusions every 2 to 4 weeks in a clinical setting had a favourable effect on fatigue, appetite, body weight, muscle strength, functional status and QoL [5]. Side effects (mainly chest discomfort, dyspnoea and urge to take a deep breath) observed during ATP infusion were mild and disappeared rapidly after lowering the infusion rate [6].

Considering the relatively mild character of ATP therapy, application of ATP infusions in palliative home care might be a promising and relatively simple treatment to improve the QoL and functional status of patients with advanced cancer. Based on this consideration, we initiated a study in preterminal cancer patients, aiming:

i. To evaluate whether ATP has favourable effects in preterminal cancer patients.

ii. To evaluate whether ATP infusions may reduce family caregiver burden and reduce the use of professional health care services.

iii. To test the feasibility of application of ATP infusions in a home care setting.

In the present paper, we describe the design, selection of patients, intervention and outcome measures of this study.

\section{METHODS/DESIGN}

\section{Study design and general outline}

Figure 1 displays the outline of the study design. The study can be characterized as an open-labelled RCT with two parallel groups. 


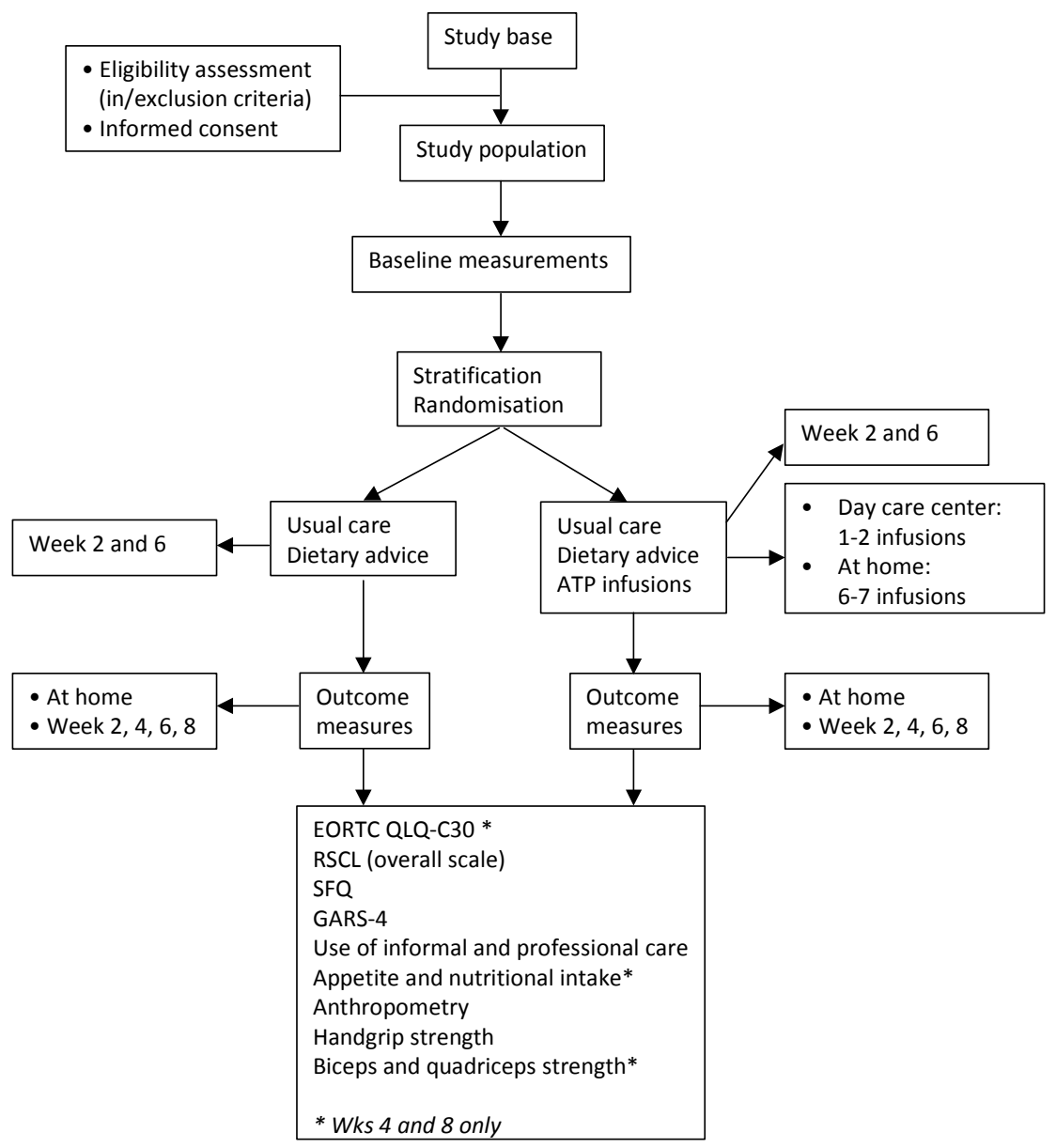

Figure 1. Study design.

Patients eligible for the study were, after stratification, randomly allocated to the intervention or control group. The intervention group received palliative care as usual and two visits by an experienced dietician for advice, and regular ATP infusions over a period of 8 weeks. The control group received palliative care as usual and dietetic advice, but no ATP. Primary and secondary outcomes were assessed at baseline and every two weeks thereafter, until eight weeks after randomisation. To minimize patient burden, all outcome measurements were taken at the patients' home. Parts of the data were collected with assistance from the patients' partner or family caregiver (e.g. dietary record, medication, use of 
professional care services). The study was approved by the Ethical Committee of the University Hospital Maastricht and Maastricht University.

\section{Study population}

Eligible were patients with cytologically or histologically confirmed cancer, for whom medical treatment options were restricted to supportive care, who had a life expectancy $<6$ months, had a WHO performance status 1 or 2 , and suffered from at least one of the following complaints: fatigue, weight loss $>5 \%$ over the last 6 months, or anorexia. Patients with a WHO performance status $>2$ were excluded because they were not able to attend the clinic and to undergo anthropometric and muscle strength measurements. Furthermore, patients with symptomatic angina pectoris, symptomatic heart failure or any form of atrioventricular (AV) block (assessed by electrocardiogram) were excluded for safety reasons [7, 8]. Other exclusion criteria were: life expectancy <4 weeks, concurrent palliative chemotherapy, cognitive dysfunction, and other diseases hampering adequate follow up. The eligibility of patients was evaluated by a medical oncologist before inclusion. Written informed consent was obtained from all patients.

\section{Patient recruitment}

Patients were recruited through the Departments of Medical Oncology and Pulmonology of five hospitals in different regions in the Netherlands (Maastricht, Heerlen, Eindhoven and Utrecht). When the last line of chemotherapy had failed and medical treatment options were restricted to supportive care, the patient was informed about the study by the oncologist or pulmonologist. In addition, general practitioners in the region of Maastricht participated in patient recruitment.

\section{Randomisation}

After baseline measurements, patients were randomly allocated to the treatment group, using random numbers generated by computer with a permuted block size of four. Before randomisation participants were stratified for tumour type (colon cancer, breast cancer, and other types of cancer) and weight loss ( $\leq 5 \%$ in 6 months vs. $>5 \%)$, since weight loss is an important prognostic factor for deterioration of physical condition and QoL [9].

\section{Intervention}

\section{General}

Patients in both the experimental and control group received care as usual, i.e. patients were allowed to use and apply for all available health care services. As an additional support for patients both in the intervention and control group, all 
patients were visited at home by an experienced dietician in week 2 and 6 of the study. At these visits, using a standard checklist, problems and complaints were noted and followed by standard nutritional advice based on the type of complaints of the patient. For this purpose, information sheets were designed containing a standard nutritional advice for any of the following complaints: weight loss, anorexia, food aversions, nausea and vomiting, swallowing problems, dry mouth, painful mouth, diarrhoea, and constipation. In case patients asked for more intensive dietary support or for specific nutritional supplements, they were referred to a regular dietician in hospital or home care.

\section{ATP}

Patients allocated to the experimental study group received weekly ATP infusions over a period of eight weeks. A longer infusion period was not considered feasible in these patients because of the expected rapidly deteriorating condition of participating patients.

In our previous study in NSCLC patients, 10 intravenous 30-h ATP infusions were given at 2 to 4 -week intervals [5]. Because of the advanced disease stage in the present study, a less intensive treatment schedule of 10 hours (range $8-12 \mathrm{~h}$ ) was chosen, in order to avoid ATP administration during the night or an overnight stay at the hospital. To increase the overall ATP dose given, ATP was administered on a weekly basis. A dose of $50 \mu \mathrm{g} / \mathrm{kg}$.min, or lower when side effects occurred, was chosen in order to maximize safety at home; in our previous study a large proportion of patients did not tolerate the dose of $75 \mu \mathrm{g} / \mathrm{kg}$.min. ATP infusions were started beginning at a dose of $20 \mu \mathrm{g} / \mathrm{kg}$.min, and were increased in steps of $10 \mu \mathrm{g} / \mathrm{kg}$.min every $10 \mathrm{~min}$ until a maximum dose of $50 \mu \mathrm{g} / \mathrm{kg}$.min, or until the maximally tolerated dose, if this was lower, had been reached. Thereafter, ATP was infused at a continuous rate. If any side effects occurred, the dose was reduced until side effects disappeared.

In the previous study ATP infusions were given in a clinical setting under strict medical supervision. Since patients in the present study were in a considerably later stage of disease, with consequently a shorter life expectancy, the majority of patients was supported by the general practitioner and was discharged from routine specialist care, with only occasional visits to the out-patient clinic, when necessary. For this reason, it was decided to basically administer most of the ATP infusions in the home setting. However, since initiation of ATP infusions under medical supervision in a clinical setting would facilitate the treatment of possible side effects, the first two ATP infusions were given at the day care centre of the participating hospitals. Based on the mild character of the noted side effects during the first two infusions in the first 22 patients, an amendment was granted by the 
Ethical Committee during the study for administering only the first ATP infusion at the day care centre, and all subsequent infusions at home.

At the end of the first infusion, the safety and tolerated dose of ATP was evaluated for each individual patient. Subsequent infusions were given at the patients' home by an experienced and trained nurse of the infusion team of the Community Health Care Organisation. The maximally tolerated dose during the first infusion at the day care centre was also the maximum dose for the next infusions at home. At home, ATP infusions also started with a dose of $20 \mu \mathrm{g} / \mathrm{kg}$. min and increased in steps of 10 $\mu \mathrm{g} / \mathrm{kg}$.min every $10 \mathrm{~min}$ until the maximum tolerated dose had been reached. To provide maximal mobility a portable infusion pump was used during ATP administration. Patients and their partners were instructed extensively regarding the infusion procedures and to call the infusion team of the Community Health Care Organisation in case of side effects or other problems, such as technical problems.

\section{Side effects and adverse events}

Side effects of all ATP infusions, adjustments of dosage schedules, and any other problems occurring during the infusions were registered systematically on a standard form by the medical and nursing staff of the day care centre of the participating hospitals, the nurses of the home infusion teams and the researcher according to the WHO Common Toxicity Criteria [10].

Any adverse event that occurred from baseline until one week after the last ATP infusion was reported by the investigator on the appropriate Case Report Form. Patients and their caregivers were instructed to contact the investigator if an adverse event occurred. All serious adverse events that were unexpected and assessed to be related to the study product were to be reported to the principal investigator of the study within 24 hours.

\section{Outcome assessment}

Most of the outcome measures were adapted from the study from Agteresch et al. [5].

\section{Primary outcome measures}

Primary outcome measures were quality of life, fatigue and physical restriction (see Table 1).

Quality of life was assessed using the EORTC Quality of Life Questionnaire (QLQC30, version 3.0) [11, 12]. The QLQ-C30 is a 30-item cancer-specific core questionnaire that addresses various domains of QoL. It contains five functional scales (physical functioning, role functioning, emotional functioning, cognitive functioning and social functioning), three symptom scales (fatigue, pain and 
nausea/vomiting), two items assessing global health and QoL, and a number of single items addressing various symptoms (constipation, diarrhoea, dyspnoea, anorexia and insomnia) and perceived financial impact. All items are scored on a 4point Likert-type scale. The content areas covered by this questionnaire reflect the multi-dimensionality of the QoL construct. The EORTC QLQ-C30 has been extensively used for assessing health-related QoL in patients with a wide range of cancers. Studies in patients with advanced cancer with a short life expectancy showed that the questionnaire was well accepted, with a high completion rate and useful in detecting the effectiveness of palliative treatment over time. Results confirmed that the EORTC QLQ-C-30 is a reliable and valid measure of the QoL in patients with advanced cancer [13, 14].

In addition to the QLQ-C30, we used the overall question from the Rotterdam Symptom Checklist (RSCL) ('overall, how did you feel over the past week') as a general indicator of perceived QoL. The RSCL was originally validated in a Dutch study [15] and has since then been used in numerous studies in cancer patients.

Fatigue was measured by the Short Fatigue Questionnaire (SFQ). The SFQ is a reliable and simple instrument to assess bodily fatigue [16]. The questionnaire comprises 4 items. Each item is scored on a 7-point Likert scale.

Physical restriction was assessed by the Groningen Activity Restraint Scale (GARS-4) [17]. The GARS-4 was developed to assess disability in the domains of personal care (11 items) and domestic activities ( 7 items). Studies in persons receiving home care, healthy seniors, patients with recent diagnosed cancer, multiple sclerosis, or rheumatoid arthritis showed that the GARS is an easy to administer, reliable, and valid measure for assessing disability in the domains of ADL (Activities of Daily Living) and IADL (Instrumental Activities of Daily Living) [18, 19].

\section{Secondary outcome measures}

Appetite was assessed by four $100 \mathrm{~mm}$ visual analogue scales (VAS) related to hunger and satiety with words anchored at each end expressing the most positive or negative sensation. Some studies have investigated the correlation between hunger ratings and energy intake, i.e. the validity of the appetite ratings. Many of these have failed to demonstrate such a relationship, while others have found that there was an association [20, 21]. Results obtained from VAS yield the most valuable information when combined with other aspects of energy balance [22].

Nutritional intake was assessed by a 3-day food diary. Patients were taught to keep records, in portion sizes, of all the foods they had eaten on several days of the study. The portion sizes were described in household measures using the utensils commonly found in their homes. These household measures were quantified by volume by the investigator. In general, a 3-day record, randomised to cover seasonal and weekday variations is recommended to assess mean food 
consumption of a group of individuals [23]. A review about the validity of selfreported energy intake showed that energy intake derived from all methods of food recording can be an imprecise measure that is substantially under-reporting in groups including adults, children and adolescents, obese persons, athletes, military personnel and trekking explorers [24]. No data about patients with cancer are available.

Medication changes were registered during each home visit.

Body height was measured to the nearest 0.1 centimetre.

Body weight was measured without shoes, using an electronic weighing scale (Soehnle 7407 Translucia, Germany) to the nearest $0.05 \mathrm{~kg}$.

Triceps skin fold thickness was measured in duplicate with a Holtain ${ }^{\circledR}$ skin fold caliper (CMS weighing equipment LTD, London UK) to calculate total body fat mass (FM) using the age- and gender-specific tables from Durnin and Womersley [25]. Fat-free mass (FFM) was calculated by subtracting fat mass from body weight.

Mid-upper arm circumference of the dominant arm was measured with a flexible measuring tape, and arm muscle area derived using the equation: (arm circumference $-\pi x$ triceps skin fold $)^{2} / 4 \pi$ [26]. Arm muscle area gives an indication of the body's muscle mass as its main protein reserve [26].

Muscle strength of two major muscle groups (i.e. elbow flexor and knee extensor muscles) was assessed at the dominant arm and leg using a hand-held Microfet ${ }^{\circledR}$ dynamometer (Biometrics Europe BV, Almere, The Netherlands). This technique has been validated in several patient groups, mostly in patients whit limited muscle strength [27-29]. The patient while sitting exerts a maximal force with the $90^{\circ}$ flexed elbow, while the examiner pushes with the dynamometer against the patients' thumb pad until muscle strength is overcome (break test). Similarly, the patient exerts a maximal force with the $90^{\circ}$ flexed knee, while the examiner pushes with the dynamometer against the patients' ankle until muscle strength is overcome. The strength of both muscle groups is measured twice at an interval of approximately one minute. Muscle strength is expressed in Newton meter (Nm) units and calculated by dividing the measured mean strength (dynamometer reading) by the distance from dynamometer position point to the medial humeral epicondylus medialis (elbow) and the medial femoral epicondylus medialis (knee).

Handgrip strength of the dominant hand was measured using a JAMAR hydraulic hand dynamometer (Saehan Corp. Masan, Korea). Handgrip strength is a simple, quick, easily performed, and readily available bedside test. Studies in several population groups showed strong positive correlations between handgrip strength and lean body mass [30]. Furthermore, handgrip strength is correlated with total body muscle strength [31]. 
In order to exclude inter-observer variability, longitudinal anthropometric and muscle strength measurements in each patient were performed by the same observer.

Table 1. Time schedule of outcome assessment.

\begin{tabular}{|c|c|c|c|c|c|c|}
\hline \multirow{2}{*}{$\begin{array}{l}\text { Outcome measure } \\
\text { Primary outcomes }\end{array}$} & \multirow{2}{*}{$\begin{array}{l}\text { Measurement scale or } \\
\text { specification }\end{array}$} & \multicolumn{5}{|c|}{ Timing (in weeks) } \\
\hline & & 0 & 2 & 4 & 6 & 8 \\
\hline Quality of Life & EORTC QLQ-C30 ${ }^{1}$ & $x$ & & $x$ & & $x$ \\
\hline Quality of Life & $\mathrm{RSCL}$, overall question ${ }^{2}$ & $x$ & $x$ & $x$ & $\mathrm{X}$ & $x$ \\
\hline Fatigue & $\mathrm{SFQ}^{3}$ & $x$ & $x$ & $x$ & $x$ & $x$ \\
\hline Physical restriction & GARS- $4^{4}$ & $x$ & $x$ & $x$ & $x$ & $x$ \\
\hline \multicolumn{7}{|l|}{ Secondary outcomes } \\
\hline Appetite & Appetite questionnaire & $x$ & & $x$ & & $x$ \\
\hline Nutritional intake & 3-Day food diary & $x$ & & $x$ & & $x$ \\
\hline Medication & Medication list & $x$ & $x$ & $x$ & $x$ & $x$ \\
\hline Body weight & Electronic weighing scale & $x$ & $x$ & $x$ & $x$ & $x$ \\
\hline Triceps skin fold & & $x$ & $x$ & $x$ & $x$ & $x$ \\
\hline Arm circumference & & $x$ & $x$ & $x$ & $x$ & $x$ \\
\hline Muscle strength & Biceps and quadriceps strength & $x$ & & $x$ & & $x$ \\
\hline Muscle strength & Handgrip strength & $x$ & $x$ & $x$ & $x$ & $x$ \\
\hline Use of professional & Diary and health care & & & & & \\
\hline care services & registration & $x$ & $x$ & $x$ & $\mathrm{X}$ & $x$ \\
\hline
\end{tabular}

\section{Caregiver burden}

The second study objective was to evaluate whether ATP infusions could relieve family caregiver burden and reduce the use of professional health care services. Caregiver burden was measured at two levels: 1 . informal care; 2 . professional care. To measure caregiver burden we used the GARS-4. For each item it must be marked whether the patient, the family caregivers or health care professionals carried out the activities (not at all, partly, completely). Use of medical care services (hospital admissions, outpatient clinic visits, general practitioner contacts), and home care (both domestic and nursing care) was recorded every visit.

\section{Process evaluation}

The evaluation of feasibility of the ATP infusions was performed by open interviews with the staff of the day care centre and the nurses of the infusion home teams after finishing patient recruitment. Aspects such as procedures concerning the 
transfer of ATP infusions from hospital to home, the responsibility of the general practitioner for the administration of home infusions and the technical and logistical bottlenecks were particularly evaluated. Furthermore, information about patient satisfaction regarding the safety and the burden of the ATP infusions was collected during each follow-up visit by one standard questionnaire for the patient and a second for his/her partner.

\section{Data management and statistical analysis}

Data were entered using Microsoft Access 2000 and checked for errors by double data entry.

Comparability of baseline characteristics among the ATP and control group were assessed for age, gender, tumour type, performance status and weight loss by descriptive statistics (SPSS 13.0 for Windows). Differences over time in the two groups were analysed according to the 'intention-to-treat' principle by repeatedmeasures analysis of covariance with the use of the linear regression model. These analyses were performed with the SAS procedure Proc Mixed (version 9.1, SAS Institute Inc., Cary, NC, USA), with the use of the independence working correlation structure. Multivariate analyses were used to adjust the estimated effects for potential confounders.

\section{Sample size/power calculation}

Data from a previous study in NSCLC patients [5] (related to 8 weeks of follow-up) were used to calculate the sample size needed to detect clinically relevant effects of ATP infusion on the primary outcome measures fatigue and physical restriction. For both measures we assumed a mean deterioration in the control group similar to the one observed in the previous study. In the experimental group, based on an expected worse condition of patients in the present study when compared with our previous study in NSCLC patients, we used a conservative estimate. Based on our previous randomised trial with ATP infusions [5], it was calculated that a total of 60 patients would be sufficient to detect a between-group difference of 0.65 units in fatigue on a 4-point scale after 8 weeks with a power of $90 \%$ and a two-tailed alpha of 0.05 . An uncertain factor in sample size calculation was the drop-out rate which was estimated to vary from $25-40 \%$. Assuming a drop-out rate of $25 \%$ during the 8 week follow-up period, a total of 80 patients (40 patients per treatment arm) would be needed; in case of higher drop out (e.g. 40\%) recruitment would be increased to 100 patients. 


\section{DISCUSSION}

From March 2002 through October 2006, a total of 100 patients have been randomised: 10 patients in 2002, 5 in 2003, 22 in 2004, 40 in 2005, and 23 in 2006. The study was closed on October 312006 and follow-up of patients was completed in December 2006.

We hope this study will demonstrate that ATP infusions lead to a reduction of frequently reported complaints in preterminal cancer patients, for which no effective treatment is yet available. In addition, we hope to show that ATP infusions can be administered safely in a home care setting. In case of positive findings, this trial may be a first step towards implementation of ATP infusions in integrated palliative care. 


\section{REFERENCES}

1. Sepulveda C, Marlin A, Yoshida T, Ullrich A. Palliative Care: the World Health Organization's global perspective. J Pain Symptom Manage 2002; 24: 91-6.

2. Lundh Hagelin C, Seiger A, Furst CJ. Quality of life in terminal care--with special reference to age, gender and marital status. Support Care Cancer 2006; 14: 320-8.

3. Courtens AM. Kenmerken van zorg en kwaliteit van leven bij patiënten met kanker. Proefschrift 1993, Universitaire Pers Maastricht.

4. Agteresch HJ, Dagnelie PC, van den Berg JW, Wilson JH. Adenosine triphosphate: established and potential clinical applications. Drugs 1999; 58: 211-32.

5. Agteresch HJ, Dagnelie PC, van Der Gaast A, Stijnen T, Wilson JH. Randomized clinical trial of adenosine 5 '-triphosphate in patients with advanced non-small-cell lung cancer. J Natl Cancer Inst 2000; 92: 321-8.

6. Agteresch HJ, Dagnelie PC, Rietveld T, van den Berg JW, Danser AH, Wilson JH. Pharmacokinetics of intravenous ATP in cancer patients. Eur J Clin Pharmacol 2000; 56: 49-55.

7. Freilich A, Tepper D. Adenosine and its cardiovascular effects. Am Heart J 1992; 123: 1324-8.

8. Zhang C. Electrophysiological effects of different dosage of adenosine triphosphate on normal sinoatrial and atrioventricular node. Chung Hua Hsin Hsueh Kuan Ping Tsa Chih 1992; 20: 98-100.

9. van Halteren HK, Bongaerts GP, Wagener DJ. Cancer cachexia: what is known about its etiology and what should be the current treatment approach? Anticancer Res 2003; 23: 5111-5.

10. National Cancer Institute. Common Toxicity Criteria, version 2.0. Publish date: April 30, 1999.

11. Aaronson NK, Ahmedzai S, Bergman B, Bullinger M, Cull A, Duez NJ et al. The European Organization for Research and Treatment of Cancer QLQ-C30: a quality-of-life instrument for use in international clinical trials in oncology. J Natl Cancer Inst 1993; 85: 365-76.

12. Aaronson NK, Cull AM, Kaasa S, Sprangers MAG. The European Organization for Research and Treatment of Canncer (EORTC) Modular Approach to Quality of Life Assessment in Oncology: An Update. Quality of Life and Pharmacoeconomics in Clinical Trials 1996, Second Edition, Chapter 21: 179-89.

13. Kyriaki M, Eleni T, Efi P, Ourania K, Vassilios S, Lambros V: The EORTC core quality of life questionnaire (QLQ-C30, version 3.0) in terminally ill cancer patients under palliative care: validity and reliability in a Hellenic sample. Int J Cancer 2001; 94: 135-9.

14. Kaasa S, Bjordal K, Aaronson N, Moum T, Wist E, Hagen S et al. The EORTC core quality of life questionnaire (QLQ-C30): validity and reliability when analysed with patients treated with palliative radiotherapy. European journal of cancer 1995; 31a: 2260-3.

15. de Haes JC, van Knippenberg FC, Neijt JP: Measuring psychological and physical distress in cancer patients: structure and application of the Rotterdam Symptom Checklist. Br J Cancer 1990; 62: 1034-8.

16. Alberts M, Smets EM, Vercoulen JH, Garssen B, Bleijenberg G: Verkorte vermoeidheidsvragenlijst: een praktisch hulpmiddel bij het scoren van vermoeidheid. NTVG 1997; 141: 1526-30.

17. Kempen GI, Miedema I, Ormel J, Molenaar W. The assessment of disability with the Groningen Activity Restriction Scale. Conceptual framework and psychometric properties. Soc SciMed 1996; 43: 1601-10.

18. Kempen GIJM, Doeglas DM, Suurmeijer TPBM. Groningen Activiteiten Restrictie Schaal (GARS): een handleiding. Groningen: Rijksuniversiteit Groningen; 1993.

19. Suurmeijer TP, Doeglas DM, Moum T, Briancon S, Krol B, Sanderman R et al. The Groningen Activity Restriction Scale for measuring disability: its utility in international comparisons. Am J Public Health 1994; 84: 1270-3.

20. de Graaf C. The validity of appetite ratings. Appetite 1993; 21: 156-60.

21. Raben A, Tagliabue A, Astrup A. The reproducibility of subjective appetite scores. The British journal of nutrition 1995; 73: 517-30.

22. Stubbs RJ, Hughes DA, Johnstone AM, Rowley E, Reid C, Elia M et al.The use of visual analogue scales to assess motivation to eat in human subjects: a review of their reliability and validity with an evaluation of new hand-held computerized systems for temporal tracking of appetite ratings. $\mathrm{Br}$ J Nutr 2000; 84: 405-15. 
23. Bingham SA, Paul AA, Haraldsdottir J, Bjorge Loken E, van Staveren WA. Methods for data collection at an individual level. In: Manual on methodology for food consumption studies. Edited by Cameron M.E vSWA. Oxford: Oxford University Press; 1988: 53-106.

24. Hill RJ, Davies PS. The validity of self-reported energy intake as determined using the doubly labelled water technique. Br J Nutr 2001; 85: 415-30.

25. Durnin JV, Womersley J. Body fat assessed from total body density and its estimation from skinfold thickness: measurements on 481 men and women aged from 16 to 72 years. Br J Nutr 1974; 32: 77-97.

26. Gurney JM, Jelliffe DB. Arm anthropometry in nutritional assessment: nomogram for rapid calculation of muscle circumference and cross-sectional muscle and fat areas. Am J Clin Nutr 1973; 26: 912-5.

27. Bohannon RW. Reference values for extremity muscle strength obtained by hand-held dynamometry from adults aged 20 to 79 years. Arch Phys Med Rehabil 1997; 78: 26-32.

28. Kwoh CK, Petrick MA, Munin MC. Inter-rater reliability for function and strength measurements in the acute care hospital after elective hip and knee arthroplasty. Arthritis Care Res 1997; 10: 12834.

29. Roy MA, Doherty TJ. Reliability of hand-held dynamometry in assessment of knee extensor strength after hip fracture. Am J Phys Med Rehabil 2004; 83: 813-8.

30. Wang AY, Sea MM, Ho ZS, Lui SF, Li PK, Woo J. Evaluation of handgrip strength as a nutritional marker and prognostic indicator in peritoneal dialysis patients. Am J Clin Nutr 2005; 81: 79-86.

31. Rantanen T, Volpato S, Ferrucci L, Heikkinen E, Fried LP, Guralnik JM. Handgrip strength and causespecific and total mortality in older disabled women: exploring the mechanism. J Am Geriatr Soc 2003; 51: 636-41. 


\section{Chapter 4}

\section{Intravenous ATP infusions can be safely administered in the home setting: a study in preterminal cancer patients}

S. Beijer, E.A. Gielisse, P.S. Hupperets, B.E. van den Borne, M. van den Beuken-van Everdingen, M.R. Nijziel, A.M. van Henten, P.C. Dagnelie

Investigational New Drugs 2007; 25: 571-579 


\section{ABSTRACT}

\section{Aim}

To investigate the safety of adenosine 5 -triphosphate (ATP) administration at home in preterminal cancer patients.

\section{Methods}

Included were patients with cancer for whom medical treatment options were restricted to supportive care, who had a life expectancy of less than 6 months, a World Health Organisation performance status 1 or 2, and suffered from at least one of the following complaints: fatigue, anorexia or weight loss $>5 \%$ over the previous 6 months. Side effects were registered systematically on a standard form according to the National Cancer Institute $(\mathrm{NCl})$ Common Toxicity Criteria.

\section{Results}

Fifty-one patients received a total of 266 intravenous ATP infusions. Of these, 11 infusions (4\%) were given at the lowest dose of $20 \mu \mathrm{g} / \mathrm{kg}$.min, 85 infusions (32\%) at $25-40 \mu \mathrm{g} / \mathrm{kg}$.min, and $170(64 \%)$ at the highest dose of $45-50 \mu \mathrm{g} / \mathrm{kg} \cdot \mathrm{min}$ ATP. The majority of ATP infusions (63\%) were without side effects. Dyspnoea was the most common side effect (14\% of infusions), followed by chest discomfort (12\%) and the urge to take a deep breath (11\%). No symptoms of cardiac ischaemia occurred in any of the infusions. All side effects were transient and resolved within minutes after lowering the ATP infusion rate. Side effects were most frequent in the presence of cardiac disorders.

\section{Conclusion}

ATP at a maximum dose of $50 \mu \mathrm{g} / \mathrm{kg}$.min can be safely administered in the home setting in patients with preterminal cancer. 


\section{INTRODUCTION}

In recent years favourable effects of adenosine 5 '-triphosphate (ATP) on nutritional and functional status and survival in cancer patients were reported [1-5]. However, ATP [6-10] and its breakdown product adenosine [11-18], given either as a continuous intravenous infusion or by intravenous bolus administration, were also reported to have side effects, which might hamper administration especially in an outpatient setting.

In cancer patients, ATP was administered as continuous intravenous infusions over several hours, in doses varying from 25 to $100 \mu \mathrm{g} / \mathrm{kg}$. min. In a Phase I study [4], 14 patients with advanced cancer received 96-h infusions of ATP once per month for a total of at least three infusions, as tolerated by the patient. In the first three patients, ATP was given at a dose of $50 \mu \mathrm{g} / \mathrm{kg}$.min. If well tolerated, subsequent dose escalations were planned in groups of three patients in increments of 25 $\mu \mathrm{g} / \mathrm{kg}$.min until the maximally tolerated dose (MTD) was reached. Patients who completed therapy without serious toxicity and later progressed were eligible for retreatment at a higher dose of ATP. Fourteen patients received a total of 43 ATP infusions: 11 patients received 29 infusions at a dose of $50 \mu \mathrm{g} / \mathrm{kg}$. min, six patients received 11 ATP infusions at a dose of $75 \mu \mathrm{g} / \mathrm{kg}$.min, and three patients who had tolerated $50 \mu \mathrm{g} / \mathrm{kg}$.min very well were reconsented and received one cycle each at a dose of $100 \mu \mathrm{g} / \mathrm{kg}$.min. In total, 179 adverse events were reported, whether or not these could be ascribed to ATP. The majority of side effects (dyspnoea, chest pain, hypotension, gastrointestinal side effects, dizziness, headache, fever and local injection site reaction) were minor (104 adverse events grade 1 (58\%) and 54 adverse events grade 2 (30\%) based on the US National Cancer Institute Toxicology Criteria. Dose-limiting toxicities of ATP were reported in seven patients, i.e. asymptomatic electrocardiographic evidence of cardiac ischaemia $(n=2)$, grade 3 cardiac toxicity (angina without evidence of infarction), and grade 4 pulmonary toxicity (dyspnoea at rest), usually occurring as a characteristic cardiopulmonary syndrome including an initial feeling of chest 'tightness' and a sensation of 'needing to take a deep breath' $(n=5)$. Dose-limiting cardiopulmonary toxicity appeared in all three $100 \mu \mathrm{g} / \mathrm{kg}$.min ATP infusions, in four (36\%) $75 \mu \mathrm{g} / \mathrm{kg}$.min infusions, and in five (17\%) $50 \mu \mathrm{g} / \mathrm{kg}$.min infusions.

In a subsequent uncontrolled phase II study [5], 15 previously untreated patients with stage IIIB/IV non-small-cell lung cancer (NSCLC) received infusions of ATP at doses of 50 (first course) and $65 \mu \mathrm{g} / \mathrm{kg}$.min (subsequent courses) for $96 \mathrm{~h}$ every 4 weeks. Reported side effects were, in decreasing frequency, chest pain, dyspnoea, coughing, anxiety, injection site pain, chest tightness, headache, insomnia, and hot flushes. According to the authors, six patients reported severe adverse events, of 
which CTC 4 dyspnoea occurred in two patients; this led to the cessation of treatment in five patients [5].

In the first randomised clinical trial with ATP [1], 28 patients with stage IIIB/IV NSCLC received a total of 176 intravenous ATP courses, at doses of maximally 75 $\mu \mathrm{g} / \mathrm{kg}$.min (tailored to the maximum tolerance of each patient) for $30 \mathrm{~h}$ every $2-4$ weeks. Twenty-nine percent of the infusions were given at rates of 25-40 $\mu \mathrm{g} / \mathrm{kg} \cdot \mathrm{min}, 27 \%$ at $45-60 \mu \mathrm{g} / \mathrm{kg} \cdot \min$ and $44 \%$ at $65-75 \mu \mathrm{g} / \mathrm{kg} \cdot \mathrm{min}$ [19]. The most frequent side effects were chest discomfort (15\%) and the urge to take a deep breath (10\%), both of which resolved within minutes after lowering the ATP dose. Electrocardiography (ECG) was performed in patients with chest pain/discomfort during the ATP infusions, but no ECG changes suggestive of myocardial ischaemia were detected [19]. In all of the above studies, ATP was administered on an inpatient basis under medical supervision.

Based on the previously reported favourable effects of ATP on quality of life, nutritional status and survival $[1,3]$, we initiated a new randomised clinical trial to investigate whether these effects of ATP could be confirmed in patients with different types of cancer in the preterminal stage of disease (life expectancy 1-6 months). In view of the short life expectancy of these patients, and based on the favourable safety profile of ATP, we decided to administer ATP in the home setting. The aim of the present study was to investigate the safety of ATP administration at home in preterminal cancer patients. We hypothesized that side effects of ATP infusions would occur mainly during the first ATP infusion, especially during assessment of the MTD of ATP. We also hypothesized that the presence of cardiac disorders and/or lung cancer would lead to a lower MTD, and a higher frequency of side effects.

\section{PATIENTS AND METHODS}

\section{Study population and design}

Patients were recruited through the Departments of Medical Oncology and Pulmonology of five hospitals in different regions in The Netherlands (Maastricht, Eindhoven, Utrecht and Heerlen) and through general practitioners in the region of Maastricht. Eligible were patients with cytologically or histologically confirmed cancer, for whom medical treatment options were restricted to supportive care, who had a life expectancy $<6$ months, had a World Health Organisation (WHO) performance status 1 or 2, and who at the time of inclusion suffered from at least one of the following complaints: fatigue, anorexia, or weight loss $>5 \%$ in the previous 6 months. Exclusion criteria were: symptomatic angina pectoris, symptomatic heart failure, atrioventricular block (checked by standard ECG in all patients before inclusion), life expectancy of less than 4 weeks, concurrent 
palliative chemotherapy at the time of inclusion, cognitive dysfunction, and the presence of other diseases hampering adequate follow up. The eligibility of patients was evaluated by a medical oncologist or pulmonologist. After baseline measurements, patients were randomly allocated to ATP or control treatment. The present report on the safety of ATP administration is restricted to patients randomised to ATP treatment. The study was approved by the Ethical Committee of University Hospital Maastricht and Maastricht University, and all patients signed written informed consent prior to the study. Details of the trial design have been published elsewhere [20].

\section{Intervention}

Adenosine $5^{\prime}$-triphosphate $\left(\right.$ ATP- $\mathrm{Na}_{2}$ ) of $>98 \%$ purity was purchased from Pharma Waldhof $\mathrm{GmbH} \&$ co. KG (Düsseldorf, Germany). For each infusion, 2.5 grams of ATP were dissolved in $500 \mathrm{ml} \mathrm{NaCl} 0.9 \%$, sterilized by ultrafiltration (Minisart 0.22 $\mu \mathrm{M})$, and supplied in sterile containers. Patients received weekly intravenous ATP infusions of 8-12 h, over a period of 8 weeks. All ATP infusions were started at a dose of $20 \mu \mathrm{g} / \mathrm{kg}$.min and then increased in steps of $10 \mu \mathrm{g} / \mathrm{kg}$.min every $10 \mathrm{~min}$, until a maximum dose of $50 \mu \mathrm{g} / \mathrm{kg}$.min, or the MTD, if this was lower, had been reached. Thereafter, ATP was infused at a continuous rate. If any side effects occurred, the dose was reduced until side effects disappeared. Blood pressure and pulse were registered before starting the infusion, at 30 min after determining the MTD, and just before the infusion was stopped.

Since initiation of ATP infusions under medical supervision in a clinical setting would facilitate the treatment of possible side effects, the first two ATP infusions were given at the day care centre of the participating hospitals. Based on evaluation of safety data in the first 22 patients, in view of the mild character of the noted side effects during the first two infusions in these patients, the Ethical Committee granted permission to administer only the first ATP infusion at the day care centre and all subsequent infusions at home. The description below applies to the procedures in case of only one hospital infusion.

At the end of the first infusion, the safety and tolerated dose of ATP was evaluated for each individual patient. Subsequent infusions were given at the patients' home by an experienced and trained nurse of a specialized infusion team, usually embedded in the regional Community Care Organisation. The MTD as determined during the first infusion at the day care centre was also the maximum dose for this patient for the next infusions at home. The same rule was applied for subsequent home infusions, so that the infusion rate in any subsequent ATP infusion course was never higher than the MTD during the previous ATP infusion. Patients and their partners were instructed extensively regarding the infusion procedures; also, they 
were instructed to immediately call the involved infusion team in case of any side effects.

\section{Documentation of side effects and adverse events}

Side effects of all ATP infusions, adjustments of dosage schedules, and any other events occurring during the infusions were registered by the infusion nurse, either a. during the infusions, or b. on completion of each infusion. In addition, the researcher called all patients after each infusion to ask whether any side effects had occurred. Side effects were scored using the $\mathrm{NCl}$ Common Toxicity Criteria [21] on a 4-point scale, according to seriousness. In this system, dyspnoea is graded as follows: 0 , no change; 1 , not defined; 2, dyspnoea on significant exertion; 3, dyspnoea at normal activity; 4, dyspnoea at rest. Since most terminal cancer patients are at rest, dyspnoea would in these cases automatically be classified as CTC grade 4, which would misrepresent the actual severity of the symptoms and disregard the intention of the $\mathrm{NCl}$ Common Toxicity Criteria (i.e. CTC grade $4=$ lifethreatening). For this reason, we decided to apply the general toxicity grading of the CTC also for dyspnoea, i.e. 1, mild; 2, moderate; 3, severe; and 4, lifethreatening.

Based on Agteresch et al. [19], we pre-defined 13 side effects: chest discomfort, urge to take a deep breath, nausea, flushing, light-headedness, dyspnoea, headache, sweating, mood alteration-anxiety, palpitations, epistaxis, symptoms of cardiac ischaemia, injection side reaction or other (to be specified). In case of persistent or severe chest pain, suspect for potential cardiac ischaemia, an ECG was made in order to exclude this.

\section{Statistical analysis}

Data were entered in a database using Microsoft Access 2000 and checked for errors by means of double data entry by two independent persons. Data were analysed using SPSS 13.0 for Windows. Changes in blood pressure and heart rate over time were tested for statistical significance by Student's paired $t$-test. To test our hypothesis that side effects would especially occur during the first infusion, we calculated the average number of side effects per infusion over all infusions. To investigate whether the MTD and frequency of side effects were dependent on the presence of cardiac disorders and/or lung cancer, linear regression models were fitted. As dependent variables, we used mean MTD per patient over all courses, and frequency of side effects per infusion. As independent variables, we included dummy variables for the presence of cardiac disorders (yes/no), and lung cancer (yes/no). To investigate the relation between the seriousness of side effects (CTC grades 2-4 vs. CTC grade 1) and the presence of cardiac disorders and/or lung cancer, Fisher's exact test was used. $P$-values of less than 0.05 indicated significance. 


\section{RESULTS}

\section{Study population}

Fifty-one patients with different types of preterminal cancer were included in the present study. Baseline characteristics of the patients are listed in Table 1. Mean age was 68.1 years (range: $45-87$ years) and the majority of patients were male (69\%). The most frequent diagnosis was lung cancer $(41 \%)$, followed by colon cancer (16\%). The majority of patients $(65 \%)$ had WHO performance status 1 , and $35 \%$ WHO status 2 . Twelve patients $(24 \%)$ suffered from cardiac disorders.

Table 1. Baseline characteristics of ATP-treated patients $(n=51)$.

\begin{tabular}{lll}
\hline & Number & Percent (\%) \\
\hline Age (years) & $68.1(45-87)^{1}$ & \\
Gender & 35 & 69 \\
Male & 16 & 31 \\
$\quad$ Female & & \\
WHO performance status ${ }^{2}$ & 33 & 65 \\
1 & 18 & 35 \\
2 & & \\
Tumour type & 21 & 41 \\
Lung & 8 & 16 \\
Colon & 6 & 12 \\
Gastrointestinal other & 5 & 10 \\
Prostate & 11 & 21 \\
$\quad$ Other & 12 & 24 \\
Presence of cardiac disorders & &
\end{tabular}

${ }^{1}$ Mean (range); ${ }^{2}$ WHO 1: restricted in physically strenuous activity but ambulatory and able to do light work; WHO 2: ambulatory (not more than $50 \%$ in bed) and capable of self-care but unable to carry out any work.

Out of 51 patients, six patients died during the intervention period because of disease progression (Figure 1). Three patients did not start because of rapid deterioration of their condition and 18 patients stopped with the ATP infusions. Reasons to stop were deterioration in medical condition $(n=11)$, fear of side effects $(n=4)$, or being unsatisfied with the effect of ATP $(n=3)$.

Over the study period of 8 weeks, a total of 266 ATP infusions were administered in 48 patients. Fifteen patients $(31 \%)$ received one to three ATP courses, nine patients (19\%) received four to seven courses, and 24 patients (50\%) completed all eight ATP infusions. Eleven infusions (4\%) of 266 infusions were given at the lowest dose of $20 \mu \mathrm{g} / \mathrm{kg} \cdot \mathrm{min}, 85$ infusions (32\%) at a dose of $25-40 \mu \mathrm{g} / \mathrm{kg} \cdot \mathrm{min}$, and 170 (64\%) at the highest dose of $45-50 \mu \mathrm{g} / \mathrm{kg} \cdot \mathrm{min}$. 
Number of infusions

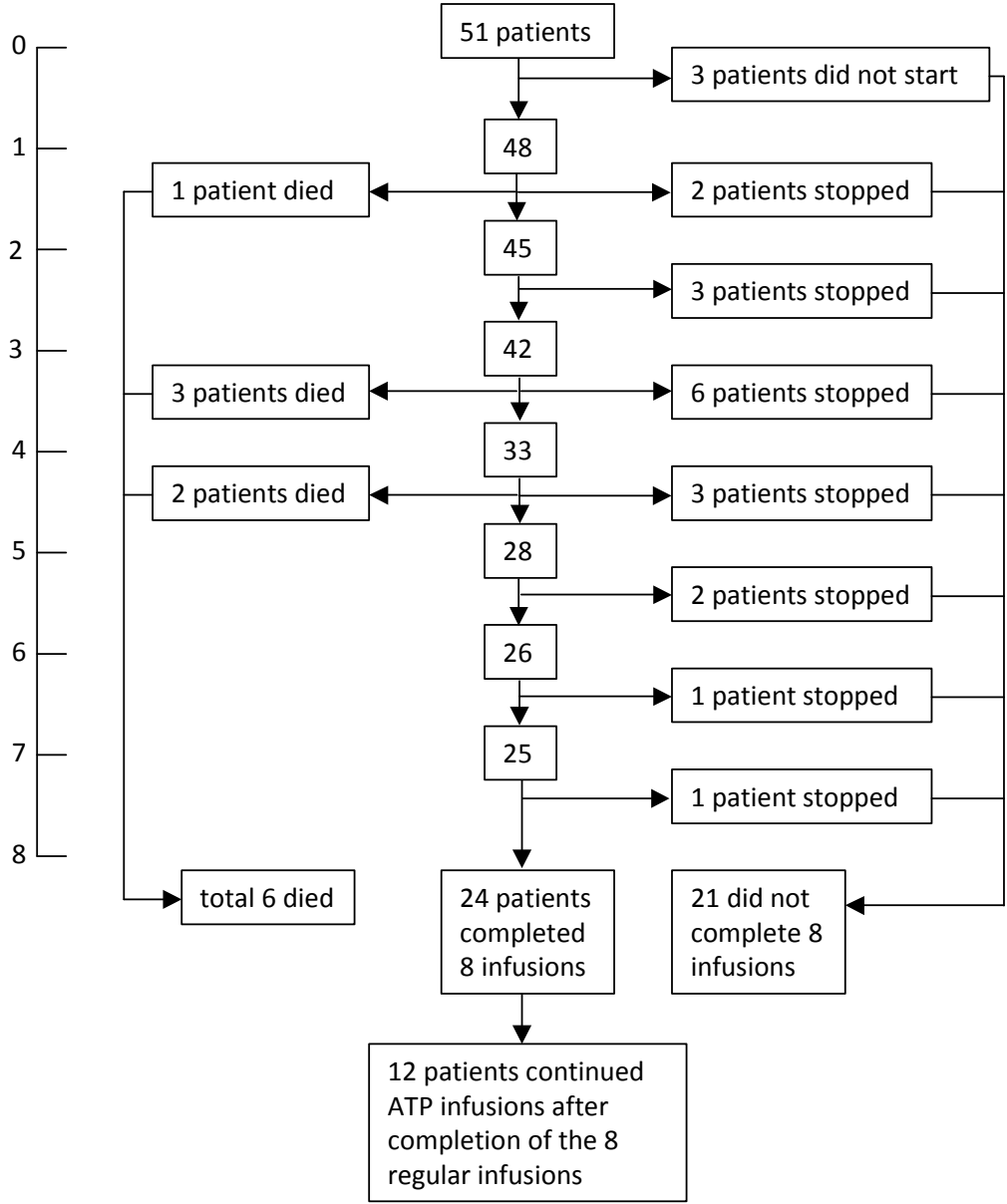

Figure 1. Flow diagram of the study.

\section{Heart rate and blood pressure}

Heart rate decreased from $86 \pm 1$ (mean \pm SEM) at baseline to $83 \pm 1$ at 30 min after reaching the MTD ( $p<0.001)$, and thereafter remained constant at $83 \pm 1$ beats $/ \mathrm{min}$, as measured at 8-10 $\mathrm{h}$ of ATP administration (comparison with baseline: $\mathrm{p}<0.001$ ). Systolic blood pressure decreased from $126 \pm 1$ at baseline to $124 \pm 2$ at $30 \mathrm{~min}$ $(p<0.001)$, but then increased to $133 \pm 2 \mathrm{~mm} \mathrm{Hg}$ at $8-10 \mathrm{~h}$ of ATP infusion (comparison with baseline: $\mathrm{p}<0.001$ ). Diastolic blood pressure also initially 
decreased from $75 \pm 1 \mathrm{~mm} \mathrm{Hg}$ to $72 \pm 1 \mathrm{~mm} \mathrm{Hg}(p<0.001)$, but then increased to $77 \pm 1$ $\mathrm{mm} \mathrm{Hg}$ at 8-10 h of ATP infusion (comparison with baseline: $p=0.02$ ).

\section{Side effects}

Ten patients out of 48 had no side effects during any of the infusions. Out of 266 infusions, 167 infusions (63\%) were without any side effects. In 48 infusions (18\%) one side effect occurred, in 29 infusions (11\%) two side effects, and in 22 infusions $(8 \%)>2$ side effects. In total, 192 side effects were reported (Figure 2): 138 side effects (72\%) were reported to the nurse, of which 96 during the infusions and 42 afterwards; and $54(28 \%)$ to the researcher when specifically asked for. The average number of side effects per infusion was 0.72 (i.e. 192 side effects in 266 infusions).

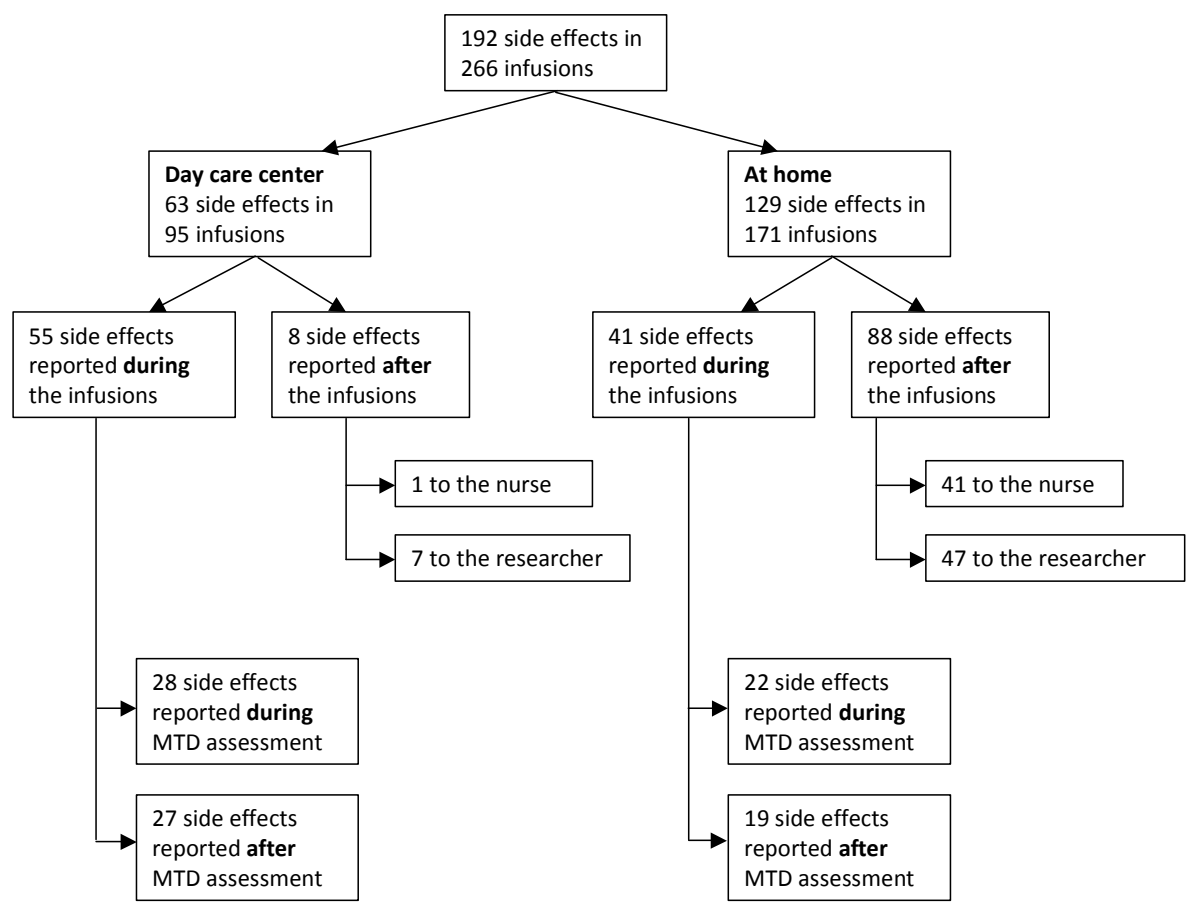

Figure 2. Reported side effects of ATP according to location (day care centre vs. home), time of reporting side effects (during vs. after the infusion), and person to whom the side effects were reported (nurse vs. researcher). 
At the day care centre, 63 side effects were reported in 95 infusions $(0.66$ side effect per infusion). Of these 63 side effects, 56 (89\%) were reported to the nurse, of which 55 during the infusions and one afterwards; and 7 (11\%) to the researcher when specifically asked for. At home, 129 side effects were reported in 171 infusions ( 0.75 side effect per infusion); of these, 82 (64\%) were reported to the nurse, of which 41 during the infusions and 41 afterwards; and 47 (36\%) to the researcher when specifically asked for. All side effects were transient and resolved within minutes after lowering the ATP infusion rate.

In a total of 99 infusions, one or more side effects were reported by patients. In the 51 infusions with one or more side effects reported during ATP administration, the infusion was stopped in 13 infusions (25\%), lowered in 30 infusions (59\%) and not changed in eight infusions (16\%). Of the latter eight infusions, the side effects had already disappeared before lowering the infusion rate in four infusions, whereas in three infusions the side effects had already been present before the start of the ATP infusions; in one infusion, extravasation occurred, and the ATP infusion was temporarily interrupted. In 48 out of the total of 99 infusions with one or more side effects, the side effects were reported by patients to the nurse or researcher only after completion of the infusion, and the infusion rate was therefore not adapted.

The frequency of specific side effects observed during the ATP infusions is shown in Table 2. Dyspnoea was the most frequent side effect, appearing in 36 out of 266 infusions (14\%), followed by chest discomfort (12\%) and the urge to take a deep breath (11\%). No symptoms of cardiac ischaemia occurred in any of the infusions.

From the 192 side effects, one side effect (lightheadedness) occurred at the day care centre and was scored by the nurse as CTC 4 because of prolonged stay (one night) at the hospital after the first infusion; there were no abnormalities on ECG. Four side effects were scored as CTC 3 (in all cases chest discomfort), and 22 side effects as CTC 2. Two CTC 3 side effects occurred at the day care centre in two patients, with no abnormalities on ECG. Of these, one patient decided to stop with the ATP infusions. The other patient wanted to continue; for safety reasons, all subsequent infusions in this patient were given at the day care centre. The remaining two CTC 3 side effects occurred at home: one in a patient during the normal procedure of stepwise increasing the infusion rate by the nurse according to protocol, in the other patient during constant ATP infusion after the nurse had left; in the latter case, the nurse was called by telephone by the patient or informal caregiver and immediately arrived. In both cases, the infusions were stopped immediately for that very day. The first patient decided to continue the ATP infusions; in this patient, all four subsequent infusions until the end of the study were given at the day care centre at the highest ATP dose (50 $\mu \mathrm{g} / \mathrm{kg}$.min), and no further side effects occurred. The second patient decided to stop the ATP infusions. 
Table 2. Side effects during a total of 266 intravenous ATP cycles in 51 patients; CTC-grading.

\begin{tabular}{|c|c|c|c|c|c|c|c|c|}
\hline \multirow[t]{2}{*}{ No side effects } & \multicolumn{6}{|c|}{ Side effects according to CTC grade } & \multicolumn{2}{|c|}{ Total side effects } \\
\hline & & 1 & 2 & 3 & 4 & $\begin{array}{l}\text { CTC grade } \\
\text { unspecified }\end{array}$ & Number & $\begin{array}{l}\text { Percent of } \\
\text { inf. (\%) }\end{array}$ \\
\hline Cardiac ischaemia & 266 & 0 & 0 & 0 & 0 & 0 & 0 & 0 \\
\hline Chest discomfort & 234 & 26 & 1 & 4 & 0 & 1 & 32 & 12 \\
\hline Dyspnoea & 230 & 35 & 1 & 0 & 0 & 0 & 36 & 14 \\
\hline Epistaxis & 266 & 0 & 0 & 0 & 0 & 0 & 0 & 0 \\
\hline Flushing & 258 & 8 & 0 & 0 & 0 & 0 & 8 & 3 \\
\hline Headache & 252 & 11 & 2 & 0 & 0 & 1 & 14 & 5 \\
\hline Injection side reaction & 261 & 5 & 0 & 0 & 0 & 0 & 5 & 2 \\
\hline Lightheadedness & 254 & 9 & 2 & 0 & 1 & 0 & 12 & 5 \\
\hline Mood alteration-anxiety & 262 & 4 & 0 & 0 & 0 & 0 & 4 & 2 \\
\hline Nausea & 251 & 14 & 1 & 0 & 0 & 0 & 15 & 6 \\
\hline Other $^{1}$ & 235 & 28 & 2 & 0 & 0 & 1 & 31 & 12 \\
\hline Palpitations & 265 & 1 & 0 & 0 & 0 & 0 & 1 & 0 \\
\hline Sweating & 260 & 2 & 3 & 0 & 0 & 1 & 6 & 2 \\
\hline Urge to take a deep breath & 238 & 18 & 10 & 0 & 0 & 0 & 28 & 11 \\
\hline Total & & 161 & 22 & 4 & 1 & 4 & 192 & \\
\hline
\end{tabular}

In some courses more than one side effect was observed. ${ }^{1}$ The side effects classified as 'Other' were cold shivering, feelings of coldness, pain in infusion arm, dry eyes, sleepiness, burning sensation of the throat, vomiting, diarrhoea, pain neck, general discomfort and unspecified.

The following CTC 2 side effects were reported by patients:

i. To the nurse during the infusions, by seven patients in seven infusions:

- Urge to breathe deeply, headache, sweating and cold shivering in one patient at the day care centre (the same patient with the CTC 3 chest discomfort and CTC 4 lightheadedness).

- Sweating in one patient at the day care centre at the end of the infusion, due to flushing the infusion line (violation of the administration protocol).

- Pain in the infusion arm (one patient) and dyspnoea (one patient), both at the day care centre.

- Urge to breathe deeply, headache and sweating in one patient at home, during the period of stepwise increasing the infusion rate by the nurse.

- Chest discomfort (once) and lightheadedness (twice) at home in two patients, who called the home nurse.

Out of these seven patients with CTC 2 side effects, two patients decided to stop the ATP infusions for the rest of the study.

ii. To the nurse after completion of the infusion, by three patients (4 infusions). 
iii. To the researcher when specifically asked for, by one patient ( 5 infusions). These nine CTC 2 side effects (eight times urge to breathe deeply, once nausea), were probably not sufficiently serious to call the home nurse. All of these patients continued the ATP infusions.

\section{Timing of side effects}

Side effects were not only present during the first infusion but also during subsequent infusions, even though the number of side effects per infusion appeared to be lower during the last three infusions (Figure 3). At the day care centre, of the 55 side effects reported during the infusions, 28 (51\%) were reported during MTD assessment and 27 side effects (49\%) after MTD assessment had been completed (Figure 2). At home, 41 side effects were reported during the infusion, 22 side effects (54\%) during MTD assessment, and 19 side effects (46\%) after MTD assessment had been completed. In the latter 19 cases of side effects, the nurse (and once the general practitioner) was called by the patient and visited the patient to lower or stop the infusion rate.

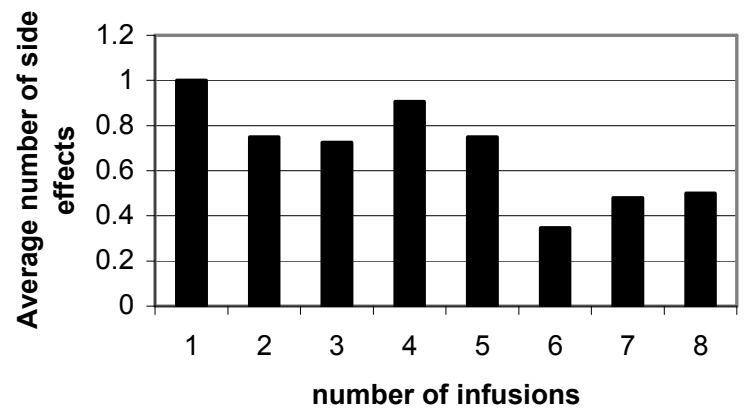

Figure 3. Average number of side effects per ATP infusion in subsequent infusions.

\section{Effect of cardiac or lung disorders on MTD and frequency of side effects}

Mean MTD was $48 \pm 2$ (mean \pm SEM) $\mu \mathrm{g} / \mathrm{kg}$. min in patients without cardiac disorders and/or lung cancer (Table 3). In the presence of cardiac disorders mean MTD was 8 $\mu \mathrm{g} / \mathrm{kg}$.min lower $(p<0.001)$ and $4 \mu \mathrm{g} / \mathrm{kg}$.min lower in the presence of lung cancer $(p=0.02)$. The mean number of side effects per infusion was $0.71 \pm 0.28$ in patients without cardiac disorders and/or lung cancer. In the presence of cardiac disorders, the number of side effects was significantly higher: $2.25 \pm 0.49 \quad(p=0.02)$. The presence of lung cancer had no significant impact on the frequency of side effects $(0.66 \pm 0.34)$. Neither the presence of cardiac disorders, nor the presence of lung 
cancer had a significant impact on the frequency of specific complaints (chest discomfort, urge to breathe deeply, nausea, lightheadedness, or dyspnoea). However, in the presence of cardiac disorders, the number of other side effects was significantly higher $(p=0.006)$. The proportion of CTC grade $2-4$ side effects in the presence of cardiac disorders and/or lung cancer (21 CTC grades 2-4 out of 133 side effects, i.e. $16 \%$ ) was similar to patients without such disorders (seven CTC grades 2-4 out of 59 side effects, i.e. $12 \%)$.

Table 3. The independent effect of the presence of cardiac disorders and/or lung cancer on MTD and frequency of side effects.

\begin{tabular}{llll}
\hline Mean & $\begin{array}{l}\text { No cardiac disorders } \\
\text { and/or lung cancer }\end{array}$ & Cardiac disorders & Lung cancer \\
\hline MTD & $48 \pm 2$ & $40 \pm 3^{* * *}$ & $44 \pm 2^{*}$ \\
All side effects & $0.71 \pm 0.28$ & $2.25 \pm 0.49^{*}$ & $0.66 \pm 0.34$ \\
Chest discomfort & $0.14 \pm 0.05$ & $0.32 \pm 0.09$ & $0.12 \pm 0.06$ \\
Urge to breathe deeply & $0.08 \pm 0.05$ & $0.25 \pm 0.08$ & $0.09 \pm 0.05$ \\
Nausea & $0.06 \pm 0.04$ & $0.18 \pm 0.07$ & $0.03 \pm 0.05$ \\
Lightheadedness & $0.06 \pm 0.04$ & $0.14 \pm 0.08$ & $0.06 \pm 0.05$ \\
Dyspnoea & $0.12 \pm 0.05$ & $0.35 \pm 0.09$ & $0.17 \pm 0.06$ \\
Other & $0.09 \pm 0.06$ & $0.42 \pm 0.11^{* *}$ & $0.05 \pm 0.07$ \\
\hline Refer & &
\end{tabular}

Reference group: patients with no cardiac disorders and/or lung cancer. ${ }^{*} \mathrm{p}<0.05 ;{ }^{* *} \mathrm{p}<0.01 ;{ }^{* * *} \mathrm{p}<0.001$

\section{Continuation of infusions after completion of the study}

Of the 24 patients who completed all eight ATP infusions, 12 decided to continue ATP administration (nine patients with lung cancer, one with prostate cancer, one with a malignant melanoma, one with liver cancer). Until the censoring date, these patients had received a total of 116 ATP infusions after completion of the regular 8week study period (range 1-34 additional infusions). Of these 116 infusions, 11 infusions (10\%) reached a dose of $\leq 20 \mu \mathrm{g} / \mathrm{kg}$.min, 72 infusions (62\%) were given at a dose of $25-40 \mu \mathrm{g} / \mathrm{kg}$. min, and $33(28 \%)$ reached a dose of $45-50 \mu \mathrm{g} / \mathrm{kg}$. min ATP. A total of 38 side effects were reported over 116 infusions ( 0.33 side effects per infusion), a number significantly lower $(p<0.001)$ than in the first 8 infusions in the same 12 patients.

\section{DISCUSSION}

The aim of this study was to investigate whether ATP can be safely administered to patients with preterminal cancer in the home setting. A total of 266 infusions were administered for 8-12 h. Although statistically significant changes in blood pressure and heart rate were observed, these were minor and clinically irrelevant, 
corroborating earlier results [19]. In total, 192 side effects were reported during the 266 ATP infusions, i.e. an average of 0.72 side effects per infusion. Most side effects were mild and transient, presumably due to the short plasma half-life of ATP and adenosine (0.6-1.5 s) [22].

We saw more side effects than in a previous study in 28 lung cancer patients by Agteresch et al. [19]. These authors observed 91 side effects during a total of 176 ATP cycles of $30 \mathrm{~h}$ (0.52 side effects per infusion), even though these infusions were administered for a longer period of time ( $30 \mathrm{~h}$ vs. 8-10 h in our study). One possible explanation of this discrepancy may be the different procedures of data collection in these two studies. For safety reasons, the safety procedure adopted in the present study was that the researcher contacted the patients after each home infusion to ask for side effects, specifically naming a number of the most common potential side effects (based on side effects listed by Agteresch et al. [19]. Our results clearly demonstrate that this procedure lead to a higher frequency of reported side effects in our study: out of a total number of 192 side effects, 54 side effects (28\%) were reported only afterwards to the researcher when specifically asked for. If these side effects (i.e. side effects which had not spontaneously been reported to the nurse during or after the infusion) are excluded, the frequency of the remaining side effects per infusion in the present study $(138 / 266 ; 0.52)$ is remarkably similar to the report by Agteresch et al. [19] (91/176; 0.52), in which trained research nurses in a dedicated clinical research unit registered the side effects.

In both our study and the studies by Haskell et al. [4, 5] and Agteresch et al. [19], chest discomfort/pain, dyspnoea and the urge to take a deep breath were frequent side effects.

Results showed that in 43 out of 51 infusions (84\%) with side effects reported during ATP administration, the infusion rate was lowered or stopped according to protocol. Reasons for not lowering the infusion rate in eight infusions were the fact that in four infusions complaints disappeared automatically; in three infusions the reported complaints were already present before the start of the infusion; and in one infusion extravasation occurred with a temporary interruption of the ATP infusion.

In 48 infusions with side effects, side effects had only been reported after completion of the concerned ATP infusion and the infusion rate was therefore not adapted. One potential explanation for this finding may be that patients were eager to receive ATP at the highest possible dose, as some patients expressed their worry that the potential effectiveness of ATP could fade in case of lowering the dose (similar to chemotherapy), despite our explicit explanation to patients prior to the study that there is currently no evidence that the efficacy of ATP would be better at higher ATP doses. Another possible explanation is that patients in our 
study population were used to experiencing far more serious complaints caused by progression of the disease and/or previous antitumour treatment.

One CTC 4 side effect, four CTC 3 side effects, and 22 CTC score 2 were observed. The CTC 4 side effect (see Results), and two CTC 3 side effects (chest discomfort) occurred at the day care centre, with no abnormalities on ECG. The other two CTC 3 side effects occurred at home, one with the nurse still being present; and in the other case, the nurse immediately arrived.

Side effects were not limited to the period of MTD assessment, nor were they limited to the first ATP infusion. The implication of this finding is that alertness with regard to potential side effects of ATP administration is necessary during all subsequent ATP infusions, and not just during the first infusion or MTD assessment. The lower MTD found in the presence of cardiac disorders or lung cancer indicates that patients with these disorders tolerate lower doses of ATP without side effects than patients without these disorders. Moreover, even at the lower MTD, side effects tend to be more frequent in the presence of cardiac disorders. Because all patients with presence of COPD also had cardiac disorders or lung cancer, this subgroup was not analysed separately.

Based on our findings, we conclude that ATP administration at home is safe. First, the majority of infusions (63\%) are without side effects, and second, our results confirm a previous study in lung cancer patients [19] showing that side effects that do appear are mild and transient, resolving within minutes after lowering the ATP infusion rate. Nevertheless, it remains possible that some side effects could be prevented by encouraging patients to report any side effects without delay. This emphasizes the need for careful instruction and facilitating patients reporting and monitoring of side effects when ATP infusions are administered at home. As patients with cardiac disorders and lung cancer appear to have a lower MTD and more side effects, these patients should be monitored with special care. 


\section{REFERENCES}

1. Agteresch HJ, Dagnelie PC, van Der Gaast A, Stijnen T, Wilson JH. Randomized clinical trial of adenosine $5^{\prime}$-triphosphate in patients with advanced non-small-cell lung cancer. J Natl Cancer Inst 2000; 92: 321-8.

2. Agteresch HJ, Rietveld T, Kerkhofs LG, van den Berg JW, Wilson JH, Dagnelie PC. Beneficial effects of adenosine triphosphate on nutritional status in advanced lung cancer patients: a randomized clinical trial. J Clin Oncol 2002; 20: 371-8.

3. Agteresch HJ, Burgers SA, van der Gaast A, Wilson JH, Dagnelie PC. Randomized clinical trial of adenosine $5^{\prime}$-triphosphate on tumor growth and survival in advanced lung cancer patients. Anticancer Drugs 2003; 14: 639-44.

4. Haskell CM, Wong M, Williams A, Lee LY. Phase I trial of extracellular adenosine $5^{\prime}$-triphosphate in patients with advanced cancer. Med Pediatr Oncol 1996; 27: 165-73.

5. Haskell CM, Mendoza E, Pisters KM, Fossella FV, Figlin RA. Phase II study of intravenous adenosine 5 '-triphosphate in patients with previously untreated stage IIIB and stage IV non-small cell lung cancer. Invest New Drugs 1998; 16: 81-5.

6. Domanovits $H$, Laske $H$, Stark G, Sterz F, Schmidinger H, Schreiber W et al. Adenosine for the management of patients with tachycardias--a new protocol. Eur Heart J 1994; 15: 589-93.

7. Rankin AC, Oldroyd KG, Chong E, Dow JW, Rae AP, Cobbe SM. Adenosine or adenosine triphosphate for supraventricular tachycardias? Comparative double-blind randomized study in patients with spontaneous or inducible arrhythmias. Am Heart J 1990; 119: 316-23.

8. Fukuda K, Hayashida M, Fukunaga A, Kasahara M, Koukita Y, Ichinohe T et al. Pain-relieving effects of intravenous ATP in chronic intractable orofacial pain: an open-label study. J Anesth 2007; 21: 24 30.

9. Komukai K, Hashimoto K, Shibata T, Iwano K, Muto M, Mogi J et al. Effect of continuous ATP injection on human hemodynamics. Circ J 2002; 66: 926-9.

10. Gaba SJ, Prefaut C. Comparison of pulmonary and systemic effects of adenosine triphosphate in chronic obstructive pulmonary disease--ATP: a pulmonary controlled vasoregulator? Eur Respir J 1990; 3: 450-5.

11. Holdgate A, Foo A. Adenosine versus intravenous calcium channel antagonists for the treatment of supraventricular tachycardia in adults. Cochrane Database Syst Rev 2006: CD005154.

12. Rankin AC, Oldroyd KG, Chong E, Rae AP, Cobbe SM. Value and limitations of adenosine in the diagnosis and treatment of narrow and broad complex tachycardias. Br Heart J 1989; 62: 195-203.

13. DiMarco JP, Miles W, Akhtar M, Milstein S, Sharma AD, Platia E et al.Adenosine for paroxysmal supraventricular tachycardia: dose ranging and comparison with verapamil. Assessment in placebo-controlled, multicenter trials. The Adenosine for PSVT Study Group [published erratum appears in Ann Intern Med 1990; 113 :996]. Ann Intern Med 1990; 113: 104-10.

14. Sethi KK, Singh B, Kalra GS, Arora R, Khalilullah M. Comparative clinical and electrophysiologic effects of adenosine and verapamil on termination of paroxysmal supraventricular tachycardia. Indian Heart J 1994; 46: 141-4.

15. Nesser HJ, Yao J, Soman P, Tkalec W, Ebner C, Steringer-Mascherbauer R et al. A head-to-head comparison of infusion and bolus doses of adenosine for stress myocardial contrast echocardiography. Echocardiography 2006; 23: 483-9.

16. Losek JD, Endom E, Dietrich A, Stewart G, Zempsky W, Smith K. Adenosine and pediatric supraventricular tachycardia in the emergency department: multicenter study and review. Ann Emerg Med 1999; 33: 185-91.

17. Seet CM. Efficacy of intravenous adenosine in treatment of paroxysmal supraventricular tachycardia in the local population. Singapore Med J 1997; 38: 525-8.

18. Verani MS, Mahmarian JJ, Hixson JB, Boyce TM, Staudacher RA. Diagnosis of coronary artery disease by controlled coronary vasodilation with adenosine and thallium-201 scintigraphy in patients unable to exercise [see comments]. Circulation 1990; 82: 80-7.

19. Agteresch HJ, Dagnelie PC, Rietveld T, van den Berg JW, Danser AH, Wilson JH. Pharmacokinetics of intravenous ATP in cancer patients. Eur J Clin Pharmacol 2000; 56: 49-55. 
20. Beijer S, van Rossum E, Hupperets PS, Spreeuwenberg C, van den Beuken M, Winkens RA et al. Application of adenosine 5 'triphosphate (ATP) infusions in palliative home care: design of a randomized clinical trial. BMC Public Health 2007; 7: 4.

21. National Cancer Institute. Common Toxicity Criteria, version 2.0. Publish date: April 30, 1999.

22. Moser GH, Schrader J, Deussen A. Turnover of adenosine in plasma of human and dog blood. Am J Physiol 1989; 256: C799-806. 



\section{Chapter 5}

Treatment adherence and patients' acceptance of home infusions with adenosine 5'-triphosphate (ATP) in palliative home care

S. Beijer, N.E. Wijckmans, E. van Rossum, C. Spreeuwenberg, R.A. Winkens, L. Ars, P.C. Dagnelie 


\section{ABSTRACT}

\section{Aim}

In preterminal cancer patients, provision of palliative care in the patients' own environment is preferred. The aim of the present study was to evaluate patients' and caregivers' treatment adherence and patients' acceptance of home infusions with adenosine $5^{\prime}$-triphosphate (ATP).

\section{Methods}

Preterminal cancer patients (life expectancy $<6$ months) with mixed tumour types were eligible for the study. Patients received a maximum of eight weekly intravenous 8-10 h ATP infusions. Evaluation of treatment adherence was based on registration of protocol deviations and patients' acceptance by structured interviews with patients.

\section{Results}

Fifty-one patients received a total of 266 intravenous ATP infusions. The infusion protocol was well executed: mean duration $\approx 8.30 \mathrm{~h}$, stepwise achievement of the maximum infusion rate within $30 \mathrm{~min}$ in $65 \%$ of the infusions, and almost no delay in weekly administration. All except one patient were not burdened by the administration of the infusions at home and none of them had felt afraid. The majority of patients found the advantages of the ATP infusions outweighing the disadvantages. However, an important bottleneck in the administration of ATP infusions at home was difficulty in establishing venous access.

\section{Conclusion}

ATP infusions at home are well accepted by patients. Difficulties in establishing venous access might be reduced by composing specialized home infusion teams working both at the day care centre and at home, or by adopting an alternative route of venous access. 


\section{INTRODUCTION}

Over the past 15 to 20 years, a major change in the delivery of health care has occurred. Increasing numbers of patients suffering from different diseases receive intravenous therapy at home including intravenous antibiotics, steroids, biphosphonates, and parenteral nutrition [8-11, 14, 17, 19, 20]. Also in cancer care, home administration of intravenous medication (chemotherapy, opiates) is becoming a widely used alternative to treatment in hospital [7, 14, 17]. Especially in terminally ill cancer patients, it is preferred to provide palliative care in their own environment $[18,19]$.

A potential agent in palliative care is adenosine $5^{\prime}$-triphosphate (ATP). A randomised clinical trial in patients with advanced non-small-cell lung cancer $[3,4]$ showed that ATP infusions had marked favourable effects on body weight, muscle strength, fatigue, nutritional intake, quality of life and survival $[1,3,4]$.

Unfortunately, ATP cannot be given by alternative routes of administration like oral application or hypodermoclysis. In studies published so far, ATP infusions were given in a clinical setting. However, several authors $[2,12,13]$ have reported that continuous application of low-dose ATP is generally safe. Dyspnoea, chest discomfort, and the urge to take a deep breath were the most common side effects; all side effects were mild and transient, resolving within minutes after lowering the ATP dose. No symptoms of cardiac ischaemia occurred in any of the infusions $[2,5]$. Because of the favourable safety profile of ATP and to diminish the burden on the patients, we decided to administer ATP at the patient's home. The aim of the present study was to evaluate patients' and caregivers' treatment adherence to the ATP infusion protocol and patients' acceptance of ATP infusions at home.

\section{PATIENTS AND METHODS}

\section{Patients}

Patients were recruited through the Departments of Medical Oncology and Pulmonology of five hospitals in the southern half of The Netherlands (located in Maastricht, Eindhoven, Utrecht and Heerlen) and through 50 general practitioners in the region of Maastricht. Eligible for the study were patients with cytologically or histologically confirmed cancer, for whom medical treatment options were restricted to supportive care, who had a life expectancy $<6$ months, and had a World Health Organisation (WHO) performance status 1 or 2 . Since the present study was part of a randomised clinical trial aiming to study the effects of ATP on nutritional status and fatigue, eligible patients also had to suffer from at least one of the following complaints: fatigue, anorexia, or weight loss $>5 \%$ over the previous 
6 months. Excluded were patients with symptomatic angina pectoris, symptomatic heart failure, or any form of atrioventricular block (assessed by electrocardiogram), life expectancy $<4$ weeks, concurrent palliative chemotherapy, and cognitive dysfunction. After baseline measurements, patients were randomly allocated to ATP or control treatment, using computer-generated random numbers with permutation blocks of four. One hundred patients were randomly assigned to the ATP $(n=51)$ or control $(n=49)$ group. The present report on treatment adherence and patients' acceptance of ATP administration at home is restricted to all 51 patients randomised to ATP treatment. Baseline characteristics of ATP-treated patients are shown in Table 1. The study was approved by the Ethical Committees of all hospitals involved in the study, and all patients signed written informed consent prior to the study. Details of the trial design have been published elsewhere [6].

Table 1. Baseline characteristics of ATP-treated patients $(n=51)$.

\begin{tabular}{lll}
\hline & Number & Percent \\
\hline Age (years) & $68.1(45-87)^{2}$ & \\
Gender & 35 & 69 \\
$\quad$ Male & 16 & 31 \\
Female & & \\
WHO performance status ${ }^{1}$ & 33 & 65 \\
1 & 18 & 35 \\
2 & & \\
Tumour type & 21 & 41 \\
Lung & 8 & 16 \\
Colon & 6 & 12 \\
Gastrointestinal other & 5 & 10 \\
Prostate & 11 & 21 \\
$\quad$ Other & & \\
\hline
\end{tabular}

${ }^{1}$ WHO 1: restricted in physically strenuous activity but ambulatory and able to do light work; WHO 2: ambulatory (not more than $50 \%$ in bed) and capable of self-care but unable to carry out any work; ${ }^{2}$ Mean (range).

\section{Treatment protocol}

Over a period of 8 weeks, patients received eight ATP courses of 8-10 h each, at weekly intervals. To prevent side effects, all ATP infusions started beginning at a dose of $20 \mu \mathrm{g} / \mathrm{kg}$.min and were increased in steps of $10 \mu \mathrm{g} / \mathrm{kg}$.min every $10 \mathrm{~min}$ until a maximum dose of $50 \mu \mathrm{g} / \mathrm{kg}$.min, or in case of side effects, until the maximally tolerated dose (MTD) had been reached. Thereafter, ATP was infused at a constant rate. Since initiation of ATP infusions under medical supervision in a clinical setting would facilitate the treatment of possible side effects, the first two ATP infusions were given at the day care centre of the participating hospitals. 
Based on the mild character of the noted side effects during the first two infusions in the first 22 patients, in order to minimize hospitalization of these preterminal patients, an amendment was granted by the Ethical Committee during the study for administering only the first ATP infusion at the day care centre. All subsequent infusions were administered at home by experienced, highly qualified, and trained nurses of the infusion team of the regional Home Care Organisation or hospital. Eligibility for home infusion therapy was checked using specific criteria (Table 2). Patients and their informal caregivers were instructed in detail on the infusion procedures and to call the infusion team in case of side effects or any other problems. All participating nurses received special instructions (verbal and written) on how to administer, increase and end the ATP infusions; what to do in case of side effects; which items had to be checked and reported; and how to instruct the patient and/or informal caregiver.

Table 2. Eligibility criteria for home infusion therapy.

Appropriate housing situation and sanitary conditions

Telephone or comparable device for external communication

Presence of informal caregiver in the home

Psychological ability of patient and family to cope with the potential stress of home infusions

Motivation of patient and informal care giver for home infusions

Acceptance of responsibility for the home infusions, i.e. to report side effects and/or or to stop the infusion in case this would be needed

\section{Data collection and analysis}

Patients' adherence was evaluated by registering the number of patients who stopped with the ATP infusions before the end of the study and the reasons for dropout. Patients' acceptance was investigated by structured interviews after four and eight infusions. Only the latest available evaluation was processed for the present paper. These interviews included questions about burden, duration, frequency, and perceived benefits and disadvantages of the infusions as well as feelings of anxiety during the infusions. Adherence to the treatment protocol was evaluated by standardized registration of the course of the infusions and all protocol deviations. All data were analysed in a descriptive way using SPSS 13.0 for Windows. 


\section{CHAPTER 5}

Number of infusions

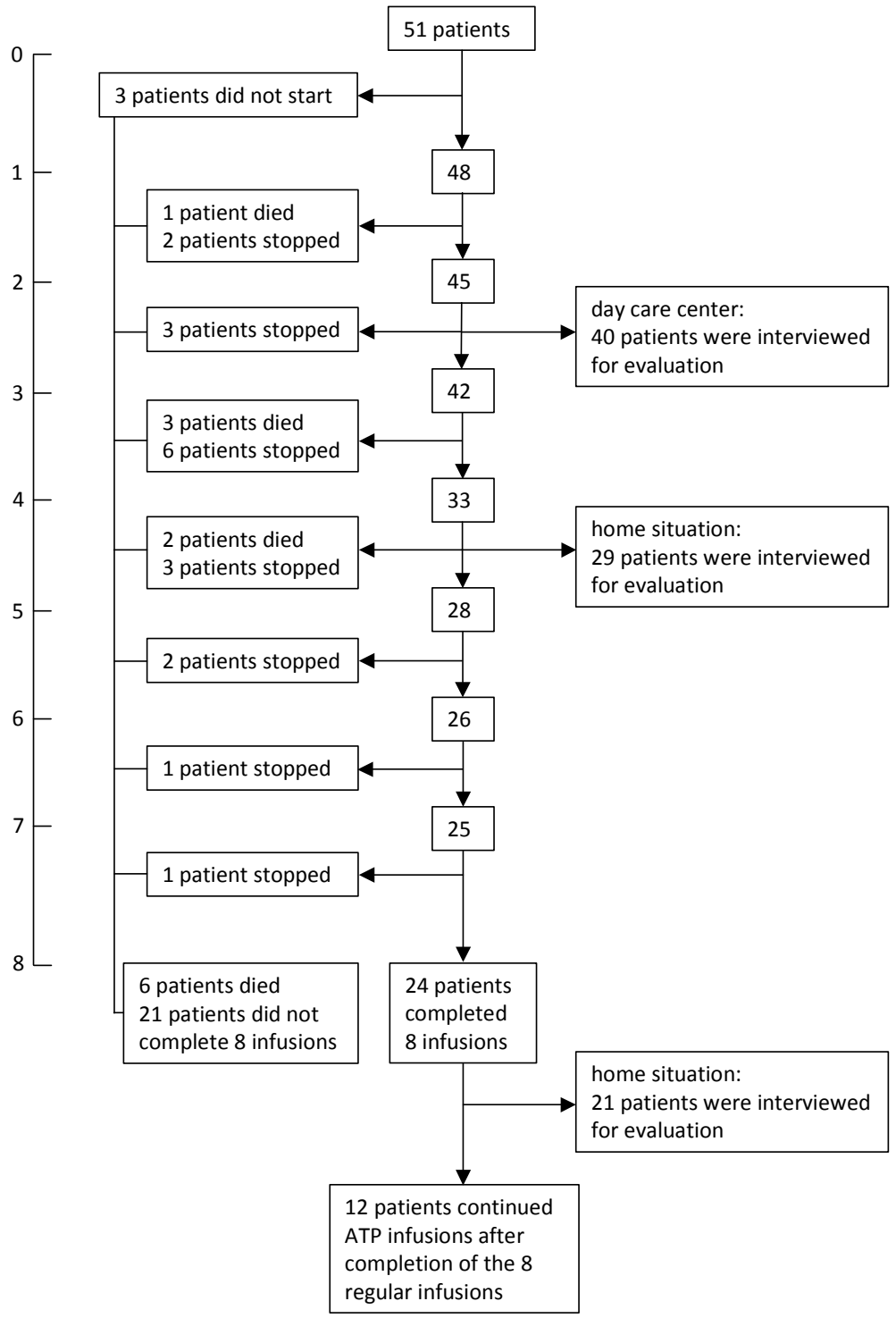

Figure 1. Flow diagram of the study. 


\section{RESULTS}

\section{Patients' adherence to ATP administration}

Of the 51 included patients, $6 \%$ did not start with ATP infusions, $29 \%$ received one to three courses, $18 \%$ four to seven courses, and $47 \%$ completed all eight infusions (Figure 1). Twelve patients decided to continue ATP administration after completion of the eight regular infusions.

Six patients died during the intervention period. Twenty-one patients stopped or did not start with ATP infusions for reasons of deterioration in medical condition $(n=14)$, fear of side effects $(n=4)$, or being unsatisfied with the effect of the ATP $(n=3)$.

\section{Acceptance by patients}

Twenty-nine patients ( $57 \%$ of total) were interviewed about their experiences with ATP infusions at home. Twenty-two patients were not assessable because of death or deterioration in medical condition. All except one patient were not burdened by the home infusions. Patients mentioned that it was more relaxed at home and that it was possible to continue daily activities in one's own environment. The infusion frequency of once a week was evaluated as 'good' by 25 patients. The duration of 8-10 $\mathrm{h}$ was experienced as too long by 11 patients, although many patients added that they accepted the infusion duration that was perceived necessary for obtaining maximal results. None of the patients had felt afraid during the home infusions. Twenty-one patients found the advantages of the ATP infusions outweighing the disadvantages. Main disadvantages of home infusions mentioned by patients were problems with establishing venous access, restriction of daily activities by the infusion, and burden for the informal caregiver.

\section{Protocol adherence}

A summary of protocol deviations is given in Table 3. Of the 408 planned ATP infusions, 142 infusions were not administered due to deterioration of medical condition or death.

Of the 266 infusions given, 95 infusions (36\%) were administered at the day care centre of the participating hospitals and 171 infusions (64\%) at home. In eight patients, more than two infusions were given at the day care centre. Reasons for this were, amongst other things, fear of side effects or the unavailability of an informal caregiver.

The mean duration of the ATP infusions at home was $8 \mathrm{~h} 33 \mathrm{~min}$ (standard deviation (SD) $1 \mathrm{~h} 35 \mathrm{~min}$ ). The mean period to reach the MTD amounted to $27 \mathrm{~min}$ at home. According to the study protocol, nurses were to stay with the patient for 30 min after reaching the MTD. The total spent time was $\approx 1 \mathrm{~h}$ at the start of each infusion and $\approx 0.5 \mathrm{~h}$ at the end of each infusion. In 22 out of 266 infusions, the 
home nurse had been called during the infusion and had to visit the patient to solve the problems (side effects, infusion pump alarm, etc.), implicating an additional time investment varying from 30-90 min.

Table 3. Protocol and deviations from protocol.

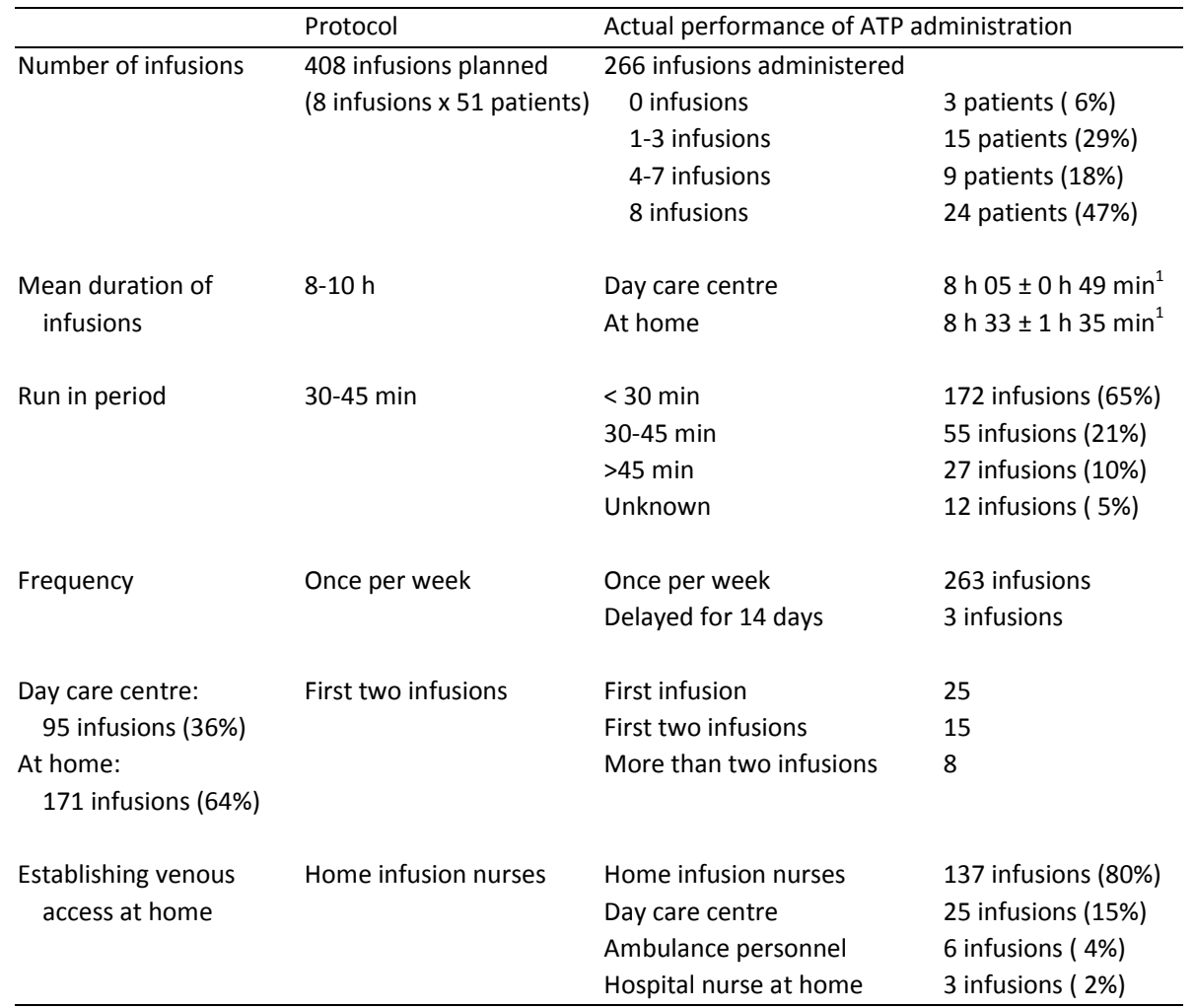

${ }^{1}$ Mean \pm SD

\section{DISCUSSION}

The objective of this study was to evaluate treatment adherence and patients' acceptance of ATP infusions at home in patients with preterminal cancer. As far as we know, this is the first study in which ATP infusions have been systematically administered at home. Results show that the administration of the infusions was largely carried out according to protocol: mean duration $\approx 8.30 \mathrm{~h}$, stepwise achievement of the maximum infusion rate within 30 minutes in $65 \%$ of the infusions, and almost no delay in weekly administration. 
However, an important bottleneck in the administration of ATP infusions at home was difficulty in establishing venous access, possibly due to the history of chemotherapy in many patients. As far as we know, little is written about this problem in the literature. In most studies, venous access devices (Port-a-cath, peripherally inserted central catheter (PICC) or peripheral venous cannula) were inserted during hospital stay or at the day care unit and left in place when the patient went home $[8,14,17,20]$. In our study the peripheral venous cannula had to be inserted at home by the home nurse of the infusion team. Lapostolle et al. [15] reported a study on a total of 671 attempts to obtain peripheral intravenous access in 495 patients in emergency care in out-of-hospital settings. The first attempt was successful in 368 cases (74\%) and unsuccessful in 127 (26\%). Peripheral intravenous access was finally achieved in $99 \%$ of the patients. Improved success rate was reported when attempts were performed by a nurse specialized in emergency care in patients without a particular medical history like chemotherapy, diabetes, or previous multiple hospitalizations. Initial teaching and regular practice significantly increased the success rate [15].

In our study, one of our participating centres solved the problem of difficulties in establishing venous access by a transmural infusion team composed of trained infusion nurses working both at the hospital and in the home situation, thus providing regular practice in inserting infusion needles. Another solution would be to choose an alternative route of venous access. In the present study, a PICC was successfully inserted in one patient.

Our finding that most patients and informal caregivers preferred home infusions is in accordance with other studies. A study comparing hospital and home antibiotic treatment for cellulitis showed that home care is the preferred treatment choice by patients, particularly for those patients who have experienced community care before [9]. In patients with colon cancer receiving chemotherapy, global patient satisfaction with health care was greater in patients receiving home chemotherapy than in patients receiving outpatient treatment [7]. In a study in patients with Fabry disease [16], most patients also preferred treatment at home.

A considerable proportion of patients (38\%) perceived the duration of the infusions at home as too long. Further investigations are warranted to explore other treatment schedules. Technological development may allow smaller, more mobile, and less noisy infusion pumps, contributing to patient comfort.

No feelings of anxiety were reported by the patients in the present study. Zimran et al. [20] also showed no feelings of fear or anxiety associated with infusion treatment at home. In contrast, study patients participating in a self-administration programme in which they had to handle the venous access device themselves [14] did show feelings of uncertainty and anxiety. With regard to the first infusion, our study indicates that patients felt safe when this infusion was administered at the day care centre. 
This evaluation study has some limitations. Inherent to the study population of preterminal cancer patients is the relatively small proportion of patients who completed all eight infusions. This may have led to selection bias since patients with the worst condition will drop out first, restricting the evaluation to patients with fewer problems and easier-to-administer infusions. Furthermore, for logistic reasons, data for the present study had to be collected by the same researcher who was involved in patient instruction and organisation of the infusion protocol. Even though great care was taken to allow patients and caregivers to freely express their opinion and feelings, the possibility of biased information by socially desired answers cannot be completely disregarded.

Despite these limitations, we conclude that patients' and caregivers' adherence to the ATP infusion protocol is high and that ATP infusions at home are well accepted by patients. Possibilities to increase the comfort for the patient would be to perform the infusion during the night. Difficulties in establishing venous access might be reduced by composing specialized home infusion teams working both at the day care centre and at home or by adopting an alternative route of venous access. 


\section{REFERENCES}

1. Agteresch HJ, Burgers SA, van der Gaast A, Wilson JH, Dagnelie PC. Randomized clinical trial of adenosine 5'-triphosphate on tumor growth and survival in advanced lung cancer patients. Anticancer Drugs 2003; 14: 639-44.

2. Agteresch HJ, Dagnelie PC, Rietveld T, van den Berg JW, Danser AH, Wilson JH. Pharmacokinetics of intravenous ATP in cancer patients. Eur J Clin Pharmacol 2000; 56: 49-55.

3. Agteresch HJ, Dagnelie PC, van Der Gaast A, Stijnen T, Wilson JH. Randomized clinical trial of adenosine 5 '-triphosphate in patients with advanced non-small-cell lung cancer. J Natl Cancer Inst 2000; 92: 321-8.

4. Agteresch HJ, Rietveld T, Kerkhofs LG, van den Berg JW, Wilson JH, Dagnelie PC. Beneficial effects of adenosine triphosphate on nutritional status in advanced lung cancer patients: a randomized clinical trial. J Clin Oncol 2002; 20: 371-8.

5. Beijer S, Gielisse EA, Hupperets PS, van den Borne BE, van den Beuken-van Everdingen M, Nijziel MR et al. Intravenous ATP infusions can be safely administered in the home setting: a study in preterminal cancer patients. Invest New Drugs 2007; 25: 571-9.

6. Beijer S, van Rossum E, Hupperets PS, Spreeuwenberg C, van den Beuken M, Winkens RA et al. Application of adenosine $5^{\prime}$-triphosphate (ATP) infusions in palliative home care: design of a randomized clinical trial. BMC Public Health 2007; 7: 4.

7. Borras JM, Sanchez-Hernandez A, Navarro M, Martinez M, Mendez E, Ponton Jlet al. Compliance, satisfaction, and quality of life of patients with colorectal cancer receiving home chemotherapy or outpatient treatment: a randomised controlled trial. BMJ 2001; 322: 826-30.

8. Chataway J, Porter B, Riazi A, Heaney D, Watt H, Hobart J et al. Home versus outpatient administration of intravenous steroids for multiple-sclerosis relapses: a randomised controlled trial. Lancet Neurol 2006; 5: 565-71.

9. Corwin P, Toop L, McGeoch G, Than M, Wynn-Thomas S, Wells JE et al. Randomised controlled trial of intravenous antibiotic treatment for cellulitis at home compared with hospital. BMJ 2005; 330: 129-34.

10. Esmond G, Butler M, McCormack AM. Comparison of hospital and home intravenous antibiotic therapy in adults with cystic fibrosis. J Clin Nurs 2006; 15: 52-60.

11. Gorski LA. Central venous access device outcomes in a homecare agency: a 7-year study. J Infus Nurs 2004; 27: 104-11.

12. Haskell CM, Mendoza E, Pisters KM, Fossella FV, Figlin RA. Phase II study of intravenous adenosine 5 '-triphosphate in patients with previously untreated stage IIIB and stage IV non-small cell lung cancer. Invest New Drugs 1998; 16: 81-5.

13. Haskell CM, Wong M, Williams A, Lee LY. Phase I trial of extracellular adenosine $5^{\prime}$-triphosphate in patients with advanced cancer. Med Pediatr Oncol 1996; 27: 165-73.

14. Johansson E, Langius-Eklof A, Engervall P, Wredling R. Patients' experience of ambulatory selfadministration of pamidronate in multiple myeloma. Cancer Nurs 2005; 28: 158-65.

15. Lapostolle F, Catineau J, Garrigue B, Monmarteau V, Houssaye T, Vecci I et al. Prospective evaluation of peripheral venous access difficulty in emergency care. Intensive Care Med 2007; 33: 1452-7.

16. Linthorst GE, Vedder AC, Ormel EE, Aerts JM, Hollak CE. Home treatment for Fabry disease: practice guidelines based on 3 years experience in The Netherlands. Nephrol Dial Transplant 2006; 21: 355-60.

17. Payne SA. A study of quality of life in cancer patients receiving palliative chemotherapy. Soc Sci Med 1992; 35: 1505-9.

18. Peters L, Sellick K. Quality of life of cancer patients receiving inpatient and home-based palliative care. J Adv Nurs 2006; 53: 524-33.

19. Smeets PM, Beusmans GH, Weber WE. Prospective study of home morphine infusion in 62 terminally ill patients. J Pain Symptom Manage 1999; 18: 390-400.

20. Zimran A, Hollak CE, Abrahamov A, van Oers MH, Kelly M, Beutler E. Home treatment with intravenous enzyme replacement therapy for Gaucher disease: an international collaborative study of 33 patients. Blood 1993; 82: 1107-9. 



\section{Chapter 6}

\section{Effect of ATP infusions on the nutritional status and survival of preterminal cancer patients}

S. Beijer, P.S. Hupperets, B.E. van den Borne, S.R. Eussen, A.M. van Henten, M. van den Beuken-van Everdingen, A. de Graeff, T.A. Ambergen, P.A. van den Brandt, P.C. Dagnelie

Anti-Cancer Drugs 2009; in press 


\section{ABSTRACT}

\section{Aim}

To investigate the effect of intravenous infusions of adenosine 5 '-triphosphate (ATP) on nutritional status and survival in preterminal cancer patients.

\section{Methods}

Ninety-nine preterminal cancer patients (estimated life expectancy 1-6 month) with mixed tumour types were randomly allocated to receive either weekly intravenous ATP infusions (8-10 h/wk, max. $50 \mu \mathrm{g} / \mathrm{kg}$.min) for 8 weeks, or no ATP (control group). Nutritional status parameters were assessed until 8 weeks, and analysed by repeated-measures analysis of covariance. Cox proportional hazards models were fitted to assess the effect of ATP on short term (0-8 weeks) and long term (0-6 months) survival.

\section{Results}

Fifty-one patients were randomised to ATP and 48 to the control group. Results showed a significant favourable effect of ATP on triceps skin fold thickness (between-group difference per 8 weeks: $1.76 \mathrm{~mm}, 95 \%$ confidence interval (Cl): 0.48 to $3.12 \mathrm{~mm} ; \mathrm{p}=0.009$ ) and on short-term survival (0-8 weeks, HR: $0.40,95 \% \mathrm{Cl}$ : 0.17 to $0.95 ; p=0.037)$. In weight-stable patients and in lung cancer patients, long term survival (0-6 months) was also significantly better in ATP-treated patients (weight stable patients: HR: $0.40,95 \% \mathrm{Cl}: 0.19-0.83 ; \mathrm{p}=0.014$; patients with lung cancer: HR: $0.35,95 \% \mathrm{Cl}: 0.14-0.88 ; \mathrm{p}=0.025)$.

\section{Conclusion}

In this population of preterminal cancer patients, ATP infusions, at the dose and schedule studied, had a favourable effect on triceps skin fold thickness and survival, especially in weight-stable patients and patients with lung cancer. Larger studies are warranted to confirm these findings and to further define the effect of ATP on tumour growth and survival. 


\section{INTRODUCTION}

Cachexia is one of the most common and devastating symptoms in patients with advanced cancer ranging from $24 \%$ early at the diagnosis of advanced cancer to more than $80 \%$ at the terminal stages [1]. The presence of weight loss is associated with decreased survival [2,3], and in some cases, excessive weight loss may itself be the cause of death [4]. Cytokines are thought to play a pivotal role in the development and progression of cancer cachexia [5-7]. So far, neither nutritional supplementation $[1,8]$ nor pharmacological interventions $[6,7,9]$ have been able to reverse cachexia. Research on novel approaches to counteract cancer cachexia therefore remains highly relevant.

A potential agent in the treatment of cancer-cachexia is adenosine $5^{\prime}$-triphosphate (ATP). A randomised clinical trial (RCT) in patients with non-small-cell lung cancer (NSCLC) $[10,11]$ showed that ATP infusions, given over $30 \mathrm{~h}$ at 2- to 4- week intervals (infusion rate max. $75 \mu \mathrm{g} / \mathrm{kg} \cdot \mathrm{min}$ ), had marked beneficial effects on nutritional intake, body weight, fat and muscle mass. ATP treatment was also associated with a highly significant survival benefit in a subgroup of patients with stage IIIB NSCLC [12]. Moreover, ATP prevented the progressive increase in plasma concentrations of C-reactive protein (CRP) and the decrease in albumin which were seen in the control group [10], providing a possible mechanism underlying the favourable effects of ATP on the nutritional status in these patients. The antiinflammatory properties of ATP were recently confirmed by Swennen et al. $[13,14]$ who, using an ex vivo model of stimulated whole blood, demonstrated that ATP inhibited TNF- $\alpha$ and enhanced IL-10 release [13] via stimulation of the P2Y 11 and $\mathrm{P} \mathrm{Y}_{12}$ receptor, respectively [14].

Based on these promising results, we initiated a RCT to investigate the effects of ATP on the nutritional status and survival in patients with different types of cancer in the preterminal stage, defined as a life expectancy $<6$ months.

\section{PATIENTS AND METHODS}

\section{Patients}

From March 2002 through October 2006, 100 patients were included in the study. The Departments of Medical Oncology and Pulmonology in five centres and 50 general practitioners in the southern half of The Netherlands participated in patient recruitment.

Eligible were patients with histologically or cytologically proven cancer, without curative treatment options, with an estimated life expectancy of 1-6 months, a World Health Organisation performance status 1 or 2 , suffering from at least one of the following complaints: fatigue, weight loss $>5 \%$ over the previous 6 months, or 
anorexia. Patients with symptomatic angina pectoris, symptomatic heart failure or any form of atrioventricular block (assessed by electrocardiography), as well as patients with cognitive dysfunction, or concurrent palliative chemotherapy were excluded.

The study was approved by the Ethical Committees of all hospitals involved in the study, and all patients signed written informed consent prior to the study.

\section{Study design}

After baseline measurements, patients were stratified for region, tumour type, and weight loss ( $\leq 5 \%$ vs. $>5 \%$ over the last 6 months), and then randomly assigned to receive either usual care, standard nutritional advice and ATP (ATP group), or usual care and standard nutritional advice alone (control group), using computergenerated random numbers with permutation blocks of four. Outcome parameters were assessed until 8 weeks.

\section{ATP intervention}

Patients allocated to the ATP group received weekly 8-10 h ATP infusions over a period of 8 weeks [15]. The first ATP infusion was offered under medical supervision at the day care centre of the participating hospitals. ATP infusions were started at a rate of $20 \mu \mathrm{g} / \mathrm{kg} \cdot \mathrm{min}$ and increased in steps of $10 \mu \mathrm{g} / \mathrm{kg} \cdot \mathrm{min}$ per $10 \mathrm{~min}$, until reaching a maximum rate of $50 \mu \mathrm{g} / \mathrm{kg} \cdot \mathrm{min}$, or the maximally tolerated dose (MTD) if this was lower, in case of side effects. Thereafter, ATP was infused at a continuous rate. Subsequent infusions were given at MTD in the patient's home.

\section{Outcome assessment}

Body weight was measured without shoes, using an electronic scale (Soehnle 7407 Translucia, Germany). Triceps skin fold thickness was measured in triplicate at the dominant arm, with a Holtain ${ }^{\circledR}$ skin fold caliper (CMS weighing equipment LTD, London UK), and the median used for further calculations. Mid-upper arm circumference was measured in duplicate at the dominant side with a flexible measuring tape, and the mean value was used for further calculations. In order to exclude inter-observer variability, longitudinal measurements in one patient were performed by one observer. Nutritional intake was assessed by a 3-day food diary, including meal preparation details, and checked by an experienced dietician. Intake of energy and protein was calculated using the Dutch Food Composition Table 2001 (NEVO, The Hague, The Netherlands), by the Software Programme Komeet (version 4.0.58, BaS Nutrition Software, Arnhem, The Netherlands).

\section{Statistical analysis}

Data were doubly entered and analysed according to the intention-to-treat principle. Curves were fitted to describe the time course of nutritional status 
parameters, and differences over time between the two groups appraised by repeated-measures analysis of covariance, using SAS Proc Mixed version 9.1 (SAS Institute Inc., Cary, NC, USA). Independent variables were the treatment indicator variable, the baseline measurement, measurement time, and the interaction between time and treatment. Statistical significance of treatment effects was assessed by testing the interaction between time and treatment. For weight analyses, patients with oedema and/or ascites were excluded.

Cox regression models were fitted including interaction terms between treatment and dummy variables for short term (i.e. during the 8-week ATP intervention) and long term survival (i.e. 0-6 months, based on the maximum life expectancy of 6 months in the study population). For the latter analysis (0-6 months), dummy variables for 0-8 wks and 8 wks- 6 mo were combined into a single dummy variable (0-6 mo) since Cox proportional hazards assumption was tested and not rejected. Median survival time was determined by extrapolation from confounder-adjusted Kaplan Meier plots. Because of previously shown survival benefit of ATP treatment in weight-losing stage IIIB NSCLC patients [12], we repeated the same analyses in 1. patients stratified by weight loss, defined as $\leq 5 \%$ or $>5 \%$ weight loss over the past 6 months [16], and 2. lung cancer patients.

All models were adjusted for confounders. Two-tailed p-values $<0.05$ were considered statistically significant.

\section{RESULTS}

\section{Study population}

One hundred patients were randomly assigned to the ATP $(n=51)$ or control $(n=49)$ group (Figure 1). One patient in the control group was excluded because cancer was not confirmed histologically or cytologically. Sixteen patients (7 ATP, 9 controls) died or dropped out before the first follow-up measurement, leaving 83 assessable patients (44 ATP, 39 controls). Fifty-seven patients ( 29 ATP, 28 controls) completed the full 8-week study period. Eleven patients died in the control group and 6 patients in the ATP group due to disease progression, unrelated to the study product. Total drop-out rates were equally distributed over ATP $(n=22)$ and control patients $(n=20)$.

\section{Baseline characteristics}

Mean age of the total study population was 66.4 years, and $66 \%$ of the patients were male. Lung cancer was the most frequent tumour type (45\%), followed by colon cancer (13\%). Seventy percent of the patients had WHO performance status 1, 30\% WHO 2. 


\section{Time scale (wks)}

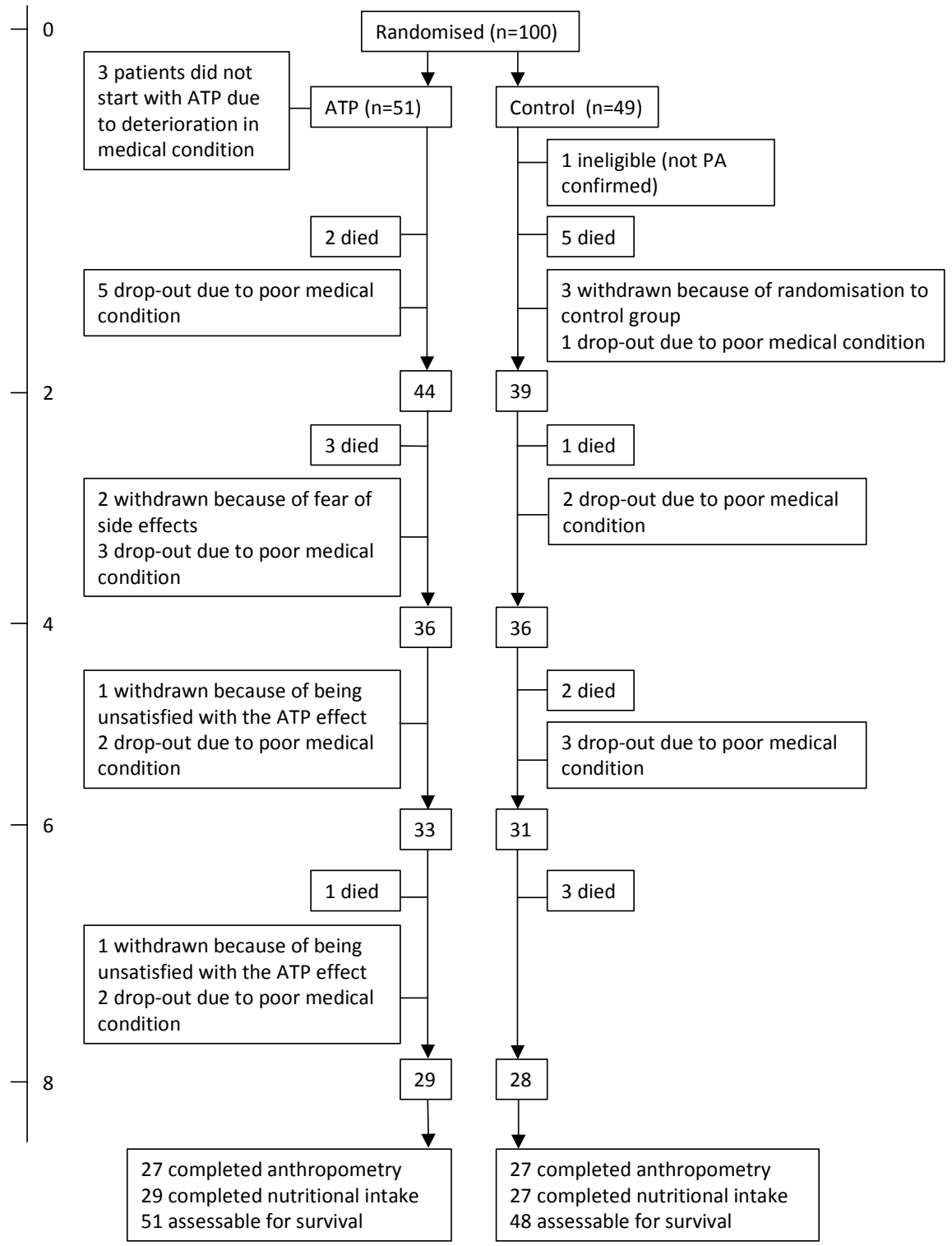

In two patients (both control group) one measurement is missing at $\mathrm{T} 2$ and in one patient (control group) one measurement is missing at T6. At T8 anthropometry was not assessed because of poor medical condition in three patients ( 2 in ATP group; 1 in control group). Nutritional intake was not assessed in one patient in the control group.

Figure 1. Flow diagram of randomised patients. 
Table 1. Baseline patient characteristics of randomly assigned and assessable patients.

\begin{tabular}{|c|c|c|c|c|}
\hline & \multicolumn{2}{|l|}{ ATP } & \multicolumn{2}{|l|}{ Control } \\
\hline & $\begin{array}{l}\text { Rand. assigned }{ }^{1} \\
(n=51)\end{array}$ & $\begin{array}{l}\text { Assessable }^{2} \\
(\mathrm{n}=44)\end{array}$ & $\begin{array}{l}\text { Rand. assigned }{ }^{1} \\
(n=49)\end{array}$ & $\begin{array}{l}\text { Assessable }^{2} \\
(n=39)\end{array}$ \\
\hline \multicolumn{5}{|l|}{ Sex } \\
\hline Male & $35(69 \%)$ & $34(77 \%)$ & $31(63 \%)$ & $26(67 \%)$ \\
\hline Female & $16(31 \%)$ & $10(23 \%)$ & $18(37 \%)$ & $13(33 \%)$ \\
\hline Age (years) & $68 \pm 9.8$ & $68 \pm 9.6$ & $65 \pm 10.5$ & $65 \pm 11.0$ \\
\hline Years of cancer at inclusion & $2.3 \pm 2.7$ & $2.5 \pm 2.9$ & $2.7 \pm 3.3$ & $2.7 \pm 3.3$ \\
\hline \multicolumn{5}{|l|}{ Tumour type } \\
\hline Lung & $21(41 \%)$ & $19(43 \%)$ & $24(49 \%)$ & $21(54 \%)$ \\
\hline Colon & $8(16 \%)$ & $8(18 \%)$ & $5(10 \%)$ & $3(8 \%)$ \\
\hline Gastrointestinal other & $6(12 \%)$ & $3(7 \%)$ & $6(12 \%)$ & $4(10 \%)$ \\
\hline Prostate & $5(10 \%)$ & $5(11 \%)$ & $4(8 \%)$ & $3(8 \%)$ \\
\hline Other & $11(21 \%)$ & $9(21 \%)$ & $10(21 \%)$ & $8(20 \%)$ \\
\hline \multicolumn{5}{|l|}{ Smoking } \\
\hline Yes & $23(45 \%)$ & $20(45 \%)$ & $15(31 \%)$ & $13(33 \%)$ \\
\hline No & $28(55 \%)$ & $24(55 \%)$ & $33(67 \%)$ & $25(64 \%)$ \\
\hline Missing & - & - & $1(2 \%)$ & $1(3 \%)$ \\
\hline \multicolumn{5}{|l|}{ WHO performance status } \\
\hline 1 & $33(65 \%)$ & $30(68 \%)$ & $37(76 \%)$ & $33(85 \%)$ \\
\hline 2 & $18(35 \%)$ & $14(32 \%)$ & $12(24 \%)$ & $6(15 \%)$ \\
\hline \multicolumn{5}{|l|}{ Fatigue } \\
\hline Yes & $48(94 \%)$ & $41(93 \%)$ & $48(98 \%)$ & 39 (100\%) \\
\hline No & $3(6 \%)$ & $3(7 \%)$ & $1(2 \%)$ & $0(0 \%)$ \\
\hline \multicolumn{5}{|l|}{ Loss of appetite } \\
\hline Yes & $36(71 \%)$ & $31(70 \%)$ & $31(63 \%)$ & $23(59 \%)$ \\
\hline No & $15(29 \%)$ & $13(30 \%)$ & $18(37 \%)$ & $16(41 \%)$ \\
\hline \multicolumn{5}{|l|}{ EORTC QLQ-C30: } \\
\hline Physical functioning & $44.0 \pm 25.9$ & $49.1 \pm 23.9$ & $45.3 \pm 26.2$ & $50.1 \pm 24.7$ \\
\hline Fatigue & $65.6 \pm 27.0$ & $62.9 \pm 27.2$ & $58.3 \pm 26.6$ & $54.1 \pm 24.3$ \\
\hline Appetite loss & $49.7 \pm 37.9$ & $48.5 \pm 37.7$ & $43.1 \pm 34.4$ & $41.0 \pm 34.6$ \\
\hline Energy intake (MJ/d) & $6.6 \pm 2.1$ & $6.8 \pm 2.1$ & $7.4 \pm 2.3$ & $7.7 \pm 2.1$ \\
\hline Weight $^{3}$ & $69.9 \pm 15.2$ & $71.4 \pm 15.3$ & $68.4 \pm 17.2$ & $72.0 \pm 16.9$ \\
\hline Body mass index $(\mathrm{BMI})\left(\mathrm{kg} / \mathrm{m}^{2}\right)^{3}$ & $23.3 \pm 4.5$ & $23.7 \pm 4.8$ & $23.1 \pm 4.6$ & $24.1 \pm 4.4$ \\
\hline Weight change in previous $6 \mathrm{mo}(\%)$ & $-3.5 \pm 7.9$ & $-2.8 \pm 7.6$ & $-2.6 \pm 9.0$ & $-1.0 \pm 9.0$ \\
\hline$\geq 5 \%$ weight loss in previous 6 mo & $18(35 \%)$ & $13(30 \%)$ & 17 (35\%) & $10(26 \%)$ \\
\hline Overall weight change $(\%)^{4}$ & $-10.9 \pm 10.0$ & $-9.9 \pm 10.0$ & $-9.1 \pm 13.5$ & $-6.1 \pm 12.4$ \\
\hline$\geq 10 \%$ overall weight loss & $27(53 \%)$ & $22(50 \%)$ & $20(41 \%)$ & $12(31 \%)$ \\
\hline Oedema and/or ascites & $14(28 \%)$ & $12(27 \%)$ & $8(17 \%)$ & $6(15 \%)$ \\
\hline Oedema & $12(24 \%)$ & $11(25 \%)$ & $8(17 \%)$ & $6(15 \%)$ \\
\hline Ascites & $6(12 \%)$ & $4(9 \%)$ & $2(4 \%)$ & $0(0 \%)$ \\
\hline Upper arm circumference (cm) & $29.4 \pm 4.4$ & $29.5 \pm 4.4$ & $28.6 \pm 4.5$ & $29.6 \pm 4.0$ \\
\hline Triceps skin fold thickness (mm) & $15.3 \pm 6.9$ & $15.1 \pm 6.8$ & $16.4 \pm 8.2$ & $17.6 \pm 7.9$ \\
\hline
\end{tabular}

Values are expressed as number (\%) or mean \pm SD; ${ }^{1}$ Data available for energy intake: $n=49$ (ATP), $n=48$ (C); for upper arm circumference: $n=51$ (ATP), $n=47$ (C); for triceps skin fold thickness: $n=50$ (ATP), $n=46$ (C); ${ }^{2}$ At least one followup analysis was performed; Data available for energy intake: $n=42$ (ATP), $n=39(C) ;{ }^{3}$ Patients with ascites or oedema were excluded from analysis; Randomly assigned: for weight: $n=27$ (ATP), $n=31$ (C); for BMI: $n=25$ (ATP), $n=31$ (C); Assessable: for weight: $n=22$ (ATP), $n=24$ (C); for BMI: $n=21$ (ATP), $n=24$ (C); ${ }^{4}$ Overall weight change = current weight minus stable pre-illness weight. 
As shown in Table 1, there was some imbalance between the randomisation groups in favour of the control group: randomised and assessable patients in the ATP group had a worse performance status, a lower energy intake, a higher frequency of oedema and ascites; also weight loss $\geq 10 \%$ at baseline was found more frequently in the ATP group.

\section{Intervention}

Of the 51 patients assigned to the ATP-group, three patients (6\%) did not start the infusion because of rapid deterioration of their condition. The remaining 48 patients received a mean of 5.5 ATP infusions per patient over the 8-week period. Twenty-four patients (47\%) completed all eight ATP infusions; of these, 12 patients pledged to continue ATP administration after completion of the regular 8-week study period. Over the subsequent four months, these patients received a mean of 7 ATP infusions per patient [15].

The mean dose of ATP administered was $45 \mu \mathrm{g} / \mathrm{kg}$. min in the first ATP infusion to $40 \mu \mathrm{g} / \mathrm{kg}$. min in the $8^{\text {th }}$ infusion, and 36 out of 48 patients received a mean ATP dose of $40-50 \mu \mathrm{g} / \mathrm{kg}$.min over all infusions. The total administered dose per patient per day was $1.42 \pm 0.43 \mathrm{~g}$ ATP per day (mean $\pm \mathrm{SD}$ ).

The majority of ATP infusions (63\%) were without side effects. Dyspnoea was the most common side effect ( $14 \%$ of infusions), followed by chest discomfort (12\%) and the urge to take a deep breath (11\%). No symptoms of cardiac ischaemia occurred in any of the infusions. All side effects were transient and resolved within minutes after lowering the ATP infusion rate [15].

\section{Co-interventions}

At baseline, 10 patients ( 5 ATP, 5 control group) were treated with hormones and 4 patients with gefitinib (2 ATP, 2 controls); no patients were treated with palliative chemotherapy or radiotherapy. During the study, one patient (control) received palliative radiotherapy for skeletal metastases, and two patients (control) started with chemotherapy. Hormone therapy was continued in nine patients (5 ATP, 4 controls) and reduced in one patient (control). Gefitinib was started in one patient (control), raised in one patient (ATP), and continued in three patients (1 ATP, 2 controls). Use of non-opioid or opioid analgesics, corticosteroids, antihypertensives, antiemetics, antidiarrhoics, laxatives, diuretics, antibiotics, antidiabetics or COPD drugs was similar in the ATP and control group (data not shown). 


\section{Effect of ATP on nutritional status}

Changes per week in anthropometric measurements during the 8-week intervention period in the ATP and control group are shown in Table 2 and changes in nutritional intake in Table 3.

Table 2. Changes per 8 weeks in anthropometric measurements in patients treated with ATP and control patients, and between-group difference.

\begin{tabular}{|c|c|c|c|c|c|c|}
\hline & \multicolumn{2}{|c|}{ ATP group } & \multicolumn{2}{|c|}{ Control group } & \multicolumn{2}{|c|}{ Between group difference } \\
\hline & Estimate & $95 \% \mathrm{Cl}$ & Estimate & $95 \% \mathrm{Cl}$ & Estimate & $95 \% \mathrm{Cl}$ \\
\hline Weight (kg) & -2.62 & -6.16 to 0.96 & -2.20 & -6.24 to 1.92 & -0.42 & -2.24 to 1.44 \\
\hline Triceps skin fold & & & & & & \\
\hline thickness (mm) & -1.84 & -3.92 to 0.24 & -3.60 & -5.84 to -1.36 & 1.76 & 0.48 to 3.12 \\
\hline $\begin{array}{l}\text { Mid-upper arm } \\
\text { circumference }(\mathrm{cm})\end{array}$ & -2.24 & -3.36 to -1.20 & -1.52 & -2.80 to -0.24 & -0.72 & -1.52 to 0.08 \\
\hline
\end{tabular}

Both in ATP-treated and control patients, weight, mid-upper arm circumference and triceps skin fold thickness decreased. However, triceps skin fold thickness decreased significantly less in the ATP group (change per 8 weeks: $-1.84 \mathrm{~mm}, 95 \%$ $\mathrm{Cl}$ : -3.92 to $0.24 \mathrm{~mm})$ than in the control group $(-3.60,95 \% \mathrm{Cl}:-5.84$ to $-1.36 \mathrm{~mm}$; between-group difference: $1.76,95 \% \mathrm{Cl}: 0.48$ to $3.12 \mathrm{~mm}, \mathrm{p}=0.009)$. No statistically significant difference between the two groups was observed for weight, mid-upper arm circumference, or intake of energy and protein. In the subgroup of patients with lung cancer, results were similar (data not shown).

Table 3. Nutritional intake at 0,4 , and 8 weeks in the ATP and control group.

\begin{tabular}{lllllllr}
\hline & ATP & & \multicolumn{3}{c}{ Control (C) } & \multicolumn{3}{c}{ ATP vs. C } \\
& 0 & 4 & 8 & 0 & 4 & 8 & p-value \\
& $(\mathrm{n}=49)$ & $(\mathrm{n}=36)$ & $(\mathrm{n}=29)$ & $(\mathrm{n}=47)$ & $(\mathrm{n}=34)$ & $(\mathrm{n}=26)$ & \\
\hline Energy intake (MJ/d) & $6.6 \pm 0.3$ & $6.6 \pm 0.4$ & $7.1 \pm 0.4$ & $7.4 \pm 0.3$ & $7.2 \pm 0.3$ & $7.7 \pm 0.4$ & 0.74 \\
Protein intake (g/d) & $60 \pm 3$ & $58 \pm 4$ & $65 \pm 5$ & $65 \pm 4$ & $61 \pm 4$ & $69 \pm 5$ & 0.52 \\
Protein intake (\%) & $15 \pm 0.5$ & $15 \pm 0.7$ & $16 \pm 0.8$ & $15 \pm 0.4$ & $14 \pm 0.6$ & $15 \pm 0.5$ & 0.47 \\
Water (L/d) & $1.9 \pm 0.1$ & $1.8 \pm 0.1$ & $1.7 \pm 0.1$ & $2.1 \pm 0.1$ & $2.1 \pm 0.1$ & $2.1 \pm 0.1$ & \\
\hline
\end{tabular}

Values are expressed as mean $\pm \mathrm{SE}$; P-value based on repeated-measures analysis of covariance. 


\section{CHAPTER 6}

A.

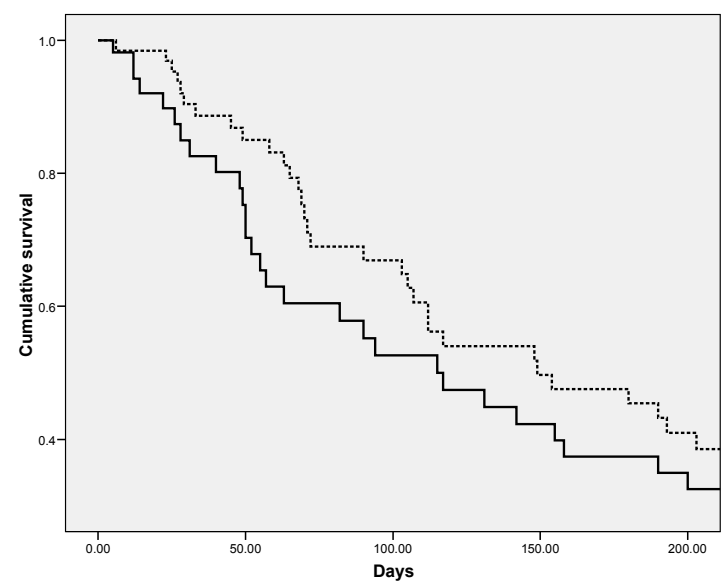

$0=$ control group $(n=48$

- 1 = ATP group $(n=51)$

B.

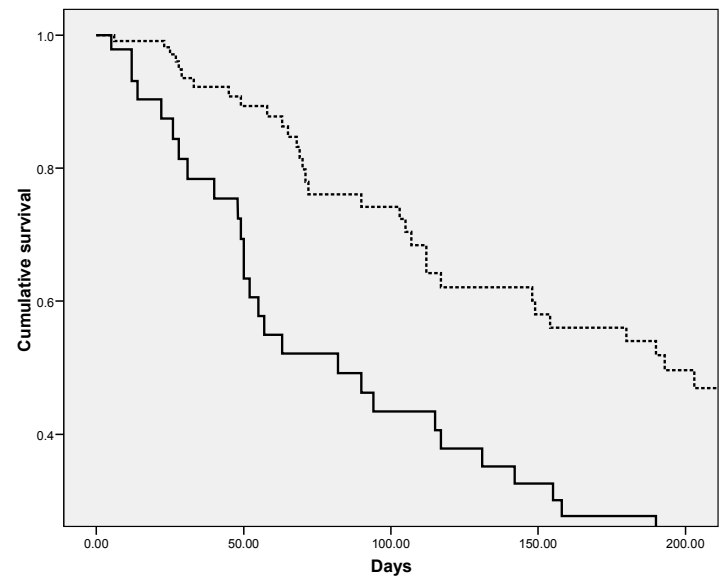

$0=$ control group $(n=31)$ -... 1 = ATP group $(n=33)$

C.

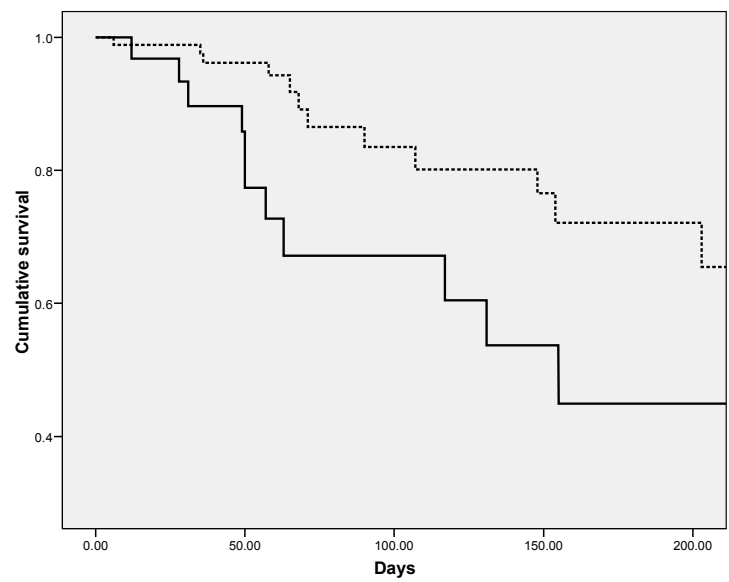

$0=$ control group $(n=23)$ -. . . 1 = ATP group $(n=21)$

Figure 2. Kaplan-Meier plots of survival in patients treated with ATP versus no ATP (control): (A) total group (ATP: $n=51$; control: $n=48$ ), (B) patients with $\leq 5 \%$ weight loss over the previous 6 months (ATP: $n=33$; control: $n=31$ ), (C) patients with lung cancer (ATP: $n=21$; control: $n=23$ ). 


\section{Effect of ATP on survival}

As shown in Figure 2A, Cox regression revealed a statistically significant difference in short-term (0-8 weeks) survival in favour of ATP-treated patients (HR of ATP vs. control: $0.40,95 \% \mathrm{Cl}: 0.17-0.95 ; p=0.037)$. Long term survival (0-6 months) was not significantly different between the ATP and control group (HR: $0.71,95 \% \mathrm{Cl}: 0.40$ 1.28; $p=0.26$ ). Median survival was 150 days in the ATP group and 115 days in the control group. On the census date of 10 September 2007, nine patients (6 ATP, 3 controls) were still alive.

Stratified analysis in weight-stable and weight-losing patients showed a significant survival benefit of ATP treatment in weight-stable patients (Figure 2B; ATP: $n=33$; control: $n=31$ ), both during the 8 -week intervention (HR: $0.20,95 \% \mathrm{Cl}$ : $0.08-0.54$; $\mathrm{p}=0.001)$ and for long term survival (0-6 months; HR: $0.40,95 \% \mathrm{Cl}: 0.19-0.83$; $p=0.014)$. No significant effect of ATP on survival was found in weight-losing patients (data not shown).

In patients with lung cancer $(n=44)$ (Figure $2 C$ ), results also indicated a significant short and long term survival benefit of ATP treatment (0-8 weeks: HR: $0.17,95 \% \mathrm{Cl}$ : $0.04-0.78 ; p=0.023 ; 0-6$ months: HR: $0.35,95 \% \mathrm{Cl}: 0.14-0.88 ; p=0.025)$.

\section{DISCUSSION}

In the present RCT we investigated the effects of ATP infusions on the nutritional status and survival in patients with preterminal cancer of different tumour types. In view of the short life expectancy of this patient population ( $<6$ months), we chose to apply a frequent ATP treatment schedule over a short period of time (i.e. weekly 8-10 h infusions of ATP over 8 weeks).

Results showed a significant advantage in short term survival (0-8 weeks) for ATPtreated patients relative to control patients (HR 0.40), which was more pronounced in weight-stable patients (HR 0.20) and patients with lung cancer (HR 0.17). Moreover, ATP treatment even showed significant benefit for long term survival (06 months) in both weight-stable patients (HR 0.40) and patients with lung cancer (HR 0.35). These results are intriguing especially since our study population was composed of refractory cancer patients with preterminal illness with an estimated life expectancy $<6$ months. Clearly, our findings will need confirmation in future rigorous studies.

The question could be raised why the observed survival benefit of ATP in our study population was especially present and lasted longer in weight-stable patients, as opposed to patients with recent weight loss. Recent weight loss is well-known to be a predictor of survival $[2,3]$, presumably due to a higher tumour stage $[17,18]$. Many malignant tumours produce humoral factors, such as cytokines or specific cachexia-inducing factors, thereby inducing weight loss [5-7, 19]. Thus, the notion 
of better effects of ATP in weight-stable patients could indicate that ATP may be more effective in patients with less advanced disease. This hypothesis is supported by Agteresch et al. [12], who reported favourable effects of ATP on survival only in NSCLC patients with locally extended disease (stage IIIB), but not in patients with metastatic disease (stage IV). However, as we did not collect blood samples for ethical reasons, especially in order to minimize burden in the control group, our data do not provide further insight in the precise mechanism involved.

It might be argued that the additional fluid administration in the ATP infusion group could have been responsible for the survival benefit in the ATP group. However, results showed that patients in the control group had a higher total fluid intake/load than patients in the intervention group $(2.1 \pm 0.6$ litre in the control group, vs. $1.8 \pm 0.7$ in the ATP group excluding the ATP infusion; Table 3 ). In addition, patients in the ATP group received just one infusion of on average $284 \mathrm{ml}$ (range: $27-556 \mathrm{ml}$ ) per day, so that total fluid intake including the infusion volume over the week in the ATP group still remained below fluid intake in the control group. We therefore conclude that the extra fluid administration by the infusions does not provide an explanation for the observed survival benefit in the ATP group. The mechanism underlying the effect of ATP remains to be elucidated. Agteresch et al. [12] speculated that the effect of ATP on survival could have been mediated by the anticachectic effect of ATP in their study population. However, based on our finding of stronger and longer lasting effects of ATP on survival in weight-stable patients, it would appear more likely that other mechanisms underlie the favourable effect of ATP on survival, such as a direct effect of ATP on malignant cell growth. Extracellular ATP has already been shown to effectively inhibit the growth of various types of malignant tumour cells [20-23] and to reduce tumour growth of various tumours in vivo [24-27]. In view of the preterminal disease stage of the patients, we did not monitor tumour growth; as a consequence, the abovementioned interpretation remains speculative.

Our findings with regard to the effects of ATP on the nutritional status partly confirm results of the earlier RCT in patients with advanced NSCLC [10, 11]. A possible explanation for the lack of effect might be that the administered ATP dose was not high enough to cause an effect on nutritional status. Although knowledge about a possible threshold for effect of ATP infusion is not available, pharmacokinetic data from Agteresch et al. [28] show that compared to baseline, ATP infusions with a dose between 25 and $60 \mu \mathrm{g} / \mathrm{kg}$. min induce a 53-56\% increase in erythrocyte ATP concentrations. Erythrocyte ATP concentrations are the presumed direct mediator of the physiological effects of ATP via P1 and P2 purinergic receptors [29]. Since in the present study, 46 out of 48 patients received a mean dose $\geq 25 \mu \mathrm{g} / \mathrm{kg}$. min, it would appear less likely that the lack of effect of ATP on the nutritional status was due to a too low infusion rate. 
Another possible explanation might be that in the earlier trial, the favourable effects of ATP on triceps skin fold thickness came into effect within 8 weeks, whereas ATP effects on body weight and mid-upper arm circumference only emerged after a delay of 8-16 weeks. The absence of significant effects of ATP on body weight and mid-upper arm circumference in the present study would suggest that our 8-week intervention in preterminal patients may have been too short to detect significant effects of ATP on the nutritional status, except for fat mass.

The question could be raised whether the presence of oedema, which was more frequently observed in the ATP group, could have biased our results in favour of the ATP group. Of note, since oedema most frequently occurs in the lower extremities, this would be expected to have little influence on the size of triceps skin fold thickness in the mid-upper arm. Nevertheless, we verified our data by performing a stratified analysis for patients with and without oedema. Both control patients with and without oedema showed a clear decrease in triceps skin fold thickness. By contrast, in ATP treated patients, triceps skin fold thickness was completely stable regardless of whether oedema was present or not, indicating that the effect of ATP on triceps skin fold thickness was independent of the presence of oedema.

Some methodological issues need to be considered. First, due to the preterminal illness of our patient population, baseline data and time changes of outcome parameters showed high between-subject variability (SD), limiting the power of the study to detect effects of ATP on nutritional status. The high drop-out rate, which was unavoidable in this preterminal study population, further reduced the power of the study.

Second, despite adequate stratification and randomisation there was an imbalance in baseline characteristics between the randomisation groups in favour of the control group. Randomised and assessable patients in the ATP group had a worse performance status, a lower energy intake, a higher frequency of oedema and ascites; also weight loss $\geq 10 \%$ at baseline was found more frequently in the ATP group. We eliminated the potential bias by this imbalance by adequately adjusting our data for potential confounding in multivariate analyses.

Third, since $40 \%$ of our study population were patients with lung cancer, the positive effect of ATP on survival reported for the whole population could just have been the result of the specific contribution of lung cancer patients. However, even though stratified analysis showed quantitatively less effect of ATP on survival in patients without lung cancer compared to lung cancer patients, the trend in both groups was identical.

Fourth, co-interventions (chemotherapy, antibiotics, corticosteroids) might also have influenced patients' nutritional status or survival. However, the only difference between the control and ATP group was the start of palliative 
radiotherapy in one control patient, palliative chemotherapy in two control patients and gefitinib in one control patient, all of which would therefore induce bias towards longer survival in the control group, and thus cannot explain our finding of a longer survival in ATP-treated patients.

Finally, for ethical reasons, our trial was not placebo-controlled. Since the belief that emotional state could affect survival exists among patients and professionals [30], the question might be raised whether the observed effect of ATP on survival in our study could have been due to a placebo effect (possibly inducing a better 'coping strategy') [30,31]. However, the majority of literature shows little evidence which would suggest that a 'fighting spirit' or psychological coping could play an important part in survival [31,32]. A review of observational studies showed no relationship between coping style and survival for the large majority of studies [31]. A meta-analysis [33] of RCTs studying the effect of psychological therapy on survival in women with metastatic breast cancer showed negative results in 4 out of 5 RCTs. More recently, a study of Andersen et al. [34] showed a reduced risk of breast cancer recurrence and death from breast cancer in patients receiving a psychologic intervention compared with controls receiving no intervention. However, this study was performed in patients without macroscopic tumour mass awaiting adjuvant chemotherapy, with long-term disease recurrence as primary end point. Furthermore, the concerned intervention not only included psychologic intervention but also strategies to increase daily activities, to improve dietary habits and to stop smoking, all of which may have contributed to the observed reduced cancer recurrence in the intervention group. Although the literature on the effects of psychological interventions on survival is not conclusive, it would appear less likely that the observed survival benefit of ATP in the present study was caused by a placebo effect, especially since the survival benefit of ATP was stronger in specific subgroups (i.e. weight-stable patients and patients with lung cancer) and, in these subgroups, had a long-term effect (i.e. 6 months), when any placebo effect would long have faded.

A number of novel aspects of the present study should be highlighted. First, this is the first RCT in humans with intravenous ATP infusions at weekly intervals (as opposed to 2-4 week intervals in previous studies), with infusions lasting only 8-10 $\mathrm{h}$ (instead of 30-96 h) and at a maximal dose of $50 \mu \mathrm{g} / \mathrm{kg} \cdot \mathrm{min}$ (instead of 75-100 $\mu \mathrm{g} / \mathrm{kg} . \mathrm{min}$ ) [10, 35]. Also, the intervention period lasted for only 8 weeks (instead of 24 weeks) [10]. The above-mentioned novel schedule of ATP administration showed significant favourable effects on survival, both at 8 weeks and, in lung cancer patients as well as in weight-stable patients, even at 6 months, i.e. 4 months after completion of the last ATP infusion. The 8-week intervention also had a significant favourable effect on fat mass but may have been too short to detect a significant effect on body weight and muscle mass. 
Second, this is the first RCT with intravenous ATP administration in patients of mixed tumour types in a very late stage of the disease. Results corroborate the previously reported favourable effects of ATP on survival in NSCLC [12], but go beyond this by showing the same trend in patients of other tumour types, notwithstanding the considerably later disease stage than in the previous study [12].

Third, this is the first study in which ATP was administered at home, showing that ATP can be safely administered in the home setting [15].

In conclusion, our data indicate that ATP infusions at the dose and schedule studied may increase survival in preterminal cancer, especially in weight-stable patients and in patients with lung cancer. These findings will need confirmation in larger studies aimed at further defining the effect of ATP on tumour growth and survival in specific types of cancer and at different tumour stages. 


\section{REFERENCES}

1. Strasser F, Bruera ED. Update on anorexia and cachexia. Hematol Oncol Clin North Am 2002; 16: 589-617.

2. Dewys WD, Begg C, Lavin PT, Band PR, Bennett JM, Bertino JR, et al. Prognostic effect of weight loss prior to chemotherapy in cancer patients. Eastern Cooperative Oncology Group. Am J Med 1980; 69: 491-7.

3. Maltoni M, Caraceni A, Brunelli C, Broeckaert B, Christakis N, Eychmueller S, et al. Prognostic factors in advanced cancer patients: evidence-based clinical recommendations--a study by the Steering Committee of the European Association for Palliative Care. J Clin Oncol 2005; 23: 6240-8.

4. Warren S. The immediate cause of death. Am J Med Sci 1932; 184: 610-5.

5. Tisdale MJ. Biology of cachexia. J Natl Cancer Inst 1997; 89: 1763-73.

6. Argiles JM, Busquets S, Moore-Carrasco R, Figueras M, Almendro V, Lopez-Soriano FJ. Targets in clinical oncology: the metabolic environment of the patient. Front Biosci 2007; 12: 3024-51.

7. Baracos VE. Cancer-associated cachexia and underlying biological mechanisms. Annu Rev Nutr 2006; 26: 435-61.

8. Tisdale MJ. Cancer cachexia: metabolic alterations and clinical manifestations. Nutrition 1997; 13: 1-7.

9. Yavuzsen T, Davis MP, Walsh D, LeGrand S, Lagman R. Systematic review of the treatment of cancer-associated anorexia and weight loss. J Clin Oncol 2005; 23: 8500-11.

10. Agteresch HJ, Dagnelie PC, van Der Gaast A, Stijnen T, Wilson JH. Randomized clinical trial of adenosine 5 '-triphosphate in patients with advanced non-small-cell lung cancer. J Natl Cancer Inst 2000; 92: 321-8.

11. Agteresch HJ, Rietveld T, Kerkhofs LG, van den Berg JW, Wilson JH, Dagnelie PC. Beneficial effects of adenosine triphosphate on nutritional status in advanced lung cancer patients: a randomized clinical trial. J Clin Oncol 2002; 20: 371-8.

12. Agteresch HJ, Burgers SA, van der Gaast A, Wilson JH, Dagnelie PC. Randomized clinical trial of adenosine 5 '-triphosphate on tumor growth and survival in advanced lung cancer patients. Anticancer Drugs 2003;14: 639-44.

13. Swennen EL, Bast A, Dagnelie PC. Immunoregulatory effects of adenosine 5'-triphosphate on cytokine release from stimulated whole blood. Eur J Immunol 2005; 35: 852-8.

14. Swennen EL, Bast A, Dagnelie PC. Purinergic receptors involved in the immunomodulatory effects of ATP in human blood. Biochem Biophys Res Commun 2006; 348: 1194-9.

15. Beijer S, Gielisse EA, Hupperets PS, van den Borne BE, van den Beuken-van Everdingen M, Nijziel $M R$, et al. Intravenous ATP infusions can be safely administered in the home setting: a study in preterminal cancer patients. Invest New Drugs 2007; 25: 571-9.

16. Stratton R, Green CJ, Elia M. Disease-related malnutrition: An evidence-based approach to treatment. Wallingford, CT: CABI publishing, 2003.

17. Ravasco P, Monteiro-Grillo I, Vidal PM, Camilo ME. Nutritional deterioration in cancer: the role of disease and diet. Clin Oncol (R Coll Radiol) 2003; 15: 443-50.

18. Fordy C, Glover C, Henderson DC, Summerbell C, Wharton R, Allen-Mersh TG. Contribution of diet, tumour volume and patient-related factors to weight loss in patients with colorectal liver metastases. Br J Surg 1999; 86: 639-44.

19. Ravasco P, Monteiro-Grillo I, Camilo M. How relevant are cytokines in colorectal cancer wasting? Cancer J 2007;13: 392-8.

20. Correale P, Tagliaferri P, Guarrasi R, Caraglia M, Giuliano M, Marinetti MR, et al. Extracellular adenosine $5^{\prime}$ triphosphate involvement in the death of LAK-engaged human tumor cells via P2Xreceptor activation. Immunol Lett 1997; 55: 69-78.

21. Schafer R, Hartig R, Sedehizade F, Welte T, Reiser G. Adenine nucleotides inhibit proliferation of the human lung adenocarcinoma cell line LXF-289 by activation of nuclear factor kappaB1 and mitogen-activated protein kinase pathways. FEBS J 2006; 273: 3756-67.

22. Conigrave $A D$, van der Weyden $L$, Holt L, Jiang L, Wilson $P$, Christopherson RI, et al. Extracellular ATP-dependent suppression of proliferation and induction of differentiation of human HL-60 leukemia cells by distinct mechanisms. Biochem Pharmacol 2000; 60: 1585-91. 
23. Wang MX, Ren LM. Growth inhibitory effect and apoptosis induced by extracellular ATP and adenosine on human gastric carcinoma cells: involvement of intracellular uptake of adenosine. Acta Pharmacol Sin 2006; 27: 1085-92.

24. Shabbir M, Thompson C, Jarmulowiczc M, Mikhailidis D, Burnstock G. Effect of extracellular ATP on the growth of hormone-refractory prostate cancer in vivo. BJU Int 2008; 102: 108-12.

25. Rapaport E. Experimental cancer therapy in mice by adenine nucleotides. Eur J Cancer Clin Oncol 1988; 24: 1491-7.

26. Shabbir M, Ryten M, Thompson C, Mikhailidis D, Burnstock G. Purinergic receptor-mediated effects of ATP in high-grade bladder cancer. BJU Int 2008; 101: 106-12.

27. White N, Knight GE, Butler PEM, Burnstock G. An in vivo model of melanoma: treatment with ATP. Purinergic Signalling; in press.

28. Agteresch HJ, Dagnelie PC, Rietveld T, van den Berg JW, Danser AH, Wilson JH. Pharmacokinetics of intravenous ATP in cancer patients. Eur J Clin Pharmacol 2000; 56: 49-55.

29. Ralevic V, Burnstock G. Receptors for purines and pyrimidines. Pharmacol Rev 1998; 50: 413-92.

30. Grulke N, Bailer H. [Fighting spirit--a key to survival in cancer patients?]. MMW Fortschr Med 2007; 149: 35-6.

31. Petticrew M, Bell R, Hunter D. Influence of psychological coping on survival and recurrence in people with cancer: systematic review. Bmj 2002; 325: 1066-75.

32. Stephen JE, Rahn M, Verhoef M, Leis $A$. What is the state of the evidence on the mind-cancer survival question, and where do we go from here? A point of view. Support Care Cancer 2007; 15: 923-30.

33. Edwards AG, Hailey S, Maxwell M. Psychological interventions for women with metastatic breast cancer. Cochrane Database Syst Rev 2004 (2): CD004253.

34. Andersen BL, Yang HC, Farrar WB, Golden-Kreutz DM, Emery CF, Thornton LM et al. Psychologic intervention improves survival for breast cancer patients. Cancer 2008; 113: 3450-8.

35. Haskell CM, Wong M, Williams A, Lee LY. Phase I trial of extracellular adenosine 5'-triphosphate in patients with advanced cancer. Med Pediatr Oncol 1996; 27: 165-73. 



\section{Chapter 7}

\section{Randomised clinical trial on the effects of ATP infusions on quality of life, functional status and fatigue in preterminal cancer patients}

S. Beijer, P.S. Hupperets, B.E. van den Borne, N.E. Wijckmans, C. Spreeuwenberg, P.A. van den Brandt, P.C. Dagnelie 


\section{ABSTRACT}

\section{Aim}

Results of an earlier randomised clinical trial showed beneficial effects of ATP infusions on quality of life (QoL) in patients with advanced non-small-cell lung cancer (NSCLC). Based on these promising results, in the present study we investigated the effects of ATP infusions on QoL parameters in patients with preterminal cancer with mixed tumour types.

\section{Methods}

Preterminal cancer patients $(n=99)$ with a life expectancy of 1-6 month were randomly allocated to receive either weekly intravenous ATP infusions (8-10 h/wk, max. $50 \mu \mathrm{g} / \mathrm{kg}$.min) for 8 weeks, or no ATP (control group). QoL parameters (EORTC QLQ-C30), physical restriction (Groningen Activity Restriction Scale), fatigue (Short Fatigue Questionnaire) and muscle strength were assessed during 8 weeks after randomisation and analysed by repeated-measures analysis of covariance.

\section{Results}

Fifty-one patients were randomised to the ATP group and 48 to the control group. Unexpectedly, in the untreated control group, the majority of outcome parameters did not deteriorate, but remained stable (overall QoL, physical, role, emotional and social functioning, fatigue) or even significantly improved over time (global health, anorexia and elbow muscle strength). Between the ATP and control group, no statistically significant differences were observed for the large majority of outcome parameters, except for strength of elbow flexor muscles in favour of the control group. In patients with lung cancer, ATP had significant favourable effects on strength of knee extensor muscles, corroborating earlier results.

\section{Conclusion}

ATP infusions of 8-10 h/wk over 8 weeks, at a maximum dose of $50 \mu \mathrm{g} / \mathrm{kg} \cdot \mathrm{min}$ in preterminal cancer patients of mixed tumour types, did not influence functional status or QoL. 


\section{INTRODUCTION}

Cancer is one of the most common causes of death in the western world [1]. Despite modern treatment advances, approximately $50 \%$ of all cancer patients still die from their disease. In the EU it is estimated that there will be $\approx 1.25$ million cancer deaths in 2015, which is almost 130,000 (11\%) more cancer deaths than in 2000 [2]. Physical comfort, quality of life (QoL) and symptom relief are the main aims of palliative care [3]. Preterminal cancer patients often suffer from multiple symptoms, such as pain, fatigue, dyspnoea, anorexia and functional decline, all of which have a negative impact on their functional status and QoL [4-10]. Cancerrelated fatigue is reported by $60 \%$ to $90 \%$ of patients with advanced cancer [11], and more than $80 \%$ of advanced cancer patients suffer from involuntary weight loss [6]. Treatment options to reverse fatigue or functional decline and thereby improve QoL in preterminal cancer patients are limited $[12,13]$.

One potential agent to improve quality of life in advanced cancer patients is adenosine 5 '-triphosphate (ATP). Results of an earlier randomised clinical trial (RCT) [14] showed that regular intravenous infusion of ATP of $30 \mathrm{~h}$, given at 2- to 4- week intervals over a period of 24 weeks, had marked beneficial effects on muscle mass, muscle strength, fatigue and QoL in patients with advanced (stage IIIB/IV) nonsmall-cell lung cancer (NSCLC). ATP treatment was also associated with a highly significant survival benefit in weight-losing patients with stage IIIB NSCLC [15].

Based on these previous results, we initiated a RCT to investigate the effects of ATP infusion on QoL, functional status and fatigue in preterminal cancer patients with mixed tumour types.

\section{PATIENTS AND METHODS}

\section{Patients}

Eligible for the study were patients with histologically or cytologically confirmed cancer, without curative treatment options, with an estimated life expectancy of 16 months, a World Health Organisation (WHO) performance status 1 or 2, suffering from at least one of the following complaints: fatigue, weight loss $>5 \%$ over the previous 6 months, or anorexia. Exclusion criteria were symptomatic angina pectoris, symptomatic heart failure, atrioventricular block (assessed by electrocardiography), cognitive dysfunction, or concurrent palliative chemotherapy. The study was approved by the Ethical Committees of all hospitals involved in the study, and all patients signed written informed consent prior to the study. 


\section{Study design}

After baseline measurements, patients were stratified for centre, tumour type and weight loss $(\leq 5 \%$ in 6 months vs. $>5 \%)$, and then randomly assigned to receive either usual care, standard nutritional advice and ATP (ATP group), or usual care and standard nutritional advice alone (control group). In both groups, QoL parameters, functional status, fatigue and muscle strength were assessed during 8 weeks after randomisation.

\section{Treatment schedule}

Patients in the ATP-treatment arm received weekly ATP infusions during 8-10 $\mathrm{h}$ over a period of 8 weeks [16]. ATP infusions were started at a rate of $20 \mu \mathrm{g} / \mathrm{kg} \cdot \mathrm{min}^{-1}$ and increased in steps of $10 \mu \mathrm{g} / \mathrm{kg} \cdot \mathrm{min}^{-1}$ every $10 \mathrm{~min}$, until a maximum rate of 50 $\mu \mathrm{g} / \mathrm{kg} \cdot \mathrm{min}^{-1}$, or the maximally tolerated dose (MTD) if this was lower, had been reached. Thereafter, ATP was infused at a continuous rate. If any side effects occurred, the dose was reduced until all side effects had completely disappeared. The first ATP infusion was offered under medical supervision at the day care centre of the participating hospitals. At the end of the first infusion, the safety and tolerated dose was evaluated for each individual patient. If considered safe, subsequent infusions were given at the patient's home, conducted by an experienced and trained nurse of the infusion team of the home care organisation. The MTD during the first infusion at the day care centre was also the maximum dose for the next infusions at home.

\section{Quality of Life}

Quality of life was assessed using the Dutch translation of the European Organisation for Research and Treatment of Cancer (EORTC) Quality of Life Questionnaire (QLQ-C30, version 3.0), a 30-item cancer-specific self-report questionnaire $[17,18]$. The EORTC QLQ-C30 contains five functional scales (physical functioning, role functioning, emotional functioning, cognitive functioning and social functioning), three symptom scales (fatigue, pain and nausea/vomiting), two items assessing global health and QoL, and a number of single items addressing various symptoms (constipation, diarrhoea, dyspnoea, anorexia and insomnia) and perceived financial impact. All items are scored on a 4-point Likert-type scale. Results were transformed into standardized scores ranging from 0 to 100 . First, a raw score (RS) was calculated from the individual item scores $\mathrm{l}_{\mathrm{i}}$ : $R S=\frac{I_{1}+I_{2}+\ldots .+I_{n}}{n}$. To transform the raw score into a 100-point scale the following formulas were used: for the functional scales and the two items assessing global health and QoL: Score $=\left(1-\frac{R S-1}{\text { range }}\right) \times 100$, in which the range is 
the difference between the possible maximum and possible minimum response to the items; a higher score for these scales represents a better level of functioning or QoL. For the symptom scales and single items: Score $=\frac{R S-1}{\text { range }} \times 100$, with a higher score representing a higher (more serious) level of symptoms.

Studies in patients with advanced cancer with a short life expectancy confirmed that the EORTC QLQ-C30 is a reliable and valid measure of the QoL in patients with advanced cancer $[19,20]$.

In addition to the EORTC QLQ-C30, we used the overall question from the Rotterdam Symptom Checklist (RSCL) [21] ('Overall, how did you feel over the past week') as a general indicator of perceived QoL. Results on this item were also transformed into standardized scores, ranging from 0 to 100 with the use of the following formula: $100-[100 *$ (item scale score - minimum item score)/ (maximum score - minimum score)]. A higher score represents a better overall QoL. The RSCL was validated in a Dutch study and has been widely accepted as a QoL measurement instrument for patients with cancer [22].

\section{Physical restriction}

Physical restriction was assessed using the Groningen Activity Restriction Scale (GARS-4) $[23,24]$. The GARS-4 was developed to assess disability in the domains of personal care (11 items) and domestic activities (7 items). Studies in subjects receiving home care, healthy seniors, patients with recent diagnosed cancer, multiple sclerosis, and rheumatoid arthritis showed that the GARS is an easy-toadminister, reliable and valid measure for assessing disability in the domains of ADL (Activities of Daily Living, i.e. self care) and IADL (Instrumental Activities of Daily Living, i.e. household activities) in subjects in different conditions [23, 24]. All items are scored on a 4-point Likert-type scale, with a higher score representing a higher level of disability.

\section{Fatigue}

Fatigue was measured by the Dutch Short Fatigue Questionnaire (SFQ). The SFQ has been developed from the Checklist Individual Strength (CIS) and the Multidimensional Fatigue Inventory (MFI), both of which were shown to have good psychometric properties $[25,26]$. The SFQ is a simple and reliable instrument to determine the intensity of the patient's physical fatigue [27]. The questionnaire comprises 4 items. Each item is scored on a 7-point Likert scale; a higher score represents a higher level of fatigue. 


\section{Muscle strength}

Handgrip strength was measured to the nearest kilogram by use of the Jamar hydraulic hand dynamometer (Saehan Corp. Masan, Korea), and strength of the elbow flexor muscles and the knee extensor muscles were measured in $\mathrm{Nm}$ as described by Agteresch et al. [14], using a hand-held Microfet ${ }^{\circledR}$ dynamometer (Biometrics Europe, Almere, The Netherlands). All measurements were measured twice at the dominant side of the patient at an interval of approximately $1 \mathrm{~min}$, and the mean value was used for further calculations.

\section{Statistical analysis}

Data were doubly entered and analysed according to the intention-to-treat principle. Curves were fitted to describe the time course of the parameters. Differences over time between the two groups were appraised by repeated measurement analysis of covariance using SAS Proc Mixed (version 9.1, SAS Institute Inc., Cary, NC, USA). Independent variables in the model were the treatment indicator variable, baseline measurement, measurement time, and the interaction between time and treatment. Statistical significance of treatment effects was assessed by testing the interaction between time and treatment. All models were adjusted for potential confounders. Because of the favourable results previously reported in patients with lung cancer [14], the same analyses as above were repeated for lung cancer patients separately. Two-tailed $p$-values below 0.05 were considered statistically significant.

\section{RESULTS}

\section{Study population}

The trial profile is summarized in Figure 1. Fifty-one patients were randomly allocated to ATP treatment and 49 patients to the control group. One patient in the control group was excluded from the analysis because cancer was not confirmed histologically or cytologically. Sixteen patients dropped out before the first followup measurement, leaving 83 assessable patients (44 ATP, 39 control) of whom 57 patients (29 ATP, 28 control) completed the 8-week study period. Drop-out rates were equally distributed over the ATP group (22 patients) and control group (20 patients).

Baseline patient characteristics are shown in Table 1. Randomised and assessable patients in the ATP group had a worse performance status, a lower energy intake, a higher frequency of oedema and ascites; also weight loss $\geq 10 \%$ at baseline was found more frequently in the ATP group. 


\section{Time scale (wks)}

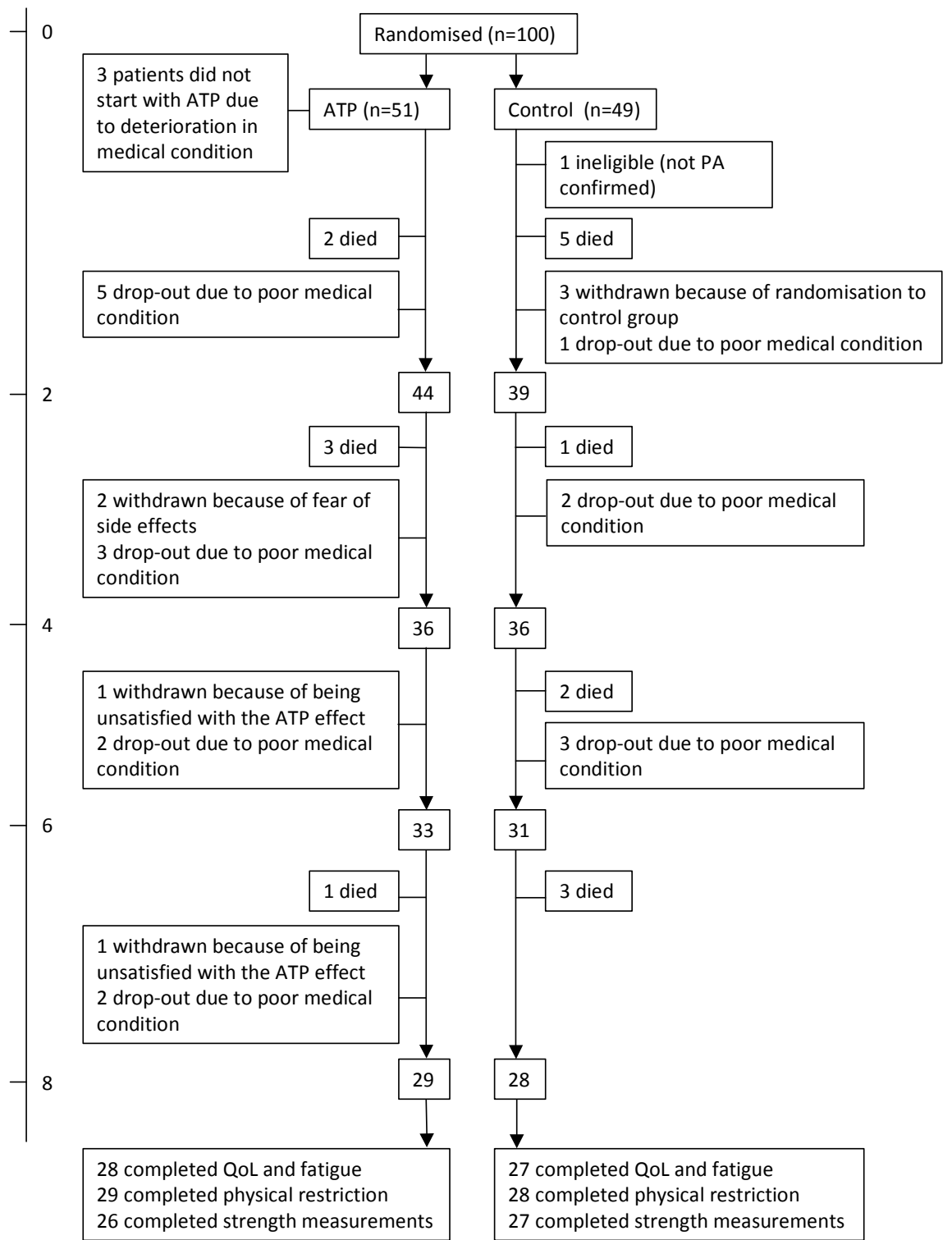

In two patients (both control group) one measurement is missing at $\mathrm{T} 2$ and in one patient (control group) one measurement is missing at T6.

Figure 1. Flow diagram of randomised patients. 


\section{CHAPTER 7}

Table 1. Baseline patient characteristics of randomly assigned and assessable patients.

\begin{tabular}{|c|c|c|c|c|}
\hline & \multicolumn{2}{|l|}{ ATP } & \multicolumn{2}{|l|}{ Control } \\
\hline & $\begin{array}{l}\text { Rand. assigned }{ }^{1} \\
(n=51)\end{array}$ & $\begin{array}{l}\text { Assessable }^{2} \\
(n=44)\end{array}$ & $\begin{array}{l}\text { Rand. assigned }{ }^{1} \\
(n=49)\end{array}$ & $\begin{array}{l}\text { Assessable }^{2} \\
(n=39)\end{array}$ \\
\hline \multicolumn{5}{|l|}{ Sex } \\
\hline Male & 35 (69\%) & $34(77 \%)$ & $31(63 \%)$ & $26(67 \%)$ \\
\hline Female & $16(31 \%)$ & $10(23 \%)$ & $18(37 \%)$ & $13(33 \%)$ \\
\hline Age (years) & $68 \pm 9.8$ & $68 \pm 9.6$ & $65 \pm 10.5$ & $65 \pm 11.0$ \\
\hline Years of cancer at inclusion & $2.3 \pm 2.7$ & $2.5 \pm 2.9$ & $2.7 \pm 3.3$ & $2.7 \pm 3.3$ \\
\hline \multicolumn{5}{|l|}{ Tumour type } \\
\hline Lung & $21(41 \%)$ & $19(43 \%)$ & $24(49 \%)$ & $21(54 \%)$ \\
\hline Colon & $8(16 \%)$ & $8(18 \%)$ & $5(10 \%)$ & $3(8 \%)$ \\
\hline Gastrointestinal other & $6(12 \%)$ & $3(7 \%)$ & $6(12 \%)$ & $4(10 \%)$ \\
\hline Prostate & $5(10 \%)$ & $5(11 \%)$ & $4(8 \%)$ & $3(8 \%)$ \\
\hline Other & $11(21 \%)$ & $9(21 \%)$ & $10(21 \%)$ & $8(20 \%)$ \\
\hline \multicolumn{5}{|l|}{ Smoking } \\
\hline Yes & $23(45 \%)$ & $20(45 \%)$ & $15(31 \%)$ & $13(33 \%)$ \\
\hline No & $28(55 \%)$ & $24(55 \%)$ & $33(67 \%)$ & $25(64 \%)$ \\
\hline Missing & - & - & $1(2 \%)$ & $1(3 \%)$ \\
\hline \multicolumn{5}{|l|}{ WHO performance status } \\
\hline 1 & $33(65 \%)$ & $30(68 \%)$ & $37(76 \%)$ & $33(85 \%)$ \\
\hline 2 & $18(35 \%)$ & $14(32 \%)$ & $12(24 \%)$ & $6(15 \%)$ \\
\hline \multicolumn{5}{|l|}{ Fatigue } \\
\hline Yes & $48(94 \%)$ & $41(93 \%)$ & $48(98 \%)$ & $39(100 \%)$ \\
\hline No & $3(6 \%)$ & $3(7 \%)$ & $1(2 \%)$ & $0(0 \%)$ \\
\hline \multicolumn{5}{|l|}{ Loss of appetite } \\
\hline Yes & $36(71 \%)$ & $31(70 \%)$ & $31(63 \%)$ & $23(59 \%)$ \\
\hline No & $15(29 \%)$ & $13(30 \%)$ & $18(37 \%)$ & $16(41 \%)$ \\
\hline Energy intake (MJ/day) & $6.6 \pm 2.1$ & $6.8 \pm 2.1$ & $7.4 \pm 2.3$ & $7.7 \pm 2.1$ \\
\hline Weight $^{3}$ & $69.9 \pm 15.2$ & $71.4 \pm 15.3$ & $68.4 \pm 17.2$ & $72.0 \pm 16.9$ \\
\hline Weight change in previous $6 \mathrm{mo}(\%)$ & $-3.5 \pm 7.9$ & $-2.8 \pm 7.6$ & $-2.6 \pm 9.0$ & $-1.0 \pm 9.0$ \\
\hline$\geq 5 \%$ weight loss in previous 6 mo & $18(35 \%)$ & $13(30 \%)$ & $17(35 \%)$ & $10(26 \%)$ \\
\hline Overall weight change $(\%)^{4}$ & $-10.9 \pm 10.0$ & $-9.9 \pm 10.0$ & $-9.1 \pm 13.5$ & $-6.1 \pm 12.4$ \\
\hline$\geq 10 \%$ overall weight loss & $27(53 \%)$ & $22(50 \%)$ & $20(41 \%)$ & 12 (31\%) \\
\hline Oedema and/or ascites & $14(28 \%)$ & $12(27 \%)$ & $8(17 \%)$ & $6(15 \%)$ \\
\hline RSCL 'overall QoL' & $49.0 \pm 19.6$ & $50.0 \pm 20.0$ & $50.0 \pm 18.8$ & $52.6 \pm 18.2$ \\
\hline \multicolumn{5}{|l|}{ EORTC-QLQ C30: } \\
\hline Physical functioning & $44.0 \pm 25.9$ & $49.1 \pm 23.9$ & $45.3 \pm 26.2$ & $50.1 \pm 24.7$ \\
\hline Role functioning & $30.1 \pm 32.0$ & $34.1 \pm 32.3$ & $39.9 \pm 37.3$ & $46.2 \pm 36.6$ \\
\hline Emotional functioning & $68.6 \pm 25.5$ & $67.2 \pm 25.1$ & $65.6 \pm 26.0$ & $67.1 \pm 26.6$ \\
\hline Cognitive functioning & $79.4 \pm 25.9$ & $80.0 \pm 25.6$ & $70.5 \pm 28.8$ & $72.6 \pm 28.0$ \\
\hline Social functioning & $71.2 \pm 29.6$ & $75.0 \pm 26.3$ & $67.0 \pm 29.0$ & $68.0 \pm 28.6$ \\
\hline Fatigue & $65.6 \pm 27.0$ & $62.9 \pm 27.2$ & $58.3 \pm 26.6$ & $54.1 \pm 24.3$ \\
\hline Nausea & $21.9 \pm 27.2$ & $19.7 \pm 26.0$ & $16.0 \pm 23.3$ & $10.7 \pm 16.9$ \\
\hline Pain & $37.3 \pm 37.0$ & $39.4 \pm 38.2$ & $34.7 \pm 30.7$ & $32.5 \pm 31.5$ \\
\hline Dyspnoea & $41.8 \pm 36.4$ & $43.2 \pm 37.1$ & $36.1 \pm 33.6$ & $36.8 \pm 33.1$ \\
\hline Insomnia & $20.3 \pm 29.9$ & $22.0 \pm 30.5$ & $22.2 \pm 31.8$ & $21.4 \pm 32.0$ \\
\hline Appetite loss & $49.7 \pm 37.9$ & $48.5 \pm 37.7$ & $43.1 \pm 34.4$ & $41.0 \pm 34.6$ \\
\hline Constipation & $24.2 \pm 32.7$ & $23.5 \pm 33.4$ & $20.1 \pm 31.3$ & $19.7 \pm 30.3$ \\
\hline
\end{tabular}


Continuation of Table 1. Baseline patient characteristics.

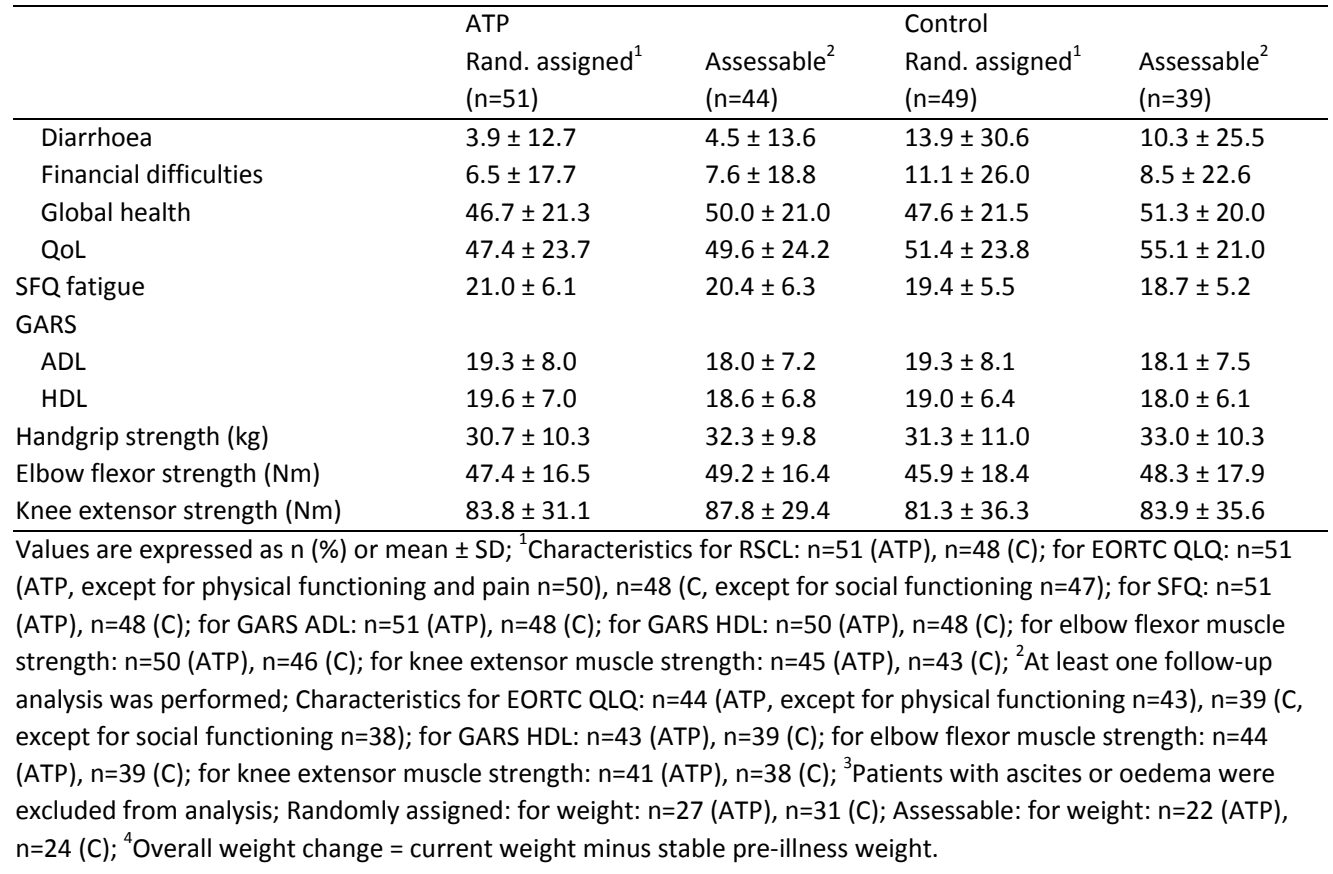

\section{Quality of life and fatigue}

Changes per 4 weeks in QoL scales and symptoms during the 8-week follow-up period in the control and ATP group and the differences between the two groups are shown in Table 2. Overall QoL showed no significant changes over time in either the ATP or control group, without significant differences between the two groups. Neither physical functioning, nor role, cognitive or social functioning changed significantly in either group, with no significant between-group differences. Emotional functioning significantly improved in the ATP group but remained stable in the control group without significant differences between the two groups. Anorexia decreased significantly over time in both groups without any significant difference between the two groups. However, two ATP-treated patients spontaneously reported a positive change in their taste perception. In patients with lung cancer, results also showed no significant differences between the two groups.

\section{Muscle strength}

Elbow flexor muscle strength in the dominant arm showed an almost significant increase in the control group (1.98; 95\% confidence interval $(\mathrm{Cl})=-0.04$ to 4.00 $\mathrm{Nm} / 4 \mathrm{wks}$ ). In contrast, results showed a non-significant decrease in the ATP group 
$(-1.27 ; 95 \% \mathrm{Cl}=-3.08$ to $0.52 \mathrm{Nm} / 4$ wks); the difference between the two groups was statistically significant $(p=0.02)$ (Table 3$)$. No differences between the intervention and control group were seen for handgrip strength and strength of knee extensor muscles.

In the subgroup of lung cancer patients, no significant differences between the ATP and control group were observed for handgrip and elbow flexor muscle strength. However, the strength of knee extensor muscles in lung cancer patients showed a significant decrease in the control group $(-17.64 ; 95 \% \mathrm{Cl}=-29.80$ to $-5.52 \mathrm{Nm} / 4$ wks) but not in the ATP group $(-9.56 ; 95 \% \mathrm{Cl}=-19.60$ to $0.48 \mathrm{Nm} / 4$ wks); the difference between the two groups was statistically significant $(p=0.02)$.

Table 2. Changes per 4 weeks in EORTC QLQ-C30 domains and symptoms in the ATP and control group, and between-group differences.

\begin{tabular}{lrrrrrrr}
\hline & ATP group & \multicolumn{3}{c}{ Control group } & \multicolumn{2}{c}{ Between group difference } \\
\hline & Estimate & $95 \% \mathrm{Cl}$ & \multicolumn{1}{c}{ Estimate } & $95 \% \mathrm{Cl}$ & Estimate & $95 \% \mathrm{Cl}$ & $\mathrm{P}$-value \\
\hline Global health $^{1}$ & 26.1 & 2.0 to 50.0 & 30.2 & 6.3 to 54.1 & -4.1 & -10.9 to 2.6 & 0.23 \\
Overall quality of life $^{1}$ & 29.4 & -5.8 to 64.7 & 25.9 & -6.0 to 57.8 & 3.5 & -2.7 to 9.8 & 0.27 \\
Role functioning $^{1}$ & 31.6 & -37.2 to 100.4 & 36.7 & -28.1 to 101.5 & -5.1 & -15.5 to 5.3 & 0.33 \\
Emotional functioning $^{1}$ & 9.3 & 1.0 to 17.6 & 6.4 & -2.9 to 15.6 & 2.9 & -2.4 to 8.3 & 0.28 \\
Cognitive functioning $^{1}$ & -10.7 & -25.0 to 3.5 & -6.7 & -21.1 to 7.7 & -4.0 & -10.4 to 2.3 & 0.21 \\
Social functioning $^{1}$ & 2.0 & -25.0 to 29.0 & 4.2 & -20.1 to 28.5 & -2.2 & -10.6 to 6.1 & 0.60 \\
Physical functioning $^{1}$ & -1.6 & -14.2 to 11.1 & 3.6 & -10.6 to 17.8 & -5.2 & -10.8 to 0.4 & 0.07 \\
Fatigue $^{2}$ & -29.9 & -68.4 to 8.7 & -31.3 & -67.0 to 4.5 & 1.4 & -5.6 to 8.4 & 0.70 \\
Anorexia $^{2}$ & -48.8 & -89.0 to -8.6 & -55.0 & -93.4 to -16.7 & 6.2 & -3.1 to 15.6 & 0.19 \\
Nausea $^{2}$ & -9.3 & -58.5 to 39.9 & -11.6 & -59.4 to 36.3 & 2.3 & -3.9 to 8.5 & 0.47 \\
Dyspnoea $^{2}$ & 18.8 & -45.5 to 83.0 & 18.7 & -42.8 to 80.2 & 0.1 & -8.1 to 8.2 & 0.99 \\
Pain $^{2}$ & 23.4 & -24.4 to 71.2 & 20.2 & -25.6 to 66.0 & 3.2 & -5.4 to 11.9 & 0.46 \\
Insomnia $^{2}$ & -50.5 & -103.7 to 2.8 & -48.9 & -101.4 to 3.7 & -1.6 & -10.7 to 7.4 & 0.72 \\
Constipation $^{2}$ & -27.1 & -67.3 to 13.2 & -28.3 & -69.4 to 12.8 & 1.2 & -6.0 to 8.4 & 0.73 \\
Diarrhoea $^{2}$ & 12.9 & -11.5 to 37.4 & 12.1 & -13.0 to 37.3 & 0.8 & -3.8 to 5.5 & 0.73 \\
Financial difficulties $^{2}$ & -10.1 & -43.4 to 23.2 & -12.0 & -47.1 to 23.0 & 1.9 & -3.1 to 6.8 & 0.45 \\
\hline
\end{tabular}

${ }^{1} \mathrm{~A}$ positive score represents a better level of functioning or quality of life; ${ }^{2} \mathrm{~A}$ positive score represents a higher (more serious) level of symptoms; $95 \% \mathrm{Cl}=95 \%$ confidence interval.

\section{Physical restriction}

Both the Activities of Daily Living score and the Instrumental Activities of Daily Living score showed no significant changes over time in either the ATP or control group, nor any differences between the two groups. In patients with lung cancer, a non-significant trend in favour of the ATP group was found for Instrumental Activities of Daily Living (between group difference: -1.40 per 4 weeks; $95 \% \mathrm{Cl}=-$ 3.04 to $0.24 ; p=0.09$ ). 
Table 3. Changes per 4 weeks in muscle strength and physical restriction in the ATP and control group, and betweengroup differences.

\begin{tabular}{lrrrrrrr}
\hline & \multicolumn{2}{c}{ ATP group } & \multicolumn{2}{c}{ Control group } & \multicolumn{3}{c}{ Between group difference } \\
\hline & Estimate & $95 \% \mathrm{Cl}$ & Estimate & $95 \% \mathrm{Cl}$ & Estimate & $95 \% \mathrm{Cl}$ & $\mathrm{P}$-value \\
\hline GARS ADL $^{1}$ & -1.20 & -6.12 to 3.72 & -2.00 & -6.88 to 2.84 & 0.80 & -0.80 to 2.40 & 0.32 \\
GARS IADL $^{1}$ & 0.80 & -3.84 to 5.48 & 0.76 & -3.56 to 5.04 & 0.04 & -1.24 to 1.36 & 0.94 \\
Handgrip strength (kg) & -2.26 & -4.16 to -0.36 & -1.55 & -3.52 to 0.44 & -0.71 & -1.80 to 0.40 & 0.20 \\
Strength biceps (Nm) & -1.27 & -3.08 to 0.52 & 1.98 & -0.04 to 4.00 & -3.25 & -6.00 to -0.52 & 0.02 \\
Strength quadriceps (Nm) & -9.80 & -18.56 to -1.04 & -12.72 & -21.68 to -3.72 & 2.92 & -2.56 to 8.36 & 0.29 \\
\hline
\end{tabular}

${ }^{1} \mathrm{~A}$ negative score represents a decrease in physical restriction; $95 \% \mathrm{Cl}=95 \%$ confidence interval.

\section{DISCUSSION}

QoL is a major issue in preterminal cancer patients. In the present study we investigated the effects of ATP infusion on QoL, functional status and fatigue. Results show no statistically significant differences between the two groups for the large majority of QoL parameters. The only exceptions were strength of elbow flexor muscles in favour of the control group and, in patients with lung cancer, strength of knee extensor muscles in favour of the ATP group.

Quite remarkably, our results did not show the expected overall deterioration in outcome parameters in the untreated control group of preterminal cancer patients. In fact, for the majority of QoL domains or symptoms we observed a stabilisation over time (overall QoL, physical, role, emotional and social functioning, fatigue, nausea, insomnia and constipation). Data for global health, anorexia and elbow muscle strength even showed a significant amelioration over time in the control group. We can only speculate on the possible causes of this totally unexpected finding in our study population. Current theory and research on the association between stressful events and indicators of well-being/QoL suggests that individuals may use a number of cognitive and behavioural strategies to counteract the negative impact of disease on their sense of well-being, a phenomenon which is known as 'response shift' [28]. Response shift in QoL is defined as a change in the meaning of a patient's self-reported QoL, reflecting a change in a subject's internal standards of measurement, a change in the importance attributed to component domains constituting QoL, or a redefinition of QoL $[29,30]$. High levels of selfreported QoL at different points in time may therefore have different meanings. Indeed, a number of authors have reported relatively high levels of QoL in patients suffering from a life-threatening illness [21, 31]. Thus, cancer patients have reported levels of QoL as high as those of less severely ill patients or even individuals from the general population [32, 33]. Sharpe et al. [34] reported that response shift was common in patients with advanced cancer and Visser et al. [35] showed that response shift may affect the measurement of change in fatigue in 
patients with mixed tumour types selected for radiotherapy. Other possible explanations include increased acceptation of the unavoidability of the terminal state, better symptom management, decreasing symptom stress, relaxing at home after a stressful period with hospital visits, additional attention by the researcher during the home visits, and the gradual fading away of adverse reaction (stress) induced by the previous bad news of incurable illness.

We do not have an explanation why elbow flexor muscle strength almost significantly increased over time in the control group, especially because handgrip strength and knee extensor muscle strength decreased as was expected. One possible explanation would be a training effect, however, this does not explain why the effect for elbow flexor muscle strength was only found in the control group.

Whatever the causes of our finding of improving QoL in untreated preterminal cancer patients may be, this finding combined with literature on response shift in patients with serious illness may pose a serious threat to validity of outcome assessment (of QoL) over time in patients with preterminal cancer. Of note, results from the present study showed strong correlations between baseline measurements of the different questionnaires used to assess QoL (EORTC QLQC30), physical restriction (GARS) and fatigue (SFQ), as an indication of criterion validity (i.e. Pearson's correlation between the physical functioning scale of the EORTC QLQ-C30 and the GARS: $-0.87, \mathrm{p}<0.001$ and between the fatigue scale of the EORTC QLQ-C30 and the SFQ: 0.77, $p<0.001$ ). Moreover, strong correlations were also found between baseline measurements of different domains and symptom scales or single items within the EORTC QLQ-C30, as an indication of construct validity (i.e. Pearson's correlation between: physical functioning and role functioning: $0.74, p<0.001$; physical functioning and fatigue: $-0.62, p<0.001$; role functioning and fatigue: $-0.64, p<0.001$; and overall QoL and fatigue: -0.66 , $p<0.001)$. This would indicate that the observed lack of responsiveness of the applied measurement instruments of QoL in the present study is not related with a low overall validity of these instruments.

For ethical reasons, our trial was not placebo-controlled. Outcome assessment might therefore have been influenced by either a placebo or a nocebo effect. Opposite to the placebo effect, the nocebo effect is a phenomenon whereby suggestion or expectation of a negative outcome may lead to the worsening of a symptom [36-38]. Thus, in our study, our careful explanation to candidate patients for the present study, in which we emphasized both the uncertainty of ATP effectiveness, the possible occurrence of side effects and the burden of ATP infusions, might have induced an unconscious feeling of worsening of symptoms and QoL levels during the ATP intervention relative to the baseline situation. Since $69 \%$ of patients had previously received chemotherapy, previous negative experiences with infusion therapy would tend to further enhance such a nocebo effect. 
The above mentioned explanations do not account for the fact that our results are markedly different from the previous study from Agteresch et al. [14] in patients with NSCLC. It therefore remains possible that the discrepancy in results between the two studies with regard to QoL, functional status, fatigue and muscle strength were caused by other factors, such as differences in study population, treatment schedule and/or study period.

First, patients in our study were in a considerably later disease stage than the population studied by Agteresch et al. [14]. Second, Agteresch's study [14] was performed in patients with NSCLC (stage IIIB/IV), i.e. a population which was homogeneous with respect to tumour type. In contrast, our study population included more than 15 different tumour types and was therefore highly heterogeneous with regard to tumour type. ATP kinetics or effector mechanisms of ATP could differ between tumour types possibly leading to differences in response. Thus, our results in lung cancer patients showed a significant beneficial effect of ATP on knee extensor muscle strength which was not found for the study population as a whole.

Third, in view of the short life expectancy of our study population we opted for a shorter follow-up period (8 weeks vs. 24 weeks). Results of Agteresch et al. [14] showed that changes in muscle strength were only present from 12 weeks onwards, suggesting that our 8-week intervention in preterminal patients may have been too short to achieve significant effects of ATP on muscle strength.

We conclude that ATP infusions of 8-10 h/wk over 8 weeks, at a maximum dose of $50 \mu \mathrm{g} / \mathrm{kg} \cdot \mathrm{min}$ in preterminal cancer patients of mixed tumour types have no effect on QoL, functional status and fatigue. Further research on the effects of dose, duration and frequency of ATP infusion in patients of specific tumour types and tumour stages is warranted. 


\section{REFERENCES}

1. WHO Mortality Database. http://www.who.int/healthinfo/morttables.

2. Quinn MJ, d'Onofrio A, Moller B, Black R, Martinez-Garcia C, Moller $H$, et al. Cancer mortality trends in the EU and acceding countries up to 2015. Ann Oncol 2003; 14: 1148-52.

3. Byock I. Completing the continuum of cancer care: integrating life-prolongation and palliation. CA Cancer J Clin 2000; 50: 123-32.

4. Teunissen SC, Wesker W, Kruitwagen C, de Haes HC, Voest EE, de Graeff A. Symptom prevalence in patients with incurable cancer: a systematic review. J Pain Symptom Manage 2007; 34: 94-104.

5. Stromgren AS, Groenvold M, Pedersen L, Olsen AK, Sjogren P. Symptomatology of cancer patients in palliative care: content validation of self-assessment questionnaires against medical records. Eur J Cancer 2002; 38: 788-94.

6. Von Roenn JH, Paice JA. Control of common, non-pain cancer symptoms. Semin Oncol 2005; 32: 200-10.

7. Lo RS, Woo J, Zhoc KC, Li CY, Yeo W, Johnson P, et al. Quality of life of palliative care patients in the last two weeks of life. J Pain Symptom Manage 2002; 24: 388-97.

8. Groenvold M, Petersen MA, Aaronson NK, Arraras JI, Blazeby JM, Bottomley A, et al. The development of the EORTC QLQ-C15-PAL: a shortened questionnaire for cancer patients in palliative care. Eur J Cancer 2006; 42: 55-64.

9. Cohen SR, Leis A. What determines the quality of life of terminally ill cancer patients from their own perspective? J Palliat Care 2002; 18: 48-58.

10. Kaasa S, Loge JH. Quality of life in palliative care: principles and practice. Palliat Med 2003; 17: 11 20.

11. Ryan JL, Carroll JK, Ryan EP, Mustian KM, Fiscella K, Morrow GR. Mechanisms of cancer-related fatigue. Oncologist 2007; 12: S22-34.

12. Minton $\mathrm{O}$, Stone $\mathrm{P}$, Richardson A, Sharpe M, Hotopf M. Drug therapy for the management of cancer related fatigue. Cochrane Database Syst Rev 2008: CD006704.

13. Radbruch L, Strasser F, Elsner F, Goncalves JF, Loge J, Kaasa S, et al. Fatigue in palliative care patients -- an EAPC approach. Palliat Med 2008; 22: 13-32.

14. Agteresch HJ, Dagnelie PC, van der Gaast A, Stijnen T, Wilson JH. Randomized clinical trial of adenosine 5 '-triphosphate in patients with advanced non-small-cell lung cancer. J Natl Cancer Inst 2000; 92: 321-8.

15. Agteresch HJ, Burgers SA, van der Gaast A, Wilson JH, Dagnelie PC. Randomized clinical trial of adenosine $5^{\prime}$-triphosphate on tumor growth and survival in advanced lung cancer patients. Anticancer Drugs 2003; 14: 639-44.

16. Beijer S, Gielisse EA, Hupperets PS, van den Borne BE, van den Beuken-van Everdingen M, Nijziel $M R$, et al. Intravenous ATP infusions can be safely administered in the home setting: a study in preterminal cancer patients. Invest New Drugs 2007; 25: 571-9.

17. Aaronson NK, Cull AM, Kaasa S, Sprangers MAG. The European Organization for Research and Treatment of Cancer (EORTC) Modular Approach to Quality of Life Assessment in Oncology: An Update. In: Spilker B, editor. Quality of Life and Pharmacoeconomics in Clinical Trials. 2nd ed. Philadelphia: Lippincott-Raven; 1996: 179-89.

18. Aaronson NK, Ahmedzai S, Bergman B, Bullinger M, Cull A, Duez NJ, et al. The European Organization for Research and Treatment of Cancer QLQ-C30: a quality-of-life instrument for use in international clinical trials in oncology. J Natl Cancer Inst 1993; 85: 365-76.

19. Kyriaki M, Eleni T, Efi P, Ourania K, Vassilios S, Lambros V. The EORTC core quality of life questionnaire (QLQ-C30, version 3.0) in terminally ill cancer patients under palliative care: validity and reliability in a Hellenic sample. Int J Cancer 2001; 94: 135-9.

20. Kaasa S, Bjordal K, Aaronson N, Moum T, Wist E, Hagen S, et al. The EORTC core quality of life questionnaire (QLQ-C30): validity and reliability when analysed with patients treated with palliative radiotherapy. European journal of cancer 1995; 31a: 2260-3.

21. de Haes JC, van Knippenberg FC. The quality of life of cancer patients: a review of the literature. Soc Sci Med 1985; 20: 809-17. 
22. de Haes JC, van Knippenberg FC, Neijt JP. Measuring psychological and physical distress in cancer patients: structure and application of the Rotterdam Symptom Checklist. Br J Cancer 1990; 62: 1034-8.

23. Kempen GIJM, Doeglas DM, Suurmeijer TPBM. Groningen Activiteiten Restrictie Schaal (GARS): een handleiding. Groningen: Rijksuniversiteit Groningen; 1993.

24. Suurmeijer TP, Doeglas DM, Moum T, Briancon S, Krol B, Sanderman R, et al. The Groningen Activity Restriction Scale for measuring disability: its utility in international comparisons. Am J Public Health 1994; 84: 1270-3.

25. Vercoulen JH, Swanink CM, Fennis JF, Galama JM, van der Meer JW, Bleijenberg G. Dimensional assessment of chronic fatigue syndrome. J Psychosom Res 1994; 38: 383-92.

26. Smets EM, Garssen B, Bonke B, De Haes JC. The Multidimensional Fatigue Inventory (MFI) psychometric qualities of an instrument to assess fatigue. J Psychosom Res 1995; 39: 315-25.

27. Alberts M, Smets EM, Vercoulen JH, Garssen B, Bleijenberg G. 'Verkorte vermoeidheidsvragenlijst': een praktisch hulpmiddel bij het scoren van vermoeidheid. NTVG 1997; 141: 1526-30.

28. Sprangers MA, Schwartz CE. Integrating response shift into health-related quality of life research: a theoretical model. Soc Sci Med 1999; 48: 1507-15.

29. Hagedoorn M, Sneeuw KC, Aaronson NK. Changes in physical functioning and quality of life in patients with cancer: response shift and relative evaluation of one's condition. J Clin Epidemiol 2002; 55: 176-83.

30. Ring L, Hofer S, Heuston F, Harris D, O'Boyle CA. Response shift masks the treatment impact on patient reported outcomes (PROs): the example of individual quality of life in edentulous patients. Health Qual Life Outcomes 2005; 3: 55.

31. Breetvelt IS, Van Dam FS. Underreporting by cancer patients: the case of response-shift. Soc Sci Med 1991; 32: 981-7.

32. Andrykowski MA, Curran SL, Studts JL, Cunningham L, Carpenter JS, McGrath PC, et al. Psychosocial adjustment and quality of life in women with breast cancer and benign breast problems: a controlled comparison. J Clin Epidemiol 1996; 49: 827-34.

33. van't Spijker A, Trijsburg RW, Duivenvoorden HJ. Psychological sequelae of cancer diagnosis: a meta-analytical review of 58 studies after 1980. Psychosom Med 1997; 59: 280-93.

34. Sharpe L, Butow P, Smith C, McConnell D, Clarke S. Changes in quality of life in patients with advanced cancer: evidence of response shift and response restriction. J Psychosom Res 2005 ; 58 : 497-504.

35. Visser MR, Smets EM, Sprangers MA, de Haes HJ. How response shift may affect the measurement of change in fatigue. J Pain Symptom Manage 2000; 20: 12-8.

36. Benedetti $F$, Lanotte $M$, Lopiano L, Colloca $L$. When words are painful: unraveling the mechanisms of the nocebo effect. Neuroscience 2007; 147: 260-71.

37. Colloca L, Sigaudo M, Benedetti F. The role of learning in nocebo and placebo effects. Pain 2008; 136: 211-8.

38. Barsky AJ, Saintfort R, Rogers MP, Borus JF. Nonspecific medication side effects and the nocebo phenomenon. JAMA 2002; 287: 622-7. 

Chapter 8

General discussion 



\section{INTRODUCTION}

In this thesis, results of the multicentre randomised clinical trial (RCT) on the administration of adenosine 5 '-triphosphate (ATP) infusions in palliative home care have been reported. Based on promising effects on nutritional status, quality of life (QoL) and survival in patients with non-small-cell lung cancer (NSCLC) [1-3], we initiated a RCT to investigate the effects of ATP in patients with different types of cancer in the preterminal stage. As primary outcome measures, QoL, fatigue and physical restriction were selected. Secondary outcome measures were nutritional status parameters including appetite, nutritional intake, fat mass and muscle strength. Based on the previously observed effects of ATP infusions on survival in patients with NSCLC, we also explored the effect of ATP on survival.

One hundred preterminal cancer patients with different tumours and a life expectancy of less than 6 months were randomly assigned to receive either ATP by infusion (ATP group) or no ATP (control group), in addition to standard nutritional advice and usual care. Based on data from Haskell et al. [4] and favourable safety and efficacy data in a phase II study applying 8-10 $\mathrm{h}$ ATP infusions at a maximum dose of $50 \mu \mathrm{g} / \mathrm{kg} \cdot \mathrm{min}$ in patients with NSCLC (E.H. Abraham, personal communication), and in order to avoid ATP administration during the night or during an overnight stay at the hospital, we adopted a schedule of 8-10 h ATP infusion once per week, at a maximal dose of $50 \mu \mathrm{g} / \mathrm{kg} . \mathrm{min}$.

As patients in the current study were selected in a preterminal disease stage, the intervention period was restricted to eight weeks. This period was based on the earlier finding [1] of significant favourable effects of ATP infusions (at a frequency of once per 2 weeks) on fatigue, physical functioning and overall QoL within 8 weeks of ATP infusions. Although effectiveness of ATP was expected to increase with the duration of the intervention, a longer period than 8 weeks was expected to lead to high drop-out rates because of the anticipated rapidly deteriorating condition of participating patients, threatening the validity of the study design.

Since previously reported side effects of ATP infusions were mild and disappeared immediately after lowering the infusion rate [5], and in order to diminish the burden of hospitalization in this population of preterminal cancer patients, only the first ATP infusion was administered in the hospital and subsequent infusions were given at the patients' home. During all infusions, side effects and protocol deviations were recorded.

The study was supported by a grant within the programme 'Palliative Care in the Terminal Phase' of the Netherlands Organisation for Health Research and Development (ZonMw) and was approved by the Ethical Committees of all hospitals participating in the study.

In this chapter, we will first discuss results of the study regarding the clinical effects of ATP in our study population related to the outcomes described above. Then, we 
will focus on our findings regarding side effects and logistic aspects of ATP infusions at home, followed by a reflection on the strengths and limitations of the study. Finally, overall conclusions and implications for future research are given.

\section{EFFECTS OF ATP ON QUALITY OF LIFE AND NUTRITIONAL STATUS IN PRETERMINAL CANCER}

Results of the present study showed no statistically significant effects of ATP on QoL, physical restriction, fatigue, muscle strength, appetite, nutritional intake and body composition, except for fat mass in favour of the ATP group. These results do not confirm earlier results reported in patients with $\operatorname{NSCLC}[1,2]$. Differences in study population and intervention as potential causes of this dissimilarity in results will be discussed below.

\section{Study population}

As described in chapter 3, 60 patients completing the 8-week RCT (30 patients per treatment arm) would be needed to reach enough power. A total of 100 patients were included in the study of whom 57 patients (29 ATP, 28 controls) completed the full 8-week study period, indicating that the required power was almost achieved.

Patients in our study were in a considerably later disease stage than the population studied by Agteresch et al. [1] as reflected by larger prior weight loss, lower muscle strength, and an aggravated overall QoL at baseline. It is possible that patients in a more advanced stage of disease show less or no response than patients in earlier stages. Additional analyses of the data from Agteresch et al. [1] indeed indicated that patients with NSCLC stage IIIB responded better to ATP with regard to parameters such as muscle mass, fat mass and functional QoL than patients with stage IV NSCLC (Dagnelie, unpublished data). It is also conceivable that patients with lung cancer respond better to ATP than patients with other tumour types.

\section{Intervention}

As usual in all clinical studies with ATP reported to date, we determined the individual maximally tolerated dose (MTD) in patients, defined as the ATP dose administered without side effects. The adoption of this procedure is simple since ATP induces immediate, specific, easy-to-recognize and rapidly reversible side effects [5]. Following this procedure, 36 out of 48 patients received a mean ATP dose of $40-50 \mu \mathrm{g} / \mathrm{kg}$.min over all infusions (Figure $1 \mathrm{~A}$ ); the average infusion rate showed a minor decrease over subsequent infusions from $45 \mu \mathrm{g} / \mathrm{kg}$.min for the first ATP infusion to $40 \mu \mathrm{g} / \mathrm{kg}$.min for the $8^{\text {th }}$ infusion (Figure $1 \mathrm{~B}$ ). 
A.

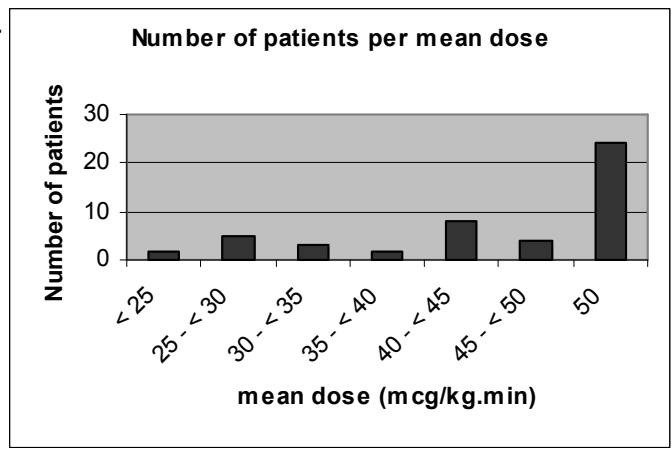

B.

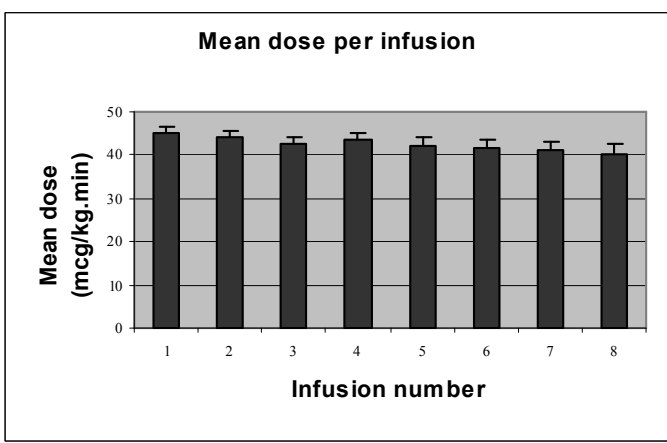

Figure 1. A. Number of patients in categories of received ATP dose (defined as each patient's average ATP dose over all infusions); B. Mean dose received by patients during subsequent ATP infusions.

The question could be raised whether variations in individual dose of ATP might have influenced the study results. Pharmacokinetic data from Agteresch et al. [42] show that erythrocyte ATP concentrations, as the presumed direct mediator of the physiological effects of ATP via P1 and P2 purinergic receptors [6], show no doseresponse relation of ATP administration between 25 and $60 \mu \mathrm{g} / \mathrm{kg}$.min [5]. This notion is in contrast with chemotherapy, of which a higher dose is considered to be directly related to stronger cytotoxicity to the tumour.

As already mentioned, because of the expected short survival of the patients in the present study, intervention and outcome measurements were limited to 8 weeks, whereas the follow-up period in the previous study by Agteresch et al. was 28 weeks. However, Agteresch et al. [1, 2] showed that the favourable effects of ATP on some parameters of the nutritional status, especially body weight and fat free mass, mainly came into effect after a delay of 12-16 weeks. This would suggest that the present intervention may have been too short to show significant effects of ATP on the nutritional status of these preterminal patients. In support of this 
hypothesis, our results confirm the favourable effect of ATP on skin fold thickness reported by Agteresch et al. [2] within 8 weeks of follow-up.

\section{EFFECTS OF ATP ON SURVIVAL}

Based on the earlier observed survival benefit of ATP in weight-losing stage IIIB NSCLC [3] and the availability of a complete registration of dates of death in the present study, we explored the effect of ATP on survival. Based on the intervention period of 8 weeks and the a priori life expectancy of $<6$ months in our study population, we investigated the survival difference over two time periods; 0-8 weeks and 0-6 months.

Power calculation showed that a group size of 100 patients would be sufficient to detect a hazard ratio of 0.50 with a power of $90 \%$ or a hazard ratio of 0.60 with a power of $80 \%$.

Cox regression models were fitted and adjusted for baseline dissimilarities as confounders. Because of a previously shown survival benefit of ATP treatment in weight-losing stage IIIB NSCLC patients [3], we conducted the same analyses in 1. patients stratified by weight loss, defined as $\leq 5 \%$ or $>5 \%$ weight loss over the past 6 months, and 2. lung cancer patients.

Results showed a significant survival benefit in the period 0-8 weeks for ATPtreated patients relative to control patients. No significant difference in survival between the overall ATP and control group was seen over the period 0-6 months. Stratified analyses showed a significant survival benefit of ATP treatment in weightstable patients and in patients with lung cancer over the period 0-6 months. No significant effect of ATP on survival was found in weight-losing patients. Clearly, these results will need confirmation in future larger placebo-controlled studies.

As described in chapter 6, Agteresch et al. [3] only observed a significant favourable effect of ATP on survival in weight-losing stage IIIB NSCLC patients, but not in weight-stable stage IIIB NSCLC patients, and speculated that the effect of ATP on survival was mediated by the anticachectic effect of ATP in their study population. In contrast, we observed a stronger and longer lasting effect of ATP on survival in weight-stable patients. One of the possible causes might be a different definition of weight loss. Agteresch et al. [1] stratified their patients by the presence of overall weight loss, i.e. long-term weight loss since the onset of the disease. Instead, based on scientific evidence showing that recent weight loss is associated with reduced survival [7], we stratified our subjects by recent weight loss, i.e. weight loss over the last 6 months [8]. Based on our findings of a stronger and longer lasting effect of ATP on survival in weight-stable patients, other mechanisms may have been responsible for the potential favourable effect of ATP on survival in this subgroup. One possibility would be that differences with regard 
to purinergic signalling exist between actively weight-losing and weight-stable patients, or between patients with slower vs. more rapid tumour progression. In in vitro studies, extracellular ATP has been shown to inhibit the growth of malignant tumour cells [9-14] and to reduce the growth of a variety of malignant tumours in vivo including Ehrlich ascites, colon, pancreatic, prostate and bladder carcinoma [15-19]. Further research will be necessary to provide more information on this issue.

\section{SIDE EFFECTS OF ATP INFUSIONS}

In chapter 4 of this thesis, we have described the side effects which have occurred during administration of 8- to $10-\mathrm{h}$ ATP infusions at a dose of $20-50 \mu \mathrm{g} / \mathrm{kg} . \mathrm{min}$ in preterminal cancer patients. As clinical drug development is often described as consisting of four temporal phases (phases 1-IV) [20], it might be argued that safety evaluation was not a logical part of this RCT. However, as stated by the FDA, 'It is important to recognize that the phase of drug development provides an inadequate basis for classification of clinical trials because one type of trial may occur in several phases. It is important to appreciate that the phase concept is a description, not a set of requirements.' The FDA also recognizes that safety data are an inherent component of all clinical trials [20].

Results showed that the majority of ATP infusions were without side effects and, when side effects did occur, they were mild and resolved within minutes after lowering the infusion rate. In two patients, an electrocardiography (ECG) was performed because of severe chest pain during ATP administration. No ECG changes suggestive of myocardial ischaemia were detected, which was consistent with the previous study by Agteresch et al. [5], who also found no ECG abnormalities in case of chest pain symptoms during ATP infusion.

During the study period of 8 weeks, 11 patients died in the control group and 6 patients in the ATP group; the latter deaths were due to disease progression and were unrelated to the administration of ATP according to the treating physicians. All serious adverse events were reported to the Ethical Committee.

As discussed in chapter 4, we hypothesized that the presence of cardiac disorders (other than symptomatic angina pectoris and symptomatic heart failure) and/or lung cancer would be associated with lower MTD and a higher frequency of side effects. This hypothesis was confirmed: not only did patients with either cardiac disorders or lung cancer tolerate lower doses of ATP than patients without these disorders, but even at these lower doses, patients with cardiac disorders experienced side effects significantly more frequently.

Overall, we conclude that ATP infusions at the individual maximally tolerated dose (between $20-50 \mu \mathrm{g} / \mathrm{kg} \cdot \mathrm{min}$ ) were without side effects in the majority of ATP 
infusions. The most common side effects were CTC grade 1 dyspnoea, chest discomfort and the urge to take a deep breath, and no symptoms of cardiac ischaemia occurred in any of the infusions. All side effects were transient and resolved within minutes after lowering the ATP infusion rate. It would therefore appear that ATP infusions can be safely administered at home in this patient population provided the following recommendations are followed:

i. Exclusion of patients with specific cardiovascular disorders such as symptomatic angina pectoris.

ii. Administration of the first infusion in an inpatient setting.

iii. Immediately lowering the infusion rate in case of any side effects and continuing at this lower dose during subsequent infusions.

iv. Remaining alert with regard to possible recurrence of side effects during subsequent infusions.

\section{LOGISTIC ASPECTS}

In chapter $\mathbf{5}$ of this thesis, we have reported treatment adherence and acceptance by patients of ATP infusions at home. Home infusions were given by experienced, highly qualified nurses of the infusion team of the home care organisation or hospital. The researcher instructed all participating infusion teams on how to administer, increase and end the ATP infusions; what to do in case of side effects; which items had to be checked and reported; and how to instruct the patient and/or informal caregiver. To transfer the ATP infusions from the hospital to the home situation, many issues needed to be organised. This organisation was performed by special nurses (transfer nurses or the coordinator of the home infusion team) from the hospital or the home care organisation.

The evaluation in chapter $\mathbf{5}$ shows that the administration of ATP infusions at home in preterminal cancer patients is well-accepted by patients. We experienced few logistic problems, presumably due to the fact that a single person was responsible for the transfer of ATP infusions from hospital to home.

In the home situation, we sometimes experienced difficulties with establishing venous access. Six patients needed to attend the hospital day care centre for intravenous access; in two patients, the ambulance personnel inserted the infusion needle, and in one patient, a nurse from the hospital inserted the infusion needle at home. Despite these difficulties, the mean duration of the ATP infusions in these patients at home was 8h03' (SD 1h24'). Only in one infusion, the total time of ATP administration was reduced by more than one hour. Based on these data we conclude that difficulties with achieving intravenous access have had only a negligible effect on the duration of ATP infusions in our study, and therefore have not influenced the results. 
The difficulties in establishing venous access in some patients may have been due to pre-treatment with chemotherapy. As $69 \%$ of the patients were pre-treated with chemotherapy, damaged blood vessels may have rendered venous access more difficult. Suggestions to improve obtaining venous access might be either the use of a transmural infusion team (i.e. trained infusion nurses working both in hospital and home situations) or choosing an alternative route of venous access. Optimization at this point will require further attention.

\section{STRENGTHS AND LIMITATIONS}

In this paragraph, we will discuss strengths of the present study as well as potential limitations with regard to the study population, interventions, co-interventions, and outcome measures.

\section{Strengths}

Controlled intervention studies in patients with preterminal cancer are scarce. Some of the strengths of the present study are:

i. With some limitations (as will be discussed below), our study demonstrates that it is feasible to perform a controlled intervention study in preterminally ill cancer patients, even with an intensive intervention such as infusion therapy. Most patients were willing to continue their participation until the end of the study even when they were randomised to the control group. This observation makes a potential role of selection bias in the current trial less likely. Moreover, many patients randomised to the ATP group opted for continuation of the infusions after the original intervention period, for periods of up to 6 months.

ii. The study also shows that extensive outcome assessment is possible in patients with preterminal cancer, mainly due to the fact that all outcome measurements were performed at the patients' home.

iii. Outcome assessment included both objective end points such as anthropometric measures and muscle strength, and subjective outcomes such as food diaries and questionnaires.

iv. All results were obtained from the patient him/herself and not from relatives or health care professionals, and assessment of one patient was always performed by the same observer.

v. Finally, this study has demonstrated that, in principle, the Dutch home care system is adequate to support ATP administration at home even in this very ill patient population. 


\section{Limitations with regard to the study population}

The study population could have been a potential limitation because of issues with patient recruitment, heterogeneity and drop-out.

\section{Patient recruitment}

It proved to be difficult to recruit sufficient patients for the present study. A growing body of literature illustrates the struggle to recruit terminally ill patients for scientific studies [21-24]. Rinck et al. [25] conducted a literature review of 11 end-of-life studies. In two studies, the researchers were unable to recruit sufficient numbers of patients in order to report valid results, while patient inclusion in the other nine studies could be completed with recruitment problems like selective patient recruitment, patient or physician refusal.

The low inclusion rate, especially during the first two years of our study might have been due to the availability of extensive palliative treatment options; patients' refusal to participate because of aversion against an additional infusion therapy, expected high burden, wary of the randomisation procedure, or just having received bad news about incurable illness. At the same time, full consulting hours of medical specialists and general practitioners may also play a role, as well as MDs having troubled feelings when informing a patient about a study immediately following a bad news message.

In an attempt to overcome problems with patient recruitment and inclusion, we extended the number of physicians participating in patient recruitment (Departments of Medical Oncology and Pulmonology of four hospitals in different regions and 50 general practitioners in southern Limburg), sending out reminders to these MDs every two weeks. As a further initiative, a journalist interview led to publication of a popular article on the study in a daily newspaper. This resulted in approximately 50 telephone calls from cancer patients who were interested in more information about the study. Only six of the interested patients met the inclusion criteria of the study.

\section{Heterogeneity}

Despite the high incidence and prevalence of breast, colon, prostate and lung cancer in the general population, these common tumour types did not constitute the majority of our study population. We only included one patient with breast cancer, 9 patients with prostate cancer and 13 patients with colon/rectum cancer, probably due to the high number of life-prolonging palliative treatment options for these tumour types. Instead, we included more than 15 different tumour types, among which a number of rare tumour types. Therefore, except for lung cancer, generalization of the present study results to specific tumour types is limited by heterogeneity in tumour types. 
We also experienced heterogeneity in length of survival, which may have been partly due to heterogeneity in tumour type. Although one of the inclusion criteria for patients was an estimated life expectancy $<6$ months, follow-up of patients showed that 31 out of 99 patients survived for more than 6 months. Literature review shows that it is extremely difficult for physicians to give a valid estimate of individual patients' life expectancy [26-28]. For instance, Higginson and Costantini [28] investigated the accuracy of a given prognosis range by the members of four multi-professional palliative care teams in patients with a survival of 1 to 734 days. These authors reported an accurate predicted range in $42 \%$ of the patients, an over-optimistic predicted range in $36 \%$, and an over-pessimistic predicted range in $22 \%$ of the patients. Estimates became slightly more reliable only at a minimum survival estimate of $<2$ weeks [28].

Furthermore, patient recruitment through different recruitment sources may also have contributed to heterogeneity in our study population. The heterogeneity of our study population is likely to have contributed to high between-subject variability in baseline data and in variability of outcome parameters over time, thereby limiting the power of our study.

Heterogeneity may also lead to a higher risk of baseline imbalance between randomisation groups. Despite performing randomisation in our study, patient characteristics at baseline differed markedly between the ATP and control group. It has been described that baseline imbalance can indicate selection bias due to the ability to predict, and sometimes to determine with certainty, upcoming allocations [29-30]. However, this is quite unlikely to be the cause of the baseline imbalance in the present study, as patients were included by more than 50 physicians, followed by central randomisation by telephone.

Stratification can be used to reduce the risk of baseline imbalance. In our study, we stratified for 1 . colon vs. other tumour types, 2. region (Maastricht vs. other regions) and 3. weight loss (yes/no). Stratification by recruitment source would also have been useful but was not feasible because of the number of participating centres $(n=5)$. We did not stratify for lung cancer because patient recruitment was started at the Department of Internal Medicine - Oncology of the University Hospital Maastricht. Due to low patient accrual in the first year of the study at this department, we decided to increase the number of participating centres, including two departments of Pulmonology with a high recruitment rate.

\section{Drop-out}

As expected in our study population of preterminal cancer patients, a high drop-out rate was observed. We included 99 patients, of whom 57 patients completed the full 8-week study period. Total drop-out rates were equally distributed over ATP 
$(n=22)$ and control patients $(n=20)$. The high drop-out rate may have limited the power of our study to detect significant effects of ATP.

To examine whether selective drop-out might have biased our data, additional analyses of the data stratified by follow-up period (i.e. patients who completed either 0,4 or 8 weeks of follow-up) were performed. As expected, results (illustrated in Figure 2 for energy intake) showed higher baseline values in patients who completed the study, as opposed to those who dropped out during the study. Importantly, as shown in Figure 2, despite this selective drop-out in both the ATP and control group, energy intake over time was similar in the ATP and control group in patients with 4 and 8 weeks follow-up, respectively. Since similar results were obtained for other outcome parameters, it is highly unlikely that selective drop-out would have biased our study results.

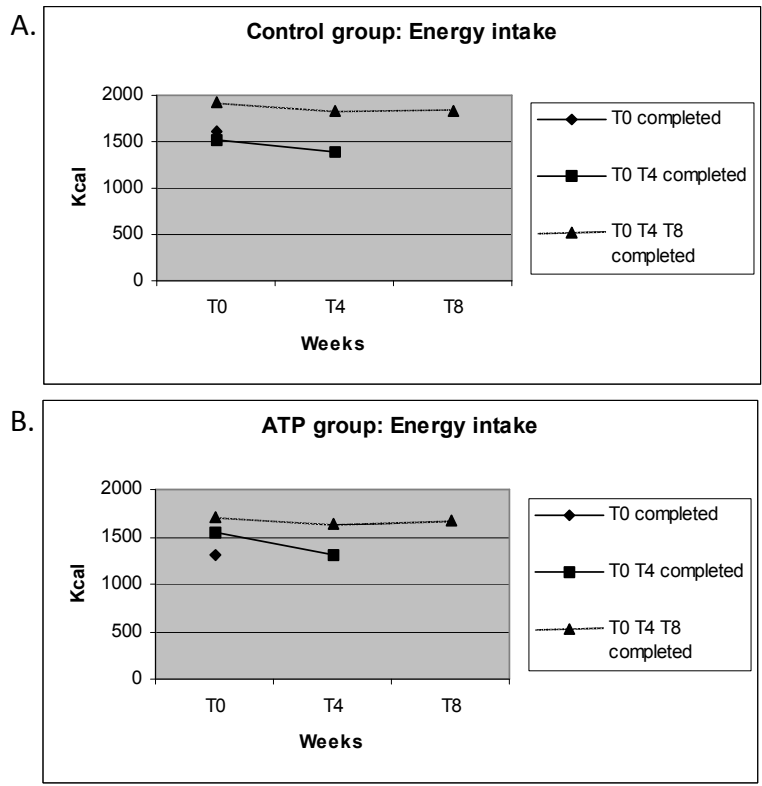

Figure 2. Effect of drop out on energy intake in the control (A) and ATP group (B).

\section{Limitations with regard to interventions and co-interventions}

\section{Interventions}

Patients in the present study were randomly assigned to intervention (ATP combined with usual care and standard nutritional advice) or control (usual care 
and standard nutritional advice, but no ATP). The idea underlying the standard nutritional advice as part of the present study, was to provide patients with additional palliative support (which presumably would have limited effect on the nutritional status, and no effect at all on muscle mass) in week 2 and 6 of the study. Using a standard checklist, problems and complaints (e.g. loss of appetite) were noted, followed by standard nutritional advice based on the specific type of complaint(s) of the patient; this information was supported by specific information sheets for each type of complaint.

The question might be raised whether this standard nutritional advice could have biased our results. Indeed, the possibility cannot be excluded that patients randomised to the control group complied better with the nutritional advice than patients receiving ATP treatment. Patients not receiving ATP would tend to grasp any options offered to improve their nutritional status, whereas ATP-treated patients would rather tend to presume that the ATP infusions by themselves would be sufficient to adequately improve their condition.

The advice most given in both groups was to substitute usual foods by energydense foods, often implicating replacing or supplementing carbohydrate-rich products by fat-rich products. Additional analyses of nutritional intake by patients in our study indeed indicated, from 0 to 8 weeks, a slight increase in the energy proportion from fat intake in the control group, whereas fat intake in the ATP group remained stable (Table 1 ).

Table 1. Nutritional intake at 0,4 , and 8 weeks in the ATP and control group.

\begin{tabular}{lllllllr}
\hline & ATP & & \multicolumn{3}{c}{ Control (C) } & \multicolumn{3}{r}{ ATP vs. C } \\
& 0 & 4 & 8 & 0 & 4 & 8 & p-value \\
& $(\mathrm{n}=49)$ & $(\mathrm{n}=36)$ & $(\mathrm{n}=29)$ & $(\mathrm{n}=47)$ & $(\mathrm{n}=34)$ & $(\mathrm{n}=26)$ & \\
\hline Energy intake (MJ/d) & $6.6 \pm 0.3$ & $6.6 \pm 0.4$ & $7.1 \pm 0.4$ & $7.4 \pm 0.3$ & $7.2 \pm 0.3$ & $7.7 \pm 0.4$ & 0.74 \\
Protein intake (g/d) & $60 \pm 3$ & $58 \pm 4$ & $65 \pm 5$ & $65 \pm 4$ & $61 \pm 4$ & $69 \pm 5$ & 0.52 \\
Protein intake (\%) & $15 \pm 0.5$ & $15 \pm 0.7$ & $16 \pm 0.8$ & $15 \pm 0.4$ & $14 \pm 0.6$ & $15 \pm 0.5$ & 0.47 \\
Carbohydrate intake (g/d) & $187 \pm 9$ & $187 \pm 11$ & $198 \pm 13$ & $203 \pm 9$ & $206 \pm 10$ & $196 \pm 11$ & 0.59 \\
Carbohydrate intake (\%) & $49 \pm 1.2$ & $50 \pm 1.7$ & $48 \pm 1.8$ & $47 \pm 1.1$ & $50 \pm 1.9$ & $43 \pm 1.6$ & 0.93 \\
Fat intake (g/d) & $60 \pm 3$ & $59 \pm 4$ & $63 \pm 5$ & $72 \pm 4$ & $65 \pm 4$ & $79 \pm 6$ & 0.98 \\
Fat intake (\%) & $33 \pm 1.2$ & $34 \pm 1.2$ & $34 \pm 1.4$ & $36 \pm 0.8$ & $34 \pm 1.4$ & $39 \pm 1.5$ & 0.94 \\
\hline
\end{tabular}

Values are expressed as mean $\pm \mathrm{SE}$; P-value based on repeated-measures analysis of covariance.

In contrast, the proportional intake of carbohydrates slightly declined in the control group, but remained stable in ATP-treated patients. However, these differences were too small to conclude that control patients may have been more compliant with the nutritional advice given, and we therefore assume that the standard nutritional advice in the present study has not biased our results. 


\section{Co-interventions}

The original inclusion criteria as approved by ZonMw as the grant organisation defined the patient population as cancer patients 'without curative treatment options'. This original definition was operationalized by the project group as cancer patients 'with a life expectancy of less than 6 months, for whom no systemic treatment is available; medical treatment options are restricted to palliative/supportive care', with as exclusion criterion 'patients receiving chemotherapy'. Thus, the project group allowed other anti-tumour treatments to continue as palliative treatment. As described in chapter 6, the study population included 10 patients ( 5 ATP, 5 control) with prostate carcinoma with progressive disease under hormonal treatment, and four patients with lung cancer who were treated with gefitinib on compassionate use (2 ATP, 2 controls). Thus, these 14 patients receiving active anti-tumour treatment were well balanced between treatment groups; moreover, when analyses were repeated without these 14 patients, observed point estimates did not change substantially.

During the study, one patient started with palliative radiotherapy for skeletal metastases, two patients started with chemotherapy and one patient started with gefitinib (all control patients). Although this might have induced bias towards longer survival in the control group, we still found that ATP-treated patients survived longer, which argues for a genuine effect of ATP on survival. We conclude that it is unlikely that our results were biased by these medical co-interventions.

\section{Limitations with regard to outcome measurements}

An additional limitation of the present study may have been placebo effect and observer bias, as well as response shift.

\section{Placebo effect and measurement bias}

In the present study, we chose to utilize neither a blinded nor placebo-controlled design for two reasons. First, because it was considered unethical to give weekly placebo infusions to cancer patients with a mean life expectancy of $<6$ months. Second, characteristic side effects of ATP infusion, which we observed regularly during the MTD determination, can be designated as a cardiopulmonary syndrome, including symptoms such as an initial feeling of chest tightness and the urge to take a deep breath. If we had treated patients in a (double-) blind placebo-controlled fashion, the characteristic side effects of ATP during MTD determination, or rather the lack of side effects in case of placebo, would have provided strong indications to a number of patients (and caregivers) regarding which treatment was actually being administered. This would have undermined proper blinding of patients and caregivers. 
Nevertheless, in the utilized unblinded study design, a placebo effect seems less obvious for different reasons:

i. Results showed a positive effect of ATP on triceps skin fold thickness which is a robust outcome measure, less sensitive to patients' perceptions of intended effects. This confirmed the previous study by Agteresch et al. [1,2], who also observed favourable effects of ATP on robust outcome measures such as body weight, muscle mass, survival and serum levels of albumin and C-reactive protein (CRP) [1-3].

ii. Results showed an improvement in reported QoL in the control group for some domains and symptoms.

iii. Effects of ATP on survival appeared to be stronger in specific subgroups such as patients with lung cancer.

The last point also argues against measurement bias.

Clearly, the use of robust outcome measures will circumvent potential placebo effects and observer bias. In the present study, objectivity would have been improved by data on effects of ATP on blood markers of nutritional status and other disease-specific outcome variables. However, in view of the preterminal disease stage of the patients, we did not collect blood samples in our study, especially in order to minimize burden in the control group.

\section{Response shift}

QoL measures currently used in clinical research were not originally designed to account for response shift but are predominantly based on the assumption that patients respond consistently on measurement scales [31]. Response shift means that persons give different answers on QoL outcomes over time, not only because their QoL has actually changed, but also because of a changed perception of the meaning of QoL to them [31,32]. In the present study, we did not account for response shift, which might be an explanation for the stabilisation or even improvement of the control group on the majority of QoL domains or symptoms (overall QoL, global health, physical, role, emotional and social functioning, fatigue, anorexia, nausea, insomnia and constipation), which was totally unexpected in this preterminal patient group. Other possible explanations include increased acceptation of the unavoidability of the terminal state, better symptom management, decreasing symptom stress, relaxing at home after a stressful period with hospital visits, additional attention by the researcher during the home visits, or the gradual fading away of adverse reaction (stress) induced by the previous bad news of incurable illness.

The question whether accounting for response shift is needed, can be addressed only in view of the aim of the study. If a study is aimed at investigating how patients experience QoL in the preterminal disease stage and how patients 
perceive their QoL during the different phases of preterminal disease, the concept of response shift is by itself irrelevant. However, if as in our study, the aim is to measure a presumably 'objective' effect of an intervention with a specific drug like ATP over time, accounting for response shift becomes essential, because otherwise a possible effect would be missed by potentially rapid changes in QoL perceptions of patients during the preterminal illness stage.

It has been proposed $[33,34]$ that accounting for response shift could be achieved by a so-called retrospective pre-test design, comprising a pre-test, a post-test and a then-test. The then-test is a retrospective assessment of the pre-test assuming that the subject uses the same criteria as for the post-test (Example: Were you tired the past three days? vs. Were you tired 4 weeks ago? with e.g. 4 Likert answer options). The difference in QoL scores between the pre-test and the then-test is then defined as a measure of response shift, and the actual change in QoL adjusted for response shift is considered equal to the difference between the then-test and the post-test score $[33,34]$. However, in the preterminal stage, it would appear questionable whether patients are still able to adequately estimate how they would in retrospect interpret their QoL at a point of time 1-4 weeks ago, especially in view of rapid disease progression and psychological instability due to ongoing mental processes such as acceptation of nearby death, potentially relieving discussions with partners, relatives and significant others, etc. The potential strength of such effects is impressively demonstrated by the observation, as already mentioned, of a stabilisation or improvement of the large majority of QoL parameters in the untreated control group over the 8-week study period.

We conclude that issues related to conceptual changes in QoL perceptions in preterminal cancer patients over time may pose a serious threat to the validity of QoL assessment in effectiveness studies in these patients. It would appear very doubtful whether this problem can be adequately solved. It could be argued that the use of a placebo-controlled design could provide a potential solution, since presumably any response shift would then be similar in the experimental and placebo arms of the study. However, in view of the apparent instability of psychological processes in this study population, it is possible that even a placebocontrolled design will no longer provide an adequate solution to the issue of measurement bias in preterminal cancer patients.

\section{CONCLUSIONS AND IMPLICATIONS FOR FURTHER RESEARCH}

Based on the findings presented in this thesis, as extensively discussed in this chapter, we conclude that ATP infusions over a period of 8 weeks, at the dose and schedule studied, in preterminal cancer patients have no effect on QoL, physical restriction, fatigue, nutritional intake and body weight, but have a significant 
positive effect on fat mass (chapters 6 and 7). The observed effects of ATP on survival are intriguing but will require confirmation in larger clinical studies before any further conclusions can be drawn. Based on the safety profile of ATP, the small number of protocol deviations and the acceptance by patients, it would appear that (provided that the first ATP infusion is administered under medical supervision) ATP can be safely administered in the home setting, though some logistic limitations - such as problems with establishing venous access - need to be considered.

Based on the observed effect of ATP on survival in weight stable preterminal cancer patients and in patients with preterminal lung cancer, in combination with the beneficial effect of ATP on survival in patients with stage IIIB NSCLC [3], further research would be valuable. This research is to be executed in larger homogeneous patient populations, using a randomised placebo-controlled design.

Suggested issues for such future research are:

i. Pharmacokinetic and pharmacodynamic studies in order to optimize ATP treatment schedules with regard to dosage, duration and frequency, using intermediary outcomes as a marker of effect.

ii. Studies in patients with cancer in earlier disease stages with disease progression, nutritional status and QoL as outcomes, and including intermediate outcomes and biomarkers of effect.

iii. Studies combining ATP treatment with common treatment modalities for cancer, including chemotherapy and radiotherapy. It has been reported that ATP may enhance the efficacy of several chemotherapeutic agents [35-38] and may inhibit radiation-induced inflammation and DNA damage in irradiated and immune-stimulated blood ex vivo [39]. 


\section{REFERENCES}

1. Agteresch HJ, Dagnelie PC, van der Gaast A, Stijnen T, Wilson JH. Randomized clinical trial of adenosine $5^{\prime}$-triphosphate in patients with advanced non-small-cell lung cancer. J Natl Cancer Inst 2000; 92: 321-8.

2. Agteresch HJ, Rietveld T, Kerkhofs LG, van den Berg JW, Wilson JH, Dagnelie PC. Beneficial effects of adenosine triphosphate on nutritional status in advanced lung cancer patients: a randomized clinical trial. J Clin Oncol 2002; 20: 371-8.

3. Agteresch HJ, Burgers SA, van der Gaast A, Wilson JH, Dagnelie PC. Randomized clinical trial of adenosine $5^{\prime}$-triphosphate on tumor growth and survival in advanced lung cancer patients. Anticancer Drugs 2003; 14: 639-44.

4. Haskell CM, Mendoza E, Pisters KM, Fossella FV, Figlin RA. Phase II study of intravenous adenosine 5 'triphosphate in patients with previously untreated stage IIIB and stage IV non-small cell lung cancer. Invest New Drugs 1998; 16: 81-5.

5. Agteresch HJ, Dagnelie PC, Rietveld T, van den Berg JW, Danser AH, Wilson JH. Pharmacokinetics of intravenous ATP in cancer patients. Eur J Clin Pharmacol 2000; 56: 49-55.

6. Ralevic V, Burnstock G. Receptors for purines and pyrimidines. Pharmacol Rev 1998; 50: 413-92.

7. Dewys WD, Begg C, Lavin PT, Band PR, Bennett JM, Bertino JR, et al. Prognostic effect of weight loss prior to chemotherapy in cancer patients. Eastern Cooperative Oncology Group. Am J Med 1980; 69: 491-7.

8. Stratton R, Green CJ, Elia M. Disease-related malnutrition: An evidence-based approach to treatment. Wallingford CT: CABI publishing; 2003.

9. Schafer R, Hartig R, Sedehizade F, Welte T, Reiser G. Adenine nucleotides inhibit proliferation of the human lung adenocarcinoma cell line LXF-289 by activation of nuclear factor kappaB1 and mitogen-activated protein kinase pathways. FEBS J 2006; 273: 3756-67.

10. Correale P, Tagliaferri P, Guarrasi R, Caraglia M, Giuliano M, Marinetti MR, et al. Extracellular adenosine $5^{\prime}$ triphosphate involvement in the death of LAK-engaged human tumor cells via P2Xreceptor activation. Immunol Lett 1997; 55: 69-78.

11. Rapaport E, Fishman RF, Gercel C. Growth inhibition of human tumor cells in soft-agar cultures by treatment with low levels of adenosine 5'-triphosphate. Cancer Res 1983; 43: 4402-6.

12. Conigrave $A D$, van der Weyden $L$, Holt L, Jiang L, Wilson $P$, Christopherson RI, et al. Extracellular ATP-dependent suppression of proliferation and induction of differentiation of human HL-60 leukemia cells by distinct mechanisms. Biochem Pharmacol 2000; 60: 1585-91.

13. Maaser K, Hopfner M, Kap H, Sutter AP, Barthel B, von Lampe B, et al. Extracellular nucleotides inhibit growth of human oesophageal cancer cells via P2Y(2)-receptors. Br J Cancer 2002; 86: 63644.

14. Janssens R, Boeynaems JM. Effects of extracellular nucleotides and nucleosides on prostate carcinoma cells. Br J Pharmacol 2001; 132: 536-46.

15. Estrela JM, Obrador E, Navarro J, Lasso De la Vega MC, Pellicer JA. Elimination of Ehrlich tumours by ATP-induced growth inhibition, glutathione depletion and X-rays. Nat Med 1995; 1: 84-8.

16. Shabbir M, Thompson C, Jarmulowiczc M, Mikhailidis D, Burnstock G. Effect of extracellular ATP on the growth of hormone-refractory prostate cancer in vivo. BJU Int 2008; 102: 108-12.

17. Rapaport E. Experimental cancer therapy in mice by adenine nucleotides. Eur J Cancer Clin Oncol 1988; 24: 1491-7.

18. Shabbir M, Ryten M, Thompson C, Mikhailidis D, Burnstock G. Purinergic receptor-mediated effects of ATP in high-grade bladder cancer. BJU Int 2008; 101: 106-12.

19. Lasso de la Vega MC, Terradez P, Obrador E, Navarro J, Pellicer JA, Estrela JM. Inhibition of cancer growth and selective glutathione depletion in Ehrlich tumour cells in vivo by extracellular ATP. Biochem J 1994; 298: 99-105.

20. Hubbard WK. International Conference on Harmonisation; Guidance on General Considerations for Clinical Trials. Food and Drug Administration. Federal Register 1997; 62: 66113-9.

21. Ewing G, Rogers M, Barclay S, McCabe J, Martin A, Todd C. Recruiting patients into a primary care based study of palliative care: why is it so difficult? Palliat Med 2004; 18: 452-9. 
22. McMillan SC, Weitzner MA. Methodologic issues in collecting data from debilitated patients with cancer near the end of life. Oncol Nurs Forum 2003; 30: 123-9.

23. Sherman DW, McSherry CB, Parkas V, Ye XY, Calabrese M, Gatto M. Recruitment and retention in a longitudinal palliative care study. Appl Nurs Res 2005; 18: 167-77.

24. Steinhauser KE, Clipp EC, Hays JC, Olsen M, Arnold R, Christakis NA, et al. Identifying, recruiting, and retaining seriously-ill patients and their caregivers in longitudinal research. Palliat Med 2006; 20: 745-54.

25. Rinck GC, van den Bos GA, Kleijnen J, de Haes HJ, Schade E, Veenhof $\mathrm{CH}$. Methodologic issues in effectiveness research on palliative cancer care: a systematic review. J Clin Oncol 1997; 15: 1697707.

26. Christakis NA, Lamont EB. Extent and determinants of error in doctors' prognoses in terminally ill patients: prospective cohort study. BMJ 2000; 320: 469-72.

27. Glare $\mathrm{P}$, Virik K, Jones $M$, Hudson $M$, Eychmuller $S$, Simes J, et al. A systematic review of physicians' survival predictions in terminally ill cancer patients. BMJ 2003; 327: 195-8.

28. Higginson IJ, Costantini M. Accuracy of prognosis estimates by four palliative care teams: a prospective cohort study. BMC Palliat Care 2002; 1 : 1.

29. Berger VW, Weinstein S. Ensuring the comparability of comparison groups: is randomization enough? Control Clin Trials 2004; 25: 515-24.

30. Berger VW, Exner DV. Detecting selection bias in randomized clinical trials. Control Clin Trials 1999; 20: 319-27.

31. Ring L, Hofer S, Heuston F, Harris D, O'Boyle CA. Response shift masks the treatment impact on patient reported outcomes (PROs): the example of individual quality of life in edentulous patients. Health Qual Life Outcomes 2005; 3: 55.

32. Hagedoorn M, Sneeuw KC, Aaronson NK. Changes in physical functioning and quality of life in patients with cancer: response shift and relative evaluation of one's condition. J Clin Epidemiol 2002; 55: 176-83.

33. Rees J, Clarke MG, Waldron D, O'Boyle C, Ewings P, MacDonagh RP. The measurement of response shift in patients with advanced prostate cancer and their partners. Health Qual Life Outcomes 2005; 3: 21.

34. Sprangers MA, Van Dam FS, Broersen J, Lodder L, Wever L, Visser MR, et al. Revealing response shift in longitudinal research on fatigue--the use of the thentest approach. Acta Oncol 1999; 38: 709-18.

35. Hatta $Y$, Itoh T, Baba M, Miyajima T, Shimojima H, Sawada $U$, et al. Purging in autologous hematopoietic stem cell transplantation using adenosine triphosphate (ATP) and 4hydroperoxycyclophosphamide (4-HC). Leuk Res 2002; 26: 477-82.

36. Maymon R, Bar-Shira Maymon B, Cohen-Armon M, Holtzinger M, Leibovici J. Enhancing effect of ATP on intracellular adriamycin penetration in human ovarian cancer cell lines. Biochim Biophys Acta 1994; 1201: 173-8.

37. Schafer R, Sedehizade F, Welte T, Reiser G. ATP- and UTP-activated P2Y receptors differently regulate proliferation of human lung epithelial tumor cells. Am J Physiol Lung Cell Mol Physiol 2003; 285: L376-85.

38. Hatta Y, Takahashi M, Enomoto Y, Takahashi N, Sawada U, Horie T. Adenosine triphosphate (ATP) enhances the antitumor effect of etoposide (VP16) in lung cancer cells. Oncol Rep 2004; 12: 113942.

39. Swennen EL, Dagnelie PC, Van den Beucken T, Bast A. Radioprotective effects of ATP in human blood ex vivo. Biochem Biophys Res Commun 2008; 367: 383-7. 

Chapter 9

Summary 



\section{SUMMARY}

This thesis describes the application of ATP infusions in palliative home care. The palliative phase starts at the moment that cure is not or no longer possible. The aim of palliative treatment is to relieve disease symptoms in order to optimize the quality of life $(\mathrm{Q} o \mathrm{~L})$ of the patient as well as his/her family and friends. Complaints like pain, progressive fatigue, dyspnoea, anorexia, involuntary weight loss and reduced functional abilities have a substantial impact on the QoL of the patient and his/her environment.

Since knowledge about aspects determining patients' perceived QoL during deterioration of disease is important to further improve end-of-life care, we first investigated the relative contributions of different domains of functioning and symptoms to overall QoL in preterminal cancer patients. Results of this study are reported in chapter 2 . Ninety-eight preterminal cancer patients participated in the study. Overall QoL, physical functioning, emotional functioning, social functioning, role functioning, cognitive functioning and symptoms such as fatigue, pain, loss of appetite and dyspnoea, were measured using the European Organisation for Research and Treatment of Cancer (EORTC) Quality of Life Questionnaire (QLQC30). Results from both univariate and multivariate analyses clearly demonstrated that, in preterminal cancer patients, fatigue is a major contributor of patientperceived overall QoL. This finding emphasizes the need for the development of intervention strategies to reduce fatigue so that the best possible overall QoL can be achieved in this preterminal stage of the disease.

So far, no effective treatment options to relieve fatigue or other symptoms like involuntary weight loss are available. A previous randomised clinical trial (RCT) in patients with advanced non-small-cell lung cancer (NSCLC) showed that ATP infusions had favourable effects on nutritional status and QoL. Based on these favourable effects, the aim of the present study was to investigate the clinical effects of ATP infusions on fatigue, physical restriction, QoL and nutritional status in preterminal cancer patients of mixed tumour types. Based on the previously observed effects of ATP on survival in patients with advanced NSCLC, we also explored the effect of ATP on survival. Moreover, in order to reduce the burden of repeated hospital visits for patients, and based on the favourable safety profile of ATP, we developed and implemented a standardized protocol for ATP administration in the home setting. In the present study, we evaluated the safety and logistic aspects, as well as patients' acceptance, of ATP infusions at home.

Chapter 3 describes the design of this RCT. Eligible were patients with cytologically or histologically confirmed cancer, without curative treatment options, who had a life expectancy of 1-6 months, had a World Health Organisation (WHO) performance status 1 or 2 (WHO 1: restricted in physically strenuous activity but ambulatory and able to do light work; WHO 2: ambulatory (not more than $50 \%$ in 
bed) and capable of self-care but unable to carry out any work), and suffered from at least one of the following complaints: fatigue, weight loss $>5 \%$ over the last 6 months, or anorexia. Patients were recruited through the Departments of Medical Oncology and Pulmonology in five centres and 50 general practitioners in the southern half of The Netherlands. After baseline measurements, patients were stratified for region, tumour type, and weight loss ( $\leq 5 \%$ vs. $>5 \%$ over the last 6 months), and then randomly assigned to receive either usual care, standard nutritional advice and ATP (ATP group), or usual care and standard nutritional advice alone (control group). Patients allocated to the ATP group received weekly 8-10 $\mathrm{h}$ ATP infusions at the maximally tolerated dose, with a maximum of 50 $\mu \mathrm{g} / \mathrm{kg} \cdot \mathrm{min}$, over a period of 8 weeks. The first or first two ATP infusions were offered under medical supervision at the day care centre of the participating hospitals. Subsequent infusions were given at the patients' home by an experienced, high qualified and trained nurse of the infusion team of the home care organisation or hospital. QoL, fatigue, physical restriction, nutritional intake, muscle strength and anthropometric measurements were assessed every two weeks until 8 weeks.

From April 2002 through October 2006, 100 patients were randomly assigned to the ATP $(n=51)$ or control group $(n=49)$. One patient had to be excluded and 16 patients died or dropped out before the first follow-up measurement (7 ATP patients; 9 control patients), leaving 83 assessable patients. Fifty-seven patients completed the full 8-week study period. Mean age of the total study population was 66.4 years, and $66 \%$ of the patients were male. Lung cancer was the most frequent tumour type (45\%), followed by colon cancer (13\%). Seventy percent of the patients had a WHO performance status 1, and $30 \%$ a WHO status 2 . Baseline patient characteristics showed that there was some imbalance between the randomisation groups in favour of the control group: randomised and assessable patients in the ATP group had a worse performance status, a lower energy intake, a higher frequency of oedema and ascites; also, weight loss $\geq 10 \%$ at baseline was found more frequently in the ATP group.

Especially in terminally ill cancer patients, it is preferred to provide palliative care in their own environment. In the present study, we therefore decided to administer ATP in the home setting, since visiting the hospital once a week would impose a considerable burden on these patients.

Chapter 4 describes the side effects of ATP infusions in this patient population. Side effects were registered systematically according to the National Cancer Institute ( $\mathrm{NCl}$ ) Common Toxicity Criteria both during the infusions, and on completion of each infusion. Out of the 51 patients allocated to the intervention group, three patients did not start because of rapid deterioration of their condition and 18 patients stopped with the ATP infusions. Over the study period of 8 weeks, a total 
of 266 ATP infusions were administered in 48 patients. Fifteen patients (31\%) received one to three ATP courses, nine patients (19\%) received four to seven courses, and 24 patients (50\%) completed all eight ATP infusions. Of the 24 patients who completed all eight ATP infusions, 12 decided to continue ATP administration. Eleven infusions (4\%) of 266 infusions were given at the lowest dose of 20 $\mu \mathrm{g} / \mathrm{kg} \cdot \mathrm{min}, 85$ infusions (32\%) at a dose of $25-40 \mu \mathrm{g} / \mathrm{kg} \cdot \mathrm{min}$, and $170(64 \%)$ at the highest dose of $45-50 \mu \mathrm{g} / \mathrm{kg}$.min. The majority of ATP infusions (63\%) were without side effects. Dyspnoea was the most common side effect, followed by chest discomfort and the urge to take a deep breath. All side effects were transient and resolved within minutes after lowering the ATP infusion rate. Patients with cardiac disorders tolerated lower doses of ATP and tend to have more side effects then patients without these disorders. Based on these findings, it would appear that ATP infusions at a maximum dose of $50 \mu \mathrm{g} / \mathrm{kg} \cdot \mathrm{min}$, can be safely administered at home in preterminal cancer patients, provided the following recommendations are followed:

i. Exclusion of patients with specific cardiovascular disorders such as symptomatic angina pectoris.

ii. Administration of the first infusion in an inpatient setting.

iii. Immediately lowering the infusion rate in case of any side effects and continuing at this lower dose as a maximum during subsequent infusions.

iv. Remaining alert with regard to possible recurrence of side effects during subsequent infusions.

In addition to the safety of ATP administration at home it is also important to test the logistic aspects and patients' acceptance. This process evaluation is described in chapter $\mathbf{5}$. Adherence to the treatment protocol was evaluated by standardized registration of the course of the infusions and all protocol deviations. Information about patients' opinion regarding the safety and the burden of the ATP infusions was collected after 4 and 8 infusions by structured interviews. Results showed that the administration of the ATP infusions at home was largely carried out according to protocol: mean duration just over $8 \mathrm{~h}$, stepwise achievement of the maximum infusion rate within $45 \mathrm{~min}$ in $86 \%$ of the infusions, and almost no delay in weekly administration. The majority of patients were not burdened by the home infusions and found the advantages of the ATP infusions outweighing the disadvantages. None of the patients had felt afraid during the home infusions. The most frequently mentioned problem was difficulty in establishing venous access at home, possibly due to the history of chemotherapy in many patients. Based on these results, we conclude that the administration of home infusions with ATP in preterminal cancer patients is possible and well accepted by patients, though some logistic limitations - such as problems with establishing venous access - need to be considered.

Chapter 6 focuses on the effect of ATP on nutritional status and survival in preterminal cancer patients. Nutritional status parameters were assessed until 8 
weeks after randomisation, and analysed by repeated-measures analysis of covariance. Cox proportional hazards models were fitted to assess the effect of ATP on short term (0-8 weeks) and long term (0-6 months) survival. Results showed a significant favourable effect of ATP on triceps skin fold thickness (between-group difference per 8 weeks: $1.76 \mathrm{~mm}, 95 \%$ confidence interval $(\mathrm{Cl}): 0.48-3.12 \mathrm{~mm}$; $\mathrm{p}=0.009$ ) and on short-term survival (0-8 weeks, HR: $0.40,95 \% \mathrm{Cl}: 0.17-0.95$; $\mathrm{p}=0.037$ ). In weight-stable patients and in lung cancer patients, long term survival (0-6 months) was also significantly better in ATP-treated patients (weight stable patients: HR: $0.40,95 \% \mathrm{Cl}: 0.19-0.83 ; p=0.014$; patients with lung cancer: HR: $0.35,95 \% \mathrm{Cl}: 0.14-0.88 ; \mathrm{p}=0.025)$. This effect of ATP on survival is intriguing especially since our study population was composed of refractory cancer patients with preterminal illness with an estimated life expectancy $<6$ months. Clearly, our findings will need confirmation in future rigorous studies.

Chapter 7 reports about the effects of ATP infusions on QoL parameters in the same study population of preterminal cancer patients. QoL parameters, physical restriction, fatigue and muscle strength were assessed every two weeks until 8 weeks after randomisation and analysed by repeated-measures analysis of covariance. Results showed no statistically significant differences between the ATP and control group for the large majority of QoL parameters. The only exceptions were strength of elbow flexor muscles in favour of the control group and, in patients with lung cancer, strength of knee extensor muscles in favour of the ATP group. Quite remarkably, our results did not show the expected overall deterioration in outcome parameters in the untreated control group. In fact, for the majority of QoL domains or symptoms, we observed either a stabilisation over time (for overall QoL, physical, role, emotional and social functioning, fatigue, nausea, insomnia and constipation) or even a significant amelioration over time (for global health and anorexia). A possible cause of this totally unexpected finding in our study population might be response shift which is defined as a change in the meaning of a patient's self-reported QoL. As a consequence of response shift, high levels of self-reported QoL at different points in time may have different meanings. Furthermore, our results with regard to QoL, functional status, fatigue and muscle strength are markedly different from the previous study in patients with NSCLC. This discrepancy in results between the two studies might be caused by differences in study population, treatment schedule and/or study period. First, patients in our study were in a considerably later disease stage than the population of lung cancer patients studied in a previous study. Second, in view of the short life expectancy of our study population, we opted for a shorter follow-up period (8 weeks vs. 24 weeks). 
The overall conclusions of this thesis are:

i. In this population of preterminal cancer patients, application of ATP infusions (max. dose $50 \mu \mathrm{g} / \mathrm{kg} \cdot \mathrm{min}$ ) for $8-10 \mathrm{~h} / \mathrm{wk}$ over a period of 8 weeks have no effect on QoL, physical restriction, fatigue, nutritional intake and body weight, but have a favourable effect on fat mass.

ii. In this population, ATP has a favourable effect on survival, which was more pronounced in weight-stable patients and in patients with lung cancer. This finding is intriguing but will require confirmation in larger clinical studies before any further conclusions can be drawn.

iii. Provided that the first ATP infusion is offered under medical supervision, ATP infusions can be safely administered at home. The majority of infusions are without side effects, and side effects that do appear are mild and transient, resolving within minutes after lowering the ATP infusion rate. Based on the small number of protocol deviations and the acceptance by patients, it would appear that ATP can be administered in the home setting, though some logistic limitations - such as problems with establishing venous access - need to be considered. 



\section{Samenvatting}

Dit proefschrift gaat over de toepassing van ATP infusen in de palliatieve thuiszorg. De palliatieve fase begint op het moment dat genezing van kanker niet of niet langer mogelijk is. Het doel van de palliatieve behandeling is het verlichten van symptomen en het bereiken van de best mogelijke kwaliteit van leven voor zowel de patiënt als voor diens naasten. Klachten zoals pijn, vermoeidheid, benauwdheid, slechte eetlust, ongewenst gewichtsverlies en lichamelijke beperkingen zijn aspecten die de kwaliteit van leven van patiënten met een preterminale vorm van kanker en hun naasten ernstig belemmeren.

Om een zo goed mogelijke kwaliteit van leven te kunnen bereiken is het van belang te achterhalen welke klachten hierop het meest van invloed zijn. Dit was de aanleiding voor het huidige onderzoek, dat is beschreven in hoofdstuk 2. Centraal hierin stond de vraag welke factoren de algemene kwaliteit van leven bij patiënten met kanker in een preterminaal stadium bepalen. Aan de hand van de European Organisation for Research and Treatment of Cancer (EORTC) kwaliteit van leven vragenlijst (QLQ-C30) werden diverse aspecten van kwaliteit van leven zoals fysiek functioneren, emotioneel functioneren, sociaal functioneren en diverse symptomen zoals vermoeidheid, pijn, slechte eetlust en benauwdheid bij 98 patiënten met kanker in een preterminaal stadium nagevraagd. De resultaten van zowel de univariate als de multivariate analyse laten zien dat in deze groep van patiënten met kanker in een preterminaal stadium, vermoeidheid de meeste invloed heeft op de door de patiënt ervaren algemene kwaliteit van leven. Dit resultaat benadrukt de noodzaak van het ontwikkelen van behandelingsvormen om vermoeidheid te verminderen.

Tot op heden zijn er echter weinig behandelingsmogelijkheden om vermoeidheid of andere klachten zoals verlies in gewicht en conditie tegen te gaan of te verlichten. Een eerdere gerandomiseerde klinische trial bij patiënten met een niet-kleincellig longcarcinoom in een vergevorderd stadium liet zien dat ATP-infusen een gunstige invloed hebben op o.a. vermoeidheid, voedingstoestand, kwaliteit van leven en overleving. Gebaseerd op deze gunstige resultaten is het doel van de huidige studie het onderzoeken van de effecten van ATP infusen op vermoeidheid, lichamelijke beperkingen, kwaliteit van leven, voedingstoestand en overleving bij patiënten met kanker in een preterminaal stadium. Gebaseerd op het gunstige veiligheidsprofiel van ATP en om de belasting voor de patiënt te verminderen is een protocol voor ATP toediening thuis ontwikkeld en geïmplementeerd. In de huidige studie worden de veiligheid en logistieke aspecten van ATP infusen thuis, evenals de acceptatie door de patiënt, geëvalueerd. 
Hoofdstuk 3 geeft een beschrijving van de opzet van deze studie. Voor deze studie kwamen patiënten in aanmerking met kanker in een preterminaal stadium waarvoor geen curatieve behandelingsmogelijkheden meer voorhanden waren, met een geschatte levensverwachting van maximaal 6 maanden, een World Health Organisation (WHO) performance status 1 of 2 (WHO 1: beperkt in het doen van zware lichamelijke activiteiten maar wel in staat om lichte activiteiten uit te voeren en niet bedlegerig; WHO 2: niet meer dan $50 \%$ bedlegerig en in staat om zichzelf te verzorgen, niet in staat tot het doen van enige werkzaamheden) en tenminste één van de volgende klachten: vermoeidheid, slechte eetlust of meer dan $5 \%$ gewichtsverlies in de laatste 6 maanden. Oncologen en longartsen van 5 ziekenhuizen en 50 huisartsen in Zuid Nederland participeerden in de werving van patiënten. Geïncludeerde patiënten werden na stratificatie voor regio, tumor type en gewichtsverlies ( $\leq 5 \%$ vs. $>5 \%$ in de afgelopen 6 maanden) volgens toeval toegewezen (gerandomiseerd) aan de interventie of de controle groep. De interventiegroep kreeg de gebruikelijke palliatieve zorg en gedurende 8 weken éénmaal per week een ATP-infuus van 8 tot 10 uur (maximale dosis $50 \mu \mathrm{g} / \mathrm{kg}$.min). Het eerste of de eerste 2 infusen werden toegediend op het dagcentrum van de participerende ziekenhuizen. Alle vervolg infusen werden thuis toegediend door een ervaren verpleegkundige van de infuusdienst van de thuiszorg of van het ziekenhuis. De controlegroep kreeg de gebruikelijke palliatieve zorg maar geen ATP. Patiënten in beide groepen ontvingen bovendien gestandaardiseerde voedingsadviezen door een diëtist. Kwaliteit van leven, vermoeidheid, lichamelijke beperkingen, voedingsinname, spierkracht en diverse antropometrische parameters werden iedere 2 weken gemeten tot 8 weken na de start van de studie. Vanaf april 2002 tot oktober 2006 zijn in totaal 100 patiënten geïncludeerd waarvan 51 patiënten at random zijn toegewezen aan de ATP groep en 49 aan de controlegroep. Eén patiënt moest worden uitgesloten en 16 patiënten zijn uitgevallen door snelle achteruitgang of overlijden (7 patiënten in de ATP groep; 9 patiënten in de controle groep). Dit resulteerde in 83 patiënten waarvan één follow-up meting beschikbaar was. Zevenenvijftig patiënten hebben de 8 weken durende studie afgemaakt. De studiepopulatie was gemiddeld 66,4 jaar en bestond voor $66 \%$ uit mannen. De meest voorkomende vorm van kanker was longkanker (45\%), gevolgd door dikke darm kanker (13\%). Zeventig procent van de patiënten had een WHO performance status 1 en 30\% een WHO performance status 2 . Helaas bestonden er, ondanks randomisatie, een aantal verschillen tussen de controle en de ATP groep. Patiënten in de ATP groep hadden bij de baseline meting een slechtere performance score, een lagere energie inname, vaker oedeem en/of ascites, en meer ATP-patiënten hadden $\geq 10 \%$ gewichtsverlies. Hieruit kan worden geconcludeerd dat de ATP-groep bij het begin van de studie in een slechtere toestand verkeerde dan de controlegroep. 
Om patiënten met kanker in een preterminaal stadium zo min mogelijk te belasten is het belangrijk palliatieve zorg zoveel mogelijk in de thuissituatie te geven. Om deze reden is er in de huidige studie voor gekozen om het eerste of de eerste twee infusen via het dagcentrum van de participerende ziekenhuizen te geven en alle vervolginfusen thuis.

Hoofdstuk 4 beschrijft de bijwerkingen van ATP infusen in deze patiëntenpopulatie. Bijwerkingen werden systematisch geregistreerd tijdens en na ieder infuus aan de hand van de National Cancer Institute (NCl) Common Toxicity Criteria. Door ernstige verslechtering zijn van de 51 patiënten die werden gerandomiseerd voor de interventiegroep 3 patiënten niet gestart met ATP en 18 patiënten voortijdig gestopt. De overgebleven 48 patiënten hebben in totaal 266 infusen gekregen binnen de 8 weken durende studie periode. Vijftien patiënten (31\%) kregen 1-3 infusen, 9 patiënten (19\%) kregen 4-7 infusen en 24 patiënten (50\%) kregen alle 8 infusen. Van deze 24 patiënten besloten 12 patiënten om met de ATP infusen door te gaan. Elf (4\%) van de 266 infusen konden worden gegeven in een dosering van $20 \mu \mathrm{g} / \mathrm{kg}$.min, 85 infusen (32\%) in een dosering van 25-40 $\mu \mathrm{g} / \mathrm{kg}$.min, en 170 (64\%) in de hoogste dosering van 45-50 $\mathrm{\mu g} / \mathrm{kg}$.min. Van de 266 infusen waren 167 infusen (63\%) zonder bijwerkingen. De meest frequent voorkomende bijwerkingen waren benauwdheid, druk of pijn op de borst en behoefte om diep adem te halen. Deze bijwerkingen waren over het algemeen mild en verdwenen binnen enkele minuten na het verlagen van de infuussnelheid. Patiënten met hartproblemen bleken een lagere dosis ATP te verdragen en hadden meer last van bijwerkingen. Op basis van deze resultaten kan worden geconcludeerd dat thuistoediening van ATP infusen in een dosering tot $50 \mu \mathrm{g} / \mathrm{kg} \cdot \mathrm{min}$ bij patiënten met kanker in een preterminaal stadium veilig mogelijk is mits aan een aantal voorwaarden wordt voldaan:

i. Uitsluiten van patiënten met bepaalde hartaandoeningen zoals symptomatische angina pectoris.

ii. Toedienen van het eerste ATP infuus in het ziekenhuis.

iii. Direct verlagen van de infuussnelheid wanneer er bijwerkingen optreden en deze lagere dosis in volgende infusen als maximum dosis hanteren.

iv. Alert blijven op het terugkeren van bijwerkingen tijdens vervolginfusen.

Naast de veiligheid is het belangrijk de logistieke aspecten en de acceptatie door de patiënt van toediening van ATP infusen thuis te evalueren. Deze evaluatie is beschreven in hoofdstuk 5. Het verloop van de infusen werd op een gestandaardiseerde wijze geregistreerd evenals alle afwijkingen op het protocol. Voor het verzamelen van ervaringen van patiënten zijn na het $4^{\mathrm{e}}$ en $8^{\mathrm{e}}$ infuus gestructureerde interviews afgenomen. Over het algemeen was het mogelijk de ATP infusen volgens protocol toe te dienen. De gemiddelde duur van de infusen was iets langer dan 8 uur, de benodigde tijd om op te klimmen tot de maximaal getolereerde dosis was minder dan 45 minuten bij $85 \%$ van de infusen en er waren slechts drie infusen die een week moesten worden uitgesteld. De meerderheid van 
de patiënten vond het niet belastend om ATP infusen toegediend te krijgen en zij vonden de voordelen opwegen tegen de nadelen. Geen enkele patiënt was angstig tijdens de ATP toediening thuis. Een knelpunt in de toediening van ATP thuis was het aanleggen van het intraveneus infuus, mogelijk door de vele chemotherapie die onze studiepopulatie heeft gehad. Deze resultaten laten zien dat thuistoediening van ATP infusen haalbaar is (met als aandachtspunt het aanleggen van een intraveneus infuus) en dat de acceptatie door patiënten goed is.

In hoofdstuk 6 worden de effecten van ATP op de voedingstoestand en overleving beschreven. Parameters voor de voedingstoestand zijn iedere 2 weken gemeten tot 8 weken na de start van de studie en geanalyseerd op basis van analyses voor herhaalde metingen. Voor de analyse van de overleving is gebruik gemaakt van Cox proportional Hazard modellen waarbij gekeken is naar de korte termijn overleving (0-8 weken) en naar de lange termijn overleving (0-6 maanden). Uit de resultaten bleek dat ATP een gunstig effect had op de dikte van de triceps huidplooi (verschil tussen de twee groepen per 8 weken: $1.76 \mathrm{~mm}, 95 \%$ betrouwbaarheidsinterval (BI): 0.48 - $3.12 \mathrm{~mm} ; \mathrm{p}=0.009)$ en de korte termijn overleving (0-8 weken, HR: 0.40, $95 \% \mathrm{Cl}: 0.17-0.95 ; \mathrm{p}=0.037)$. Bij patiënten met longkanker en patiënten met minder dan $5 \%$ gewichtsverlies in de afgelopen 6 maanden werd ook een gunstig effect van ATP gezien in de periode 0-6 maanden (patiënten met stabiel gewicht: HR: 0.40, 95\% BI: 0.19 - 0.83; p=0.014; patiënten met longkanker: HR: 0.35, 95\% BI: $0.14-0.88 ; p=0.025)$. Hoewel deze resultaten met enige voorzichtigheid moeten worden geïnterpreteerd, is dit effect opmerkelijk omdat onze studiepopulatie bestond uit patiënten met een geschatte levensverwachting van minder dan 6 maanden, die allen niet meer reageerden op levensverlengende behandeling. Deze bevindingen moeten uiteraard door toekomstig onderzoek worden bevestigd. Gecombineerd met de resultaten van de eerdere studie bij patiënten met longkanker lijkt dit de theorie te ondersteunen dat ATP vooral een gunstig effect op de overleving kan hebben bij bepaalde vormen van kanker, en met name in een eerder ziektestadium.

Hoofdstuk 7 beschrijft de effecten van ATP op kwaliteit van leven, vermoeidheid, lichamelijke beperkingen en spierkracht in dezelfde studiepopulatie. Deze uitkomstmaten zijn iedere 2 weken gemeten tot 8 weken na de start van de studie. In tegenstelling tot de eerdere gerandomiseerde klinische trial met ATP lieten resultaten van de huidige studie voor het merendeel van de uitkomstmaten geen verschil zien tussen de ATP- en controlegroep, met uitzondering van de armspierkracht (biceps) die significant beter was in de controlegroep. In de subgroep van patiënten met longkanker werd een positief effect van ATP gezien op de beenspierkracht. Opmerkelijk was dat de kwaliteit van leven van patiënten in de controlegroep niet verslechterde, maar zelfs op een aantal punten significant verbeterde. Dit fenomeen kan mogelijk verklaard worden door 'response shift', waarmee wordt bedoeld dat patiënten in de loop van hun ziekte (met name als zij 
in conditie achteruitgaan) hun oordeel over hun kwaliteit van leven in positieve zin aanpassen. Response shift kan echter niet de verschillen met de voorgaande studie verklaren. Deze verschillen worden mogelijk veroorzaakt door verschillen in de studiepopulatie, behandelingsschema en/of studie periode. Onze zeer heterogene studiepopulatie was bij het begin van de studie in een aanmerkelijk slechtere conditie dan de patiënten met longkanker in de voorgaande studie. Verder is in de huidige studie, gezien de korte levensverwachting van de patiënten, gekozen voor een kortere vervolgperiode ( 8 weken vs. 24 weken).

De algemene conclusies van dit proefschrift zijn:

i. In deze populatie van patiënten met kanker in een preterminaal stadium heeft toediening van ATP infusen (max. $50 \mu \mathrm{g} / \mathrm{kg}$.min) gedurende 8-10 uur over een periode van maximaal 8 weken geen effect op de kwaliteit van leven, lichamelijke beperkingen, vermoeidheid, voedingsinname en lichaamsgewicht, maar wel een gunstig effect op de vetmassa.

ii. In deze populatie zien we een gunstig effect van ATP infusen op de overleving, met name bij patiënten met longkanker en patiënten met een stabiel gewicht. Deze bevinding zal echter in grotere, placebo-gecontroleerde studies moeten worden bevestigd alvorens hieruit definitieve conclusies kunnen worden getrokken.

iii. Mits het eerste infuus wordt toegediend in het ziekenhuis, is het mogelijk om ATP infusen veilig thuis toe te dienen. Het merendeel van de infusen verloopt zonder bijwerkingen en als er bijwerkingen optreden, zijn deze mild en verdwijnen snel na het verlagen van de infuussnelheid. Gezien het lage aantal afwijkingen van het protocol en de goede acceptatie door patiënten lijkt het haalbaar om thuis ATP infusen toe te dienen. Een aandachtspunt hierbij is het aanleggen van het intraveneus infuus. 



\section{Dankwoord}

Een proefschrift schrijf je niet alleen. Ik had dit promotietraject nooit kunnen volbrengen zonder de hulp en inzet van heel veel mensen. Al deze mensen wil ik graag hartelijk bedanken.

Allereerst wil ik alle patiënten en hun naasten bedanken. Patiënten die wisten dat ze niet meer beter zouden worden en toch hun zo kostbare tijd wilde besteden aan dit onderzoek. Die dit wilden doen om het mogelijk voor andere patiënten in de toekomst dragelijker te maken. Zonder $u$ was het niet mogelijk geweest deze studie uit te voeren. Van de bezoeken bij u thuis, de hartelijke ontvangst en de openhartige gesprekken krijg ik nog een warm gevoel.

Een speciaal woord van dank aan mijn projectleider en copromotor Pieter Dagnelie die mij de mogelijkheid heeft geboden dit promotietraject te volgen. Pieter, bedankt voor je grote betrokkenheid, inzet en begeleiding bij dit onderzoek. Ik heb bewondering voor je doorzettingsvermogen en het vertrouwen dat we dit tot een goed eind zouden brengen.

Daarnaast wil ik Erik van Rossum bedanken, bij de start van het project mijn tweede begeleider. Erik, je deur stond altijd voor me open en ik vond het jammer dat je door het veranderen van baan je werkzaamheden voor dit project niet meer kon voortzetten.

Ook een woord van dank aan mijn promotor Piet van den Brandt. Piet, bedankt voor je adviezen tijdens mijn promotietraject en je kritische aanvullingen op mijn proefschrift. Bij moeilijke momenten was je door je objectieve houding voor mij een enorme steun.

Vervolgens wil ik de projectgroep bedanken. Jullie waren vanaf het eerste moment betrokken bij de opzet en uitvoering van de studie. Marieke, Pierre, Cor, Lisette en Ron heel erg bedankt voor jullie enthousiaste en kritische inbreng.

Vele mensen waren betrokken bij de praktische uitvoering van dit onderzoek. Allereerst wil ik alle artsen bedanken die betrokken waren bij de werving van patiënten in het bijzonder Pierre Hupperets, Ben van den Borne, Alexander de Graeff, Arjen van Henten, Marten Nijziel en een groot aantal huisartsen in Maastricht en omgeving. Zonder jullie was het niet mogelijk geweest de patiënten te bereiken. 
Natuurlijk ook een woord van dank aan alle medewerkers van de dagcentra van het Maastricht Universitair Medisch Centrum, het Catharina Ziekenhuis Eindhoven, het Maxima Medisch Centrum Eindhoven en het Universitair Medisch Centrum Utrecht voor het toedienen van de ATP infusen. Ondanks de drukte lukte het jullie altijd om een plekje voor de patiënten te vinden en een sfeer van rust en vertrouwen te creëren.

Verder wil ik ook alle medewerkers van de infuusteams van GroenekruisDomicura Maastricht, MeanderGroep Zuid-Limburg, Zuidzorg (Eindhoven/Kempen) en de afdeling Thuiszorgtechnologie van het UMC Utrecht bedanken. Door jullie inzet was het mogelijk de infusen ook thuis toe te dienen zodat de belasting voor de patiënt aanzienlijk werd verminderd. Bedankt voor jullie grote betrokkenheid en voor de prettige samenwerking. Wat ik van de patiënten terug hoorde was alleen maar lof. Ook een woord van dank aan de medewerkers van de apotheken van de deelnemende centra voor het bereiden van de ATP-infusen en apotheek 't Hofke te Eindhoven voor het leveren van de infusen bij de patiënten thuis.

Verder wil ik alle ATP-ers en ex-ATP-ers bedanken. Ilja, Martijn, Anke, Els, Erik, Vanessa, Nicole, Brigitte, Adri, Arno, Maartje, Emilie, Anouk, Christine, Maggy en Shireen bedankt voor de gezelligheid, de prettige samenwerking en jullie niet aflatende interesse ook toen het langer duurde dan we hadden gedacht. Arno, 'oud' kamergenoot, bedankt voor je luisterend oor. Martijn, bedankt voor je hulp bij het moeilijkste stuk van mijn proefschrift.

Uiteraard wil ik ook alle andere collega's van de vakgroep Epidemiologie bedanken in het bijzonder Jos, Harry, Yvonne en Nathalie. Ontelbare malen heb ik met ICT en secretariële problemen aan jullie bureau gestaan en ik werd altijd even snel en goed geholpen.

Ook zijn er een aantal stagiaires geweest die ieder hun steentje hebben bijgedragen aan dit proefschrift. Eric, Esther, Simone, Emiel, Sander, Jetty en Agatha, bedankt voor jullie inzet, enthousiasme en frisse kijk op de zaak. Hilde en Monique, bedankt voor het coderen en berekenen van de voedingsdagboekjes. Wat een klus. En niet te vergeten Valery, bedankt voor je geduldig uitleggen van SAS. Ik heb het uiteindelijk toch onder de knie gekregen.

De leden van de leescommissie onder leiding van Prof. Dr. M.F. von Meyenfeldt wil ik hartelijk bedanken voor de zorgvuldige beoordeling van het manuscript.

Vervolgens een speciaal woord van dank aan mijn paranimfen. Het geeft me een heel gerust gevoel dat jullie 1 juli naast mij zullen staan. Nicole, jij hebt me enorm geholpen met de logistiek en de metingen van dit onderzoek. Ik wil je bedanken 
voor je enthousiasme, de gezelligheid en de fijne samenwerking en ik hoop dat we dat in de toekomst nog lang kunnen voortzetten.

José, we zaten in hetzelfde schuitje en dat schept een band. Het is heel prettig om met een 'lotgenoot' alle ups en downs te kunnen uitwisselen. Ik hoop dat we ook na het afronden van onze proefschriften nog vaak kunnen gaan lunchen in Maaseik.

Ook de afdeling diëtetiek van het Maastricht Universitair Medisch Centrum wil ik bedanken voor de belangstelling voor het wel en wee van mijn promotie perikelen. Ondanks dat ik al geruime tijd weg ben voelt het nog steeds heel vertrouwd om bij jullie de afdeling op te wandelen.

Verder een woord van dank aan het 'turboteam'. Anne, Niki en Jeanne, met jullie is het allemaal begonnen, mijn passie voor de voeding voor de patiënt met kanker. Jullie zijn mijn grote voorbeeld waar ik nog steeds door geïnspireerd word. Bedankt voor alle steun ook buiten het werk. De asperges zijn er door de drukte dit jaar bij in geschoten maar dat maken we weer goed.

Lieve familie en vrienden, ik wil jullie bedanken voor alle steun die jullie me elk op je eigen manier hebben gegeven. Hartverwarmend was jullie belangstelling en betrokkenheid. De gezelligheid buiten het werk was heel belangrijk en verschafte de nodige afleiding. Ik heb het mogelijk wel eens laten afweten omdat er weer een deadline moest worden gehaald maar dat wordt van nu af aan anders.

Een laatste woord van dank aan de belangrijkste mensen in mijn leven.

Pap en mam, bedankt dat jullie er altijd voor mij zijn en voor jullie onvoorwaardelijke steun. Ik weet dat ik altijd bij jullie terecht kan.

Eric, bedankt voor je rust, standvastigheid en relativeringsvermogen, dit heeft me vaak overeind gehouden.

Lieve Ilse en Kim, jullie zijn het mooiste wat me is gegeven. Van jullie vrolijkheid en enthousiasme krijg ik altijd weer nieuwe energie. Nu ik thuis niet meer zo vaak hoef te werken kunnen we weer meer dingen samen doen. 



\section{Over de auteur}

Sandra Beijer werd geboren op 27 december 1966 in Heerlen. Na het voltooien van het Atheneum aan de scholengemeenschap St. Ursula te Horn volgde zij van 1984 tot 1988 de opleiding voor Voeding en Diëtetiek aan de hogeschool de Wachtendonck te Heerlen. Van 1988 tot 1990 werkte zij als diëtist in het Academisch Ziekenhuis Leiden en bij het Groene Kruis te Zoetermeer. Vervolgens was zij van 1990 tot 1995 verbonden aan het Integraal Kankercentrum Zuid (IKZ) te Eindhoven waar zij samen met drie collega diëtisten de 'Leidraad voor voedingsdeskundigen bij kanker', de 'Voedingsgids voor mensen met kanker' en de cursus 'De oncologische patiënt en voeding' ontwikkelde. Deze werkzaamheden werden gecombineerd met een parttime baan bij de kankerregistratie van het IKZ. Vanaf 1995 werkte zij als diëtist in het Academisch Ziekenhuis Maastricht op de afdelingen KNO en gastroenterologie en binnen het Radiotherapeutisch Instituut Maastricht. Vanaf eind 2001 was zij als parttime promovenda werkzaam bij de vakgroep Epidemiologie van de Universiteit Maastricht. Hier voerde zij een gerandomiseerde klinische studie uit naar de toepassing van ATP infusen in de palliatieve thuiszorg, uitmondend in dit proefschrift. Bovendien schreef zij in 2006, in samenwerking met Dr.ir. P.C. Dagnelie, een onderzoeksvoorstel naar de effecten van ATP infusen op vermoeidheid na curatieve behandeling voor kanker, dat door de Stichting Nationaal Fonds tegen Kanker werd gehonoreerd.

Op dit moment is zij werkzaam als postdoc bij de vakgroep Epidemiologie van de Universiteit Maastricht. Zij is tevens lid van de Werkgroep Diëtetiek van het Integraal Kankercentrum Limburg, van de Landelijke Werkgroep Diëtisten Oncologie en voorzitter van de expertgroep van de multidisciplinaire Oncoline richtlijn 'Ondervoeding bij kanker'.

Sandra is getrouwd met Eric van Eck en zij hebben twee dochters, Ilse en Kim. 



\section{List of publications}

\section{FULL PAPERS}

Vogel J, Beijer S, Doornink N, Wipkink A. Voeding als ondersteunende therapie bij kanker. Oncologica 1992; 4: 20-23.

Beijer S, Doornink N, Vogel J, Wipkink A. Voedingsbeleid bij colorectale tumoren. TVZ 1992; 17: 613-616.

Beijer S, Doornink N, Vogel J, Wipkink A. Slijmvorming door melk; feit of fictie? Ned Tijdschr Diëtisten 1992; 47: 83-85.

Barendregt K, Beijer S. Ziektespecifieke voeding. Hoe te beoordelen? Ned Tijdschr Diëtisten 1999; 54: 222-227.

Doornink N, Vogel J, Wipkink A, Beijer S. Van wensdieet naar palliatieve voeding. Ned Tijdschr Diëtisten 2000; 12: 262-267.

Barendregt K, Cox-Reijven PLM, Hogen van den E, Beijer S, Geerlings P, Soeters PB. Case study of the clinical usefulness of bioelectrical impedance spectroscopy in evaluating nutritional status. J Hum Nutr Diet 2002; 15: 189-192.

Beijer S, van Rossum E, Hupperets PS, Spreeuwenberg C, van den Beuken $M$, Winkens RA, Ars L, van den Borne BE, de Graeff A, Dagnelie PC. Application of adenosine 5 -triphosphate (ATP) infusions in palliative home care: design of a randomised clinical trial. BMC Public Health 2007; 7: 4.

Dagnelie PC, Pijls-Johannesma MC, Lambin P, Beijer S, De Ruysscher D, Kempen GI. Impact of fatigue on overall quality of life in lung and breast cancer patients selected for high-dose radiotherapy. Ann Oncol 2007; 18: 940-944.

Beijer S, Gielisse EA, Hupperets PS, van den Borne BE, van den Beuken-van Everdingen M, Nijziel MR, van Henten AM, Dagnelie PC. Intravenous ATP infusions can be safely administered in the home setting: a study in preterminal cancer patients. Invest New Drugs 2007; 25: 571-579. 
Beijer S, Kempen GIJM, Pijls-Johannesma MCG, Graeff de A, Dagnelie PC. Determinants of overall quality of life in preterminal cancer patients. Int J Cancer 2008; 123: 232-235.

Beijer S, Wijckmans NEG, van Rossum E, Spreeuwenberg C, Winkens RAG, Ars L, Dagnelie PC. Treatment adherence and patients' acceptance of home infusions with adenosine $5^{\prime}$-triphosphate (ATP) in palliative home care. Support Care Cancer 2008; 16: 1419-1424.

Beijer S, Hupperets PS, van den Borne BE, Eussen SR, van Henten AM, van den Beuken-van Everdingen $M$, de Graeff A, Ambergen T, van den Brandt PA, Dagnelie PC. Effect of ATP infusions on the nutritional status and survival of preterminal cancer patients: a randomised clinical trial. Anti-Cancer Drugs 2009; in press.

Beijer S, Hupperets PS, van den Borne BE, Wijckmans NEG, Spreeuwenberg C, van den Brandt PA, Dagnelie PC. Randomised clinical trial on the effects of ATP infusions on quality of life, functional status and fatigue in preterminal cancer patients. Submitted.

\section{ABSTRACTS}

Dagnelie PC, Beijer S. Does caffeine block the favourable effects of adenosine $5^{\prime}$ triphosphate (ATP) on the nutritional status of cancer patients? Clin Nutr 2003; 22(Suppl 1): S61.

Beijer S, Dagnelie PC, Wijckmans NEG. Application of adenosine 5'-triphosphate (ATP) infusions in palliative home care: a multicentre randomised clinical trial. $8^{\text {th }}$ International Symposium on Adenosine and Adenine Nucleotides, Ferrara, Italy, May 2006. Purinergic Signalling 2006; 2: 118-119.

Dagnelie P, Pijls-Johannesma M, Lambin Ph, Beijer S, de Ruysscher D, Kempen R. Determinants of overall quality of life in patients selected for high-dose radiotherapy. Radiother Oncol 2006; 81: S149.

Beijer S, Kempen GIJM, Pijls-Johannesma MCG, de Graeff A, Dagnelie PC. Determinants of overall quality of life in preterminal cancer patients: a longitudinal study. WEON, Maastricht, The Netherlands, June 2007. 
Beijer S, Dagnelie PC, Wijckmans NEG. Application of adenosine 5'-triphosphate (ATP) infusions in palliative home care: a multicentre randomised clinical trial. WEON, Maastricht, The Netherlands, June 2007.

Beijer S, Gielisse EAR, Hupperets PS, van den Borne BEEM, van den Beuken-van Everdingen M, Nijziel MR, van Henten AMJ, Dagnelie PC. Intravenous ATP infusions can be safely administered in the home setting: a study in preterminal cancer patients. Purines Meeting, Copenhagen, Denmark, June 2008. Purinergic Signalling 2008; 4 (Suppl 1): S195.

Dagnelie PC, Beijer S, Hupperets PS, van den Borne BEEM, Eussen SR, van Henten $A M J$, van den Beuken-van Everdingen $M$, de Graeff $A$, Ambergen $T$, van den Brandt PA. Do ATP infusions enhance survival of preterminal cancer patients? - a randomised clinical trial. Purines Meeting, Copenhagen, Denmark, June 2008. Purinergic Signalling 2008; 4 (Suppl 1): S197-198.

Dagnelie PC, van Beurden M, Beijer S. ATP infusions improve disease-related symptoms and physical functioning in patients with advanced non-small-cell lung cancer. Purines Meeting, Copenhagen, Denmark, June 2008. Purinergic Signalling 2008; 4 (Suppl 1): S197.

\section{BOOKS AND BOOK CONTRIBUTIONS}

Doornink N, Vogel J, Wipkink A, Beijer S. Leidraad voor voedingsdeskundigen bij kanker. De Toorts, 1992 (geactualiseerd in 1999, 2003 en 2006).

Beijer S, Doornink N, Vogel J, Wipkink A. Voedingsgids voor mensen met kanker. De Toorts, 1994.

Vogel J, Beijer S, Doornink N. Voeding bij kanker. In: Informatorium voor Voeding en Diëtetiek, Bohn Stafleu Van Loghum, band 4 XIla, 1997: 19-41.

van Stijgeren A, Beijer S. Voeding bij de behandeling van kanker. In: Behandeling van kanker, Bohn Stafleu Van Loghum, 2000: 75-89.

Beijer S. Richtlijn Inflammatoire Darmziekten. Elsevier, 2005. 